\title{
The development, implementation and evaluation of two worksite health programs aimed at preventing alcohol problems
}

Citation for published version (APA):

Vasse, R. M. (1997). The development, implementation and evaluation of two worksite health programs aimed at preventing alcohol problems. [Doctoral Thesis, Maastricht University]. Universiteit Maastricht. https://doi.org/10.26481/dis.19971003rv

Document status and date:

Published: 01/01/1997

DOI:

10.26481/dis.19971003rv

Document Version:

Publisher's PDF, also known as Version of record

Please check the document version of this publication:

- A submitted manuscript is the version of the article upon submission and before peer-review. There can be important differences between the submitted version and the official published version of record.

People interested in the research are advised to contact the author for the final version of the publication, or visit the DOI to the publisher's website.

- The final author version and the galley proof are versions of the publication after peer review.

- The final published version features the final layout of the paper including the volume, issue and page numbers.

Link to publication

\footnotetext{
General rights rights.

- You may freely distribute the URL identifying the publication in the public portal. please follow below link for the End User Agreement:

www.umlib.nl/taverne-license

Take down policy

If you believe that this document breaches copyright please contact us at:

repository@maastrichtuniversity.nl

providing details and we will investigate your claim.
}

Copyright and moral rights for the publications made accessible in the public portal are retained by the authors and/or other copyright owners and it is a condition of accessing publications that users recognise and abide by the legal requirements associated with these

- Users may download and print one copy of any publication from the public portal for the purpose of private study or research.

- You may not further distribute the material or use it for any profit-making activity or commercial gain

If the publication is distributed under the terms of Article $25 \mathrm{fa}$ of the Dutch Copyright Act, indicated by the "Taverne" license above, 
The development, implementation and evaluation of two worksite health programs aimed at preventing alcohol problems 
The development, implementation and evaluation of two worksite health programs aimed at preventing alcohol problems

\section{PROEFSCHRIFT}

ter verkrijging van de graad van doctor aan de Universiteit Maastricht, op gezag van de Rector Magnificus, Prof.Mr. M.J. Cohen, volgens het besluit van het College van Decanen in het openbaar te verdedigen op vrijdag 3 oktober 1997 om 14.00 uur

door

Remkina Margot Vasse

geboren te Groningen op 7 augustus 1967 


\section{Promotores:}

Prof.dr. F.J.N. Nijhuis

Prof.dr. G.J. Kok

\section{Beoordelingscommissie:}

Prof.dr. J.A.M. Maarse (voorzitter)

Prof.dr. H.F.L. Garretsen (Instituut voor Verslavingsonderzoek, Rotterdam)

Prof.dr. C.M.H. Hosman (Katholieke Universiteit Nijmegen/

Universiteit Maastricht)

Dr. R.A. Knibbe

Prof.dr. M.A.J. Kompier (Katholieke Universiteit Nijmegen)

ISBN: 90-9010813-0

The study presented in this thesis was performed at the Maastricht Health Research Institute for Prevention and Care (HEALTH), which participates in the Netherlands School of Primary Care Research (CaRe), acknowledged in 1995 by the Royal Dutch Academy of Science (KNAW).

The research was financed by the Dutch Ministry of Welfare, Health and Cultural Affairs.

- R.M. Vasse, Maastricht 1997. 


\section{Contents}

$1 \quad$ General overview $\ldots \ldots \ldots \ldots \ldots \ldots \ldots \ldots \ldots \ldots$

1.1 Introduction . . . . . . . . . . . . . . . . . . . . . 9

1.2 Literature study on problem drinking and its consequences for the worksite .......................... 11

Definitions and prevalence of alcohol drinking patterns . . . . . 11

Consequences of problem drinking for the worksite ........ 12

1.3 Literature study on determinants of workers' alcohol drinking behavior and existing worksite alcohol programs .......... 14

Determinants of workers' alcohol drinking behavior . . . . . . 14

Existing worksite alcohol programs and their effectiveness ...... 15

1.4 Two field studies: Development and implementation of a primary and a secondary preventive worksite alcohol program . . . . . 18

Participation principle $\ldots \ldots \ldots \ldots \ldots \ldots \ldots \ldots$

Finding worksites . . . . . . . . . . . . . . 18

Implementation of the secondary preventive alcohol program ... . 19

Implementation of the primary preventive alcohol program . . . . , 19

1.5 Evaluation of the two field studies . . . . . . . . . . . 20

Effectiveness of the secondary preventive alcohol program . . . . 20

Effectiveness of the primary preventive alcohol program ...... 23

Process evaluation of two alcohol programs . . . . . . . . . 24

1.6 A theoretical study on the effect of drinking to cope with stress on sickness absence . . . . . . . . . . . . . . . 25

The hypothesized model . . . . . . . . . . . . . . . 25

Methods ... . . . . . . . . . . . . . . . . . . . . 26

Results . . . . . . . . . . . . . . . . . . . 27

1.7 Discussion and conclusions $\ldots \ldots \ldots \ldots \ldots \ldots \ldots \ldots$

Content of secondary and primary preventive alcohol programs . . . 28

Planning of worksite alcohol programs ... . . . . . . . 31

Methodological limitations . . . . . . . . . . . . . . . 33

Ethical limitations ................... . . 37

Conclusions and implications $\ldots \ldots \ldots \ldots \ldots \ldots$

2 Effectiveness of a worksite alcohol program . . . . . . . . . . 43

2.1 Abstract ........................ . . 43

2.2 Introduction . . . . . . . . . . . . . . . . . 44

Theoretical background and program goals $\ldots \ldots \ldots \ldots \ldots 45$

2.3 Methods . . . . . . . . . . . . . . . . . . . . . 48

Design and samples . . . . . . . . . . . . . . . . 48

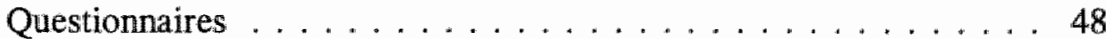

Group and individual interviews ............... . . 49

Analyses . . . . . . . . . . . . . . . . . . . . . . . . . . . . 49 
2.4 Results . . . . . . . . . . . . . . . . . . . . . 50

Response and sociodemographic characteristics ......... 50

Participation and evaluation of program components ....... 50

Effects on social medical workers . . . . . . . . . . . 51

Effects on supervisors $\ldots \ldots \ldots \ldots \ldots \ldots \ldots \ldots$

Effects on workers $\ldots \ldots \ldots \ldots \ldots \ldots \ldots \ldots \ldots \ldots$

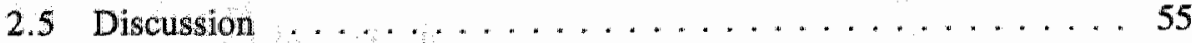

3 Effectiveness of a personalized Health Profile for blue-collar workers . . . . . . . . . . . . . . . . . . . . . . . 59

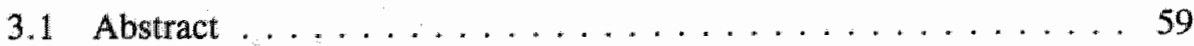

3.2 Introduction . . . . . . . . . . . . . . . . . 59

Theoretical basis and goals of the Health Profile . . . . . . . 61

Technical background of the Health Profile . . . . . . . . 62

Research questions . . . . . . . . . . . . . . 62

3.3 Methods . . . . . . . . . . . . . . . . . . . 62

Study population and procedure $\ldots \ldots \ldots \ldots \ldots \ldots 6 \ldots \ldots \ldots$

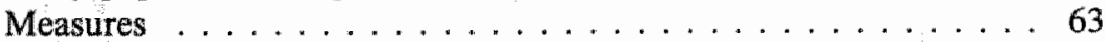

Analyses . . . . . . . . . . . . . . . . . . . 65

3.4 Results . . . . . . . . . . . . . . . . . . . 65

Response ... . . . . . . . . . . . . . . . . 65

Prevalence of health behaviors, Behavior Risk Index scores, subjec-

tive beliefs on healthiness of behavior, and self-reported health . . . . . . . . . . . . . . . . . 66

Effects on behavioral determinants . . . . . . . . . . 67

Relation between Behavior Risk Index score and a) subjective belief

(i.e. awareness) and b) intention to change behavior . . . . 68

Evaluation of the Health Profile . . . . . . . . . . . . . . . 69

3.5 Discussion . . . . . . . . . . . . . . . . . . . . . . . 69

4 Process evaluation of two worksite alcohol programs . . . . . . . 71

4.1 Abstract . . . . . . . . . . . . . . . . . 71

4.2 Introduction . . . . . . . . . . . . . . 71

Programs: plans, theoretical basis and effectiveness . . . . . 72

Behavior change models \& content of the programs $\ldots \ldots \ldots 72$

PRECEDE-PROCEED Model \& organizational plan . . . . . . 73

Program implementation and effectiveness . . . . . . . . . . . 73

4.3 Methods . . . . . . . . . . . . . . . . . . . . . 74

Process evaluation . . . . . . . . . . . . . . . . 74

General Model of Planned Change . . . . . . . . . . . . . 75

Data collection . . . . . . . . . . . . . . . . 75

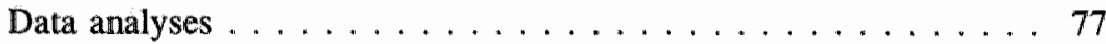

4.4 Results . . . . . . . . . . . . . . . . . . . . . 77

Project implementation . . . . . . . . . . . 77 
Site response $\ldots \ldots \ldots \ldots \ldots \ldots \ldots \ldots \ldots \ldots$

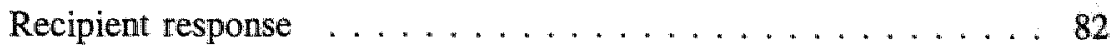

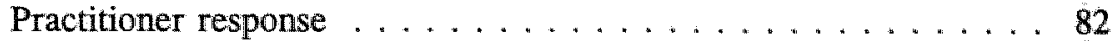

Competencies of personnel $\ldots \ldots \ldots \ldots \ldots$

4.5 Discussion and conclusions . . . . . . . . . . . . 83

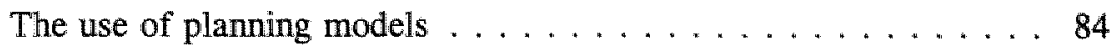

The role of external consultants $\ldots \ldots \ldots \ldots \ldots \ldots$

Participation of the worksite $\ldots \ldots \ldots \ldots \ldots \ldots$

Incorporation of research $\ldots \ldots \ldots \ldots . \ldots . \ldots 86$

Content of primary and secondary preventive programs . . . . . 86

Integration with other programs $\ldots \ldots \ldots \ldots . \ldots . \ldots 77$

5 Associations between work stress, alcohol consumption and sickness absence. . . . . . . . . . . . . . . . . . . . . . . . . . . 89

5.1 Abstract . . . . . . . . . . . . . . . . . . . . . . . 89

5.2 Introduction . . . . . . . . . . . . . . . . . . . . . . 89

Theoretical background . . . . . . . . . . . . . . . . 90

Definitions and the hypothesized model . . . . . . . . . . . 91

5.3 Methods . . . . . . . . . . . . . . . . . . . . . . 92

Study population . . . . . . . . . . . . . . 92

Data gathering . . . . . . . . . . . . . . . 92

Measures ........................ 93

Analyses . . . . . . . . . . . . . . . . . . . . 93

5.4 Results . . . . . . . . . . . . . . . . . . . . . . . . 94

Response . . . . . . . . . . . . . . . . . . . . . . 94

Sociodemographics . . . . . . . . . . . . . . . . . . 94

Representativeness of the sample . . . . . . . . . . . . 95

Prevalence of health variables $\ldots \ldots \ldots \ldots \ldots \ldots$

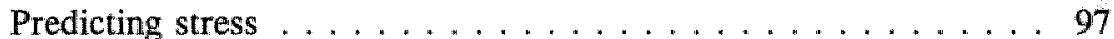

Predicting alcohol consumption . . . . . . . . . . . 98

Predicting sickness absence . . . . . . . . . . . . . . . 98

5.5 Discussion ....................... 101

Appendix A: Questions on work stressors. . . . . . . . . . 106

Appendix B: Logistic regression of sociodemographic variables and medicine use on abstinence. . . . . . . . . . . . . 107

References . . . . . . . . . . . . . . . . . . . . . . . . . . 109

Summary . . . . . . . . . . . . . . . . . . . . 113

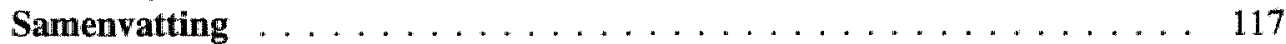

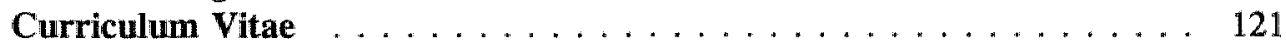

Acknowledgements . . . . . . . . . . . . . . . . . . . . 123 


\section{General overview}

\subsection{Introduction}

Workers" alcohol problems cost Dutch employers about 588 million guilders per year (Meijer and Tjioe, 1990) and create serious health and social problems for the individual problem drinker. Therefore in 1990 the Dutch Ministry of Welfare, Health and Cultural Affairs initiated a project to investigate the feasibility and the effects of two different worksite health programs aimed at preventing workers' alcohol problems. The Alcohol Consultancy Netherlands (ALCON) Foundation had experience with worksite alcohol programs and was asked to implement the project. The Maastricht University evaluated the project.

This thesis describes the process of development, implementation and evaluation of the project. The first program in the project was a secondary preventive worksite alcohol program based on existing ALCON programs. It focused on early detection of problem drinkers and assisting them to solve their problems. Program components were an alcohol policy (including regulations and procedures), skills training for supervisors and staff personnel on the constructive confrontation method, and alcohol education. The second program was a primary preventive Health Promotion Prow gram. In addition to alcohol, this program included other themes closely related to alcohol (stress, nutrition, exercise, smoking). Such a broader program was hypothesized to increase workers' resistance against illnesses in general, and to promote healthy, moderate drinking behavior.

The evaluation study included the evaluation of the effectiveness of both programs as well as the process of implementation and was intended to result in recommendations on the best way to implement these kinds of programs in Dutch companies.

The development of interventions that can promote behavioral change requires a systematic approach, including a study on the health problem, the behaviors related to this problem and the determinants of these risk behaviors, and, subsequently, the development, implementation and evaluation of the interventions (Green and Kreuter, 1991). The diagnostic phases of the present project (analysis of the problem, beha- 
vior and determinants) were based on literature study (described in this overview). Then, global plans for the two interventions were developed. These global plans were offered to several worksites. Two worksites agreed to participate in the project: a large pharmaceutical company $(\mathrm{N}=1600)$ and a municipal garbage coliecting department $(\mathrm{N}=328)$ of a large city. In these worksites diagnostic planning steps were repeated, but were now applied to the specific worksite situation. Thus, this project consists of two field studies.

Chapter 2 of this thesis describes the first field study on the development, implementation and evaluation of a secondary preventive alcohol program at the pharmaceutical company. Chapter 3 describes the second field study on the development, implementation and evaluation of a primary preventive alcohol program at the municipal garbage collecting department.

The process evaluation of both programs describes in detail the activities that have taken place in all phases of planning and evaluation. This results in recommendations on tasks and roles for project members internal and external to the worksite at different stages, and on improvements on the content of program elements. To enable comparisons between the two worksites the process evaluation of the two programs is combined in chapter 4.

The literature study on determinants of workers' drinking behavior revealed a body of theoretical knowledge on worksite risk factors for alcohol drinking behavior, especially on the relation between work stress and alcohol drinking. But only a few empirical studies were found on determinants and effects of workers' alcohol drinking behavior. Therefore we decided to add to the field studies a theoretical study that tested the social learning perspective on alcohol drinking as a coping response to stress (Abrams \& Niaura, 1987; Marlatt \& Gordon, 1985; Wills \& Shiffman, 1985). Alcohol drinking is considered a maladaptive coping response because it does not solve but increases problems and, with respect to work for example, can result in increased sickness absence. We conducted secondary analyses on the data from the pharmaceutical company and the municipal departments to test the relation between work stressors, work stress, alcohol drinking behavior and sickness absence. This theoretical study is described in chapter 5 .

This overview continues with a problem analysis based on literature study (section 1.2). The problem analysis is followed by a short review of what is known from the literature about determinants of workers' drinking behavior, and about worksite alcohol programs and their effectiveness (section 1.3). Subsequently, section 1.4 describes the development and implementation of our own two worksite alcohol programs. Section 1.5 presents the results of the field studies including a process evalution. Section 1.6 continues with a summary of the theoretical study on the relation between work stressors, work stress, alcohol drinking and sickness absence. Finally, this overview closes with a general discussion on the results and formulates overall conclusions and implications for research and practice. 


\subsection{Literature study on problem drinking and its consequences for the worksite}

The central health behavior problem in this thesis is workers' problem drinking. This section presents definitions and prevalence figures of problem drinking and other alcohol drinking patterns. Secondly, the consequences of workers' problem drinking for the worksite are discussed.

\section{Definitions and prevalence of alcohol drinking patterns}

There is no clear consensus about how much alcohol is too much. Different countries have different norms partly depending on their cultural habits. But there are also great differences between individuals' sensitivity to alcohol that make it difficult to establish clear boundaries for healthy drinking. One of the most important factors that influences sensitivity is gender. Because of the difference in body composition between men and women (women have a lower amount of body water per killogram body weight), women will have a higher blood alcohol concentration (BAC) than men after drinking the same amount of alcohol because alcohol is spread over the total amount of body water. Therefore, different norms are commonly used for men and women.

In the Netherlands, definitions in line with those of McDonald (1982) and Anderson (1986) are used for recommendations to the public by the Netherlands Bureau for Food and Nutrition. For women the cut-off point between moderate drinking and excessive drinking is defined as drinking 14 glasses or more per week and for men 21 glasses per week or more. When drinkers drink excessively and create physical, psychological or social problems for themselves or their environment, they are called problem drinkers (Garretsen, 1983). Garretsen (1983) distinguishes five problem areas: psychological dependency, symptomatic drinking, problems with people in the environment (family, friends, neighbors, at work, police and justice), health problems and accidents, and finally frequently being intoxicated and/or having a hangover. One form of problem drinking is alcoholism, the main characteristic of which is physical and mental dependency (Te Wierik, 1991; Garretsen, 1983).

In general, alcohol consumption in the Netherlands increased threefold (see figure 1) in the period between 1960 and 1980 (Ministry of Welfare, Health and Cultural Affairs, 1993).

Both frequency and quantity of the drinking increased in this period. Subsequently alcohol consumption slightly decreased and stabilized at 982 glasses per year per drinker (excluding abstainers) in 1990. This is about 2.5 glasses per day. On the world ranking list the Netherlands is positioned in the middle.

More detailed prevalence rates can be obtained from the data $(\mathrm{N}=6,603)$ of the Central Bureau for Statistics (CBS) (Knibbe and Swinkels, 1992). The excessive drinking rate $(\geq 22$ glasses per week) of the general Dutch population in 1989 was 
Figure 1: Yearly alcohol use per drinker (number of glasses)

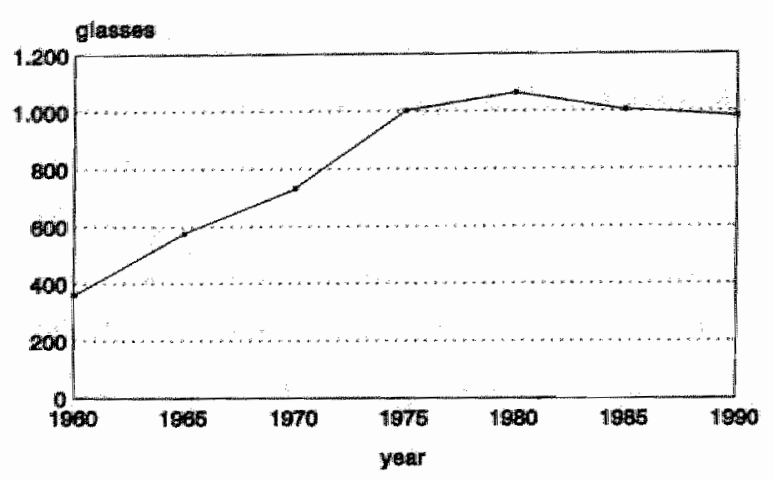

$8.8 \%$ (14.4\% for men, $3.2 \%$ for women). The average abstinence rate was $18.4 \%$ (11.5\% for men, $25.2 \%$ for women). The mean consumption (including abstainers) was 11.4 glasses per week for men and 4.9 for women. Unfortunately, this study does not use different norms for men and women.

A study of the general Dutch population that does take into account different norms for men and women (excessive drinking is $>21$ glasses/week for men and $>14$ glasses/week for women) indicates that differences in excessive drinking rate between men and women gradually decreased in the period between 1958 and 1989 but still existed in 1989 except in the older age category (41-70 years) (Neve, Knibbe and Swinkels, 1994).

The drinking pattern of the working population does not differ greatly from that in the general population (see figure 2). A large study $(N=10,000)$ of Gründemann $(1988,1989 \mathrm{a}, 1989 \mathrm{~b})$ among a representative sample of the Dutch working population in 1987 revealed that $12 \%$ drink excessively ( $\geq 21$ glasses per week) (13.6\% for men, $2.5 \%$ for women). The abstinence rate among workers was $7.1 \%$ ( $5.5 \%$ for men, $10.4 \%$ for women). The mean consumption (including abstainers) was 9.5 glasses per week (11.3 for men, 5.0 for women).

\section{Consequences of problem drinking for the worksite}

Alcohol drinking on or off the job increases the risk of safety problems related to reduced nervous and psychomotor functions. It is estimated that $10-30 \%$ of the accidents at work are related to alcohol and that problem drinkers have a 2-4 times higher chance of an accident than non-drinkers (Bijl and Ziekemeyer, 1990). In general, alcohol problems result in a low quality and quantity of work performance. Furthermore, alcohol problems themselves or health problems related to alcohol drinking result in higher sickness absence. It is estimated that problem drinkers have a $2-6$ times higher sickness absence than average and it has been found that $13 \%$ of the sickness absence is related to alcohol problems (Bijl and Ziekemeyer, 1990). 


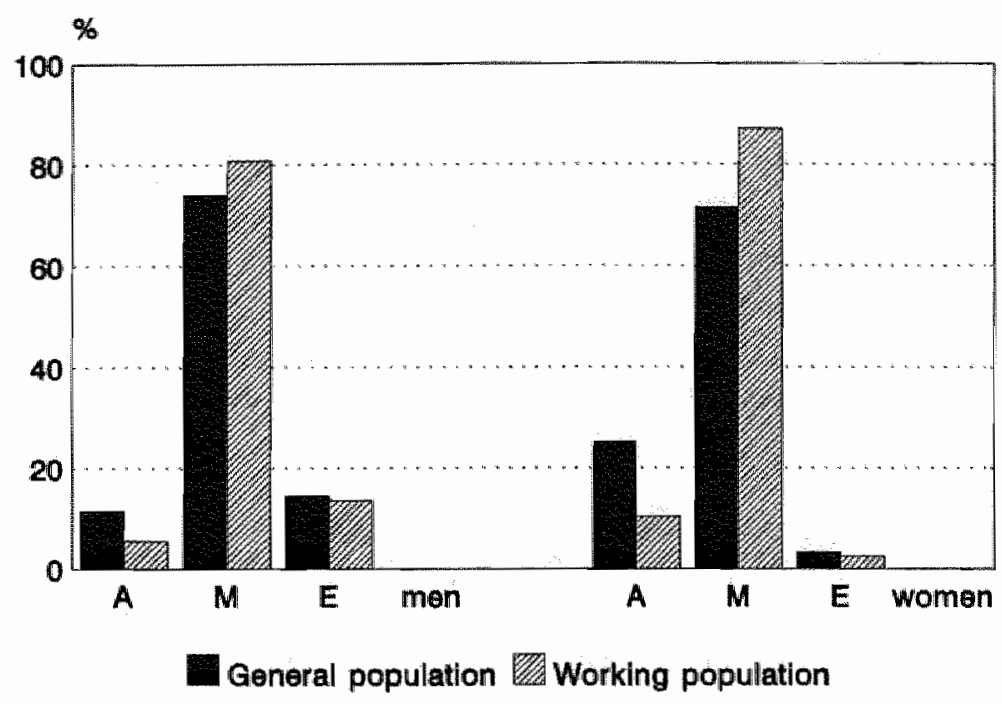

Two empirical studies among Dutch and British civil servants (Van Deursen, Raat \& Garretsen, 1989; Marmot, North, Feeney \& Head, 1993) indeed both found a relation between alcohol drinking and sickness absence. This relation is U-shaped, i.e. both abstainers and excessive drinkers have an increased sickness absence compared to moderate drinkers. The reason why abstainers have an increased risk of sickness absence remains unclear. On the contrary, another Dutch study (Schroër, 1993) showed that, compared to work stressors, workers' alcohol drinking behavior had only minor influences on health indicators. Unfortunately, the latter study did not include sickness absence.

At company level it is estimated that problem drinkers have a productivity of $75 \%$ of their normal level. This means that $25 \%$ of their salary costs is lost. On average this means a yearly loss of HFL 62,500 per 100 employees for the company (Bijl and Ziekemeyer, 1990).

At national level, the Dutch Economic Institute (Meijer and Tjioe, 1990) estimated the one-year (1987) work-related costs of alcohol problems on HFL 588 million. These are costs due to loss of production caused by extra sickness absence of excessive drinkers compared to moderate drinkers, death from alcohol-related illnesses, death from alcohol-related violence, death from alcohol-related traffic accidents, and disability insurance (WAO/AAW). Excessive drinkers' extra sickness absence accounts for the largest part of these costs $(95.7 \%)$. 
Although results are mixed, it can be concluded that existing research strongly indicates an increased risk of dysfunctioning and sickness absence for workers with alcohol problems. Excessive drinkers (about $12 \%$ of the working population) form the major risk group, but also abstainers seem to have an increased risk of sickness absence.

\subsection{Literature study on determinants of workers' alcohol drinking behavior and existing worksite alcohol programs}

This section first gives a short review of what is known from the literature about determinants of workers" problem drinking. Second, it reviews what is known about the type of alcohol programs that are implemented at the worksite, and about their effectiveness.

\section{Determinants of workers' alcohol drinking behavior}

Over the past 15-20 years, and based on findings from studies in various occupational settings, researchers have contributed to the development of a theoretical approach for organizing alcohol-related risk factors in the workplace (Trice and Sonnenstuhl, 1988, 1990; Ames and Janes, 1992; Ames, 1993). This resulted in three conceptual categories for determinants of workers' problem drinking. The first category is called normative regulation of drinking. The second category concerns quality and organization of work. The third category includes factors external to the workplace.

Figure 3 shows the relations between work-related drinking, its causes and its consequences. Normative regulation of drinking subsumes subcategories of (formal and informal) social control and availability of alcohol. Formal social control includes culturally embedded rules and actions that explicitly regulate alcohol use in work-related contexts (such as alcohol policy and the degree to which it is actually enforced). Informal social control includes values, attitudes, and expectations of particular occupational subgroups, job situations, or the workplace in general. Elements of social control influence the availability of alcohol. Availability reflects access to alcohol (physical availability) and to individuals or groups who engage in social drinking at work (social availability). Availability may interact with social control factors to support or inhibit the development of drinking subcultures. Quality and organization of work subsumes subcategories of job stressors and alienating factors. These objective positive and negative environmental factors in the workplace influence workers' feelings of well-being (subjective stress or alienation) with respect to work. Factors external to the workplace include characteristics of a person's background and current life circumstances that influence a tendency to develop or resist a high-risk drinking pattern when exposed to worksite risk factors. These characteristics include alcohol-related beliefs and values derived from family and ethnic background, drinking history, friendship networks, and individual coping 
style, among others. These individual variables determine a person's vulnerability for problem drinking.

Together these worksite and individual factors influence a worker"s alcohol consumption (on or off the job) and consequently, long-term alcohol-related prob. lems such as, for example, sickness absence, accidents and injuries, and disciplinary action.

As stated above, this model has been built upon different studies (ethnographic and survey studies). Each study focuses on one or two specific relations, the model has never been tested comprehensively. The relation between work stress and alcohol has, relatively, been studied in great extent. But a review by Cooper, Russell and Frone (1990) reveals that findings of these studies are mixed and most studies suffer from methodological limitations.

Figure 3: A cultural approach to conceptualizing alcohol and the workplace (Ames and Janes, 1992).

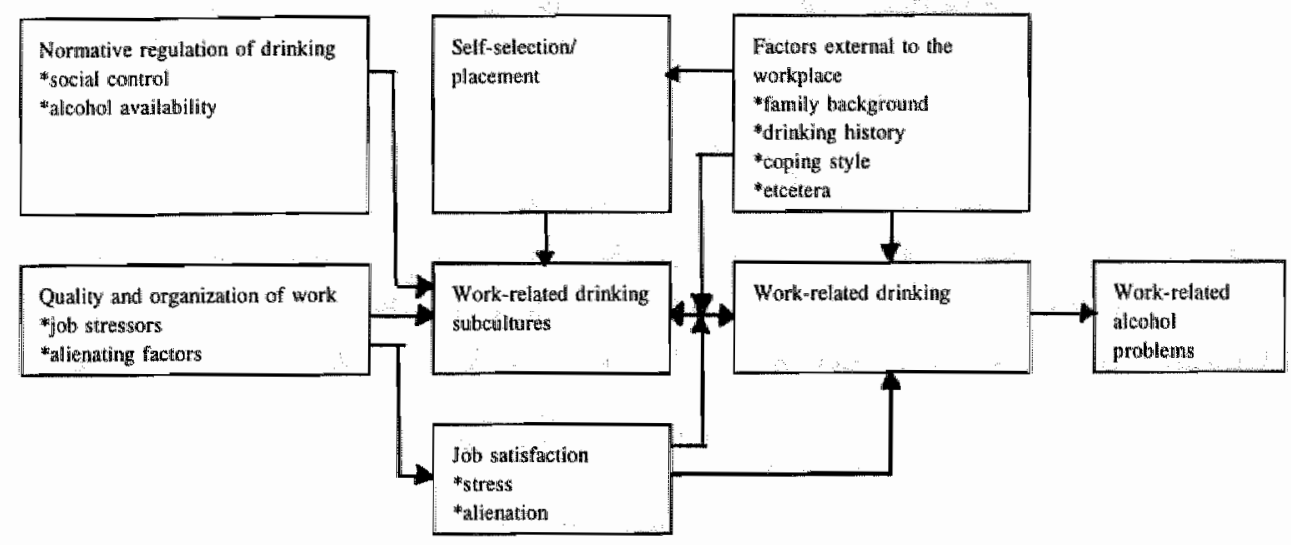

In the Netherlands, we know of one representative study among the Dutch working population (Gründemann, 1989a) that gives insight into determinants of workers" problem drinking. The findings strongly support the importance of the alcohol climate at work (i.e. attitudes of management and colleagues) and the availability of alcohol at work as determinants. In addition, work pressure (i.e. overwork) was found an important determinant.

The next section reviews which worksite health programs try to influence what determinants of workers" alcohol problems.

\section{Existing worksite alcohol programs and their effectiveness}

A review of Sonnenstuhl (1988) indicates three types of programs aimed at preventing alcohol problems: Employee Assistance Programs, Health Promotion Programs and Quality of Work Life Programs. Employee Assistance Programs have the longest 
tradition; these programs try to break through the dynamics of denial that characterize alcohol problems. They are found effective in identifying problem drinkers and encouraging them to change by a dual strategy of constructive confrontation and counseling (Trice and Beyer, 1984; Gerstein, Eichenhofer, Bayer, Valutis \& Jankowski, 1989). Health Promotion Programs treat alcohol use as a factor increasing one"s risk of death from several diseases. These programs focus on educating employees about the consequences of excessive drinking and on promoting a moderate drinking behavior. The impact of Health Promotion Programs on alcohol problems remains speculative and experimental. Quality of Work Life Programs stem from the organization development movement. These programs do not explicitly address alcohol abuse and dependence but it is thought that improvement in working conditions, job satisfaction, and workers' self-esteem will reduce employees' drinking problems. Empirical research indicates several worksite factors that contribute to alcohol abuse. But evaluations of Quality of Work Life Programs have thus far failed to include drinking behavior as an outcome variable so the belief that changing work organization will alleviate drinking problems remains untested (Sonnenstuhl, 1988).

A recent review of Roman and Blum (1996) indicates that the current state of the art is more or less unchanged compared to 1988. In the period between 1970 and 199524 articles were found that reported the results of studies on the impact of worksite alcohol programs on health and behavioral outcomes. Most of the programs (19) are directed at employees and can all but one be characterized as Employee Assistance Programs (EAPs). The studies evaluate the effectiveness of treatment that is offered to problem drinkers. Major outcome measures are job performance and sickness absence. The second type of program is directed at managers or supervisors (5 studies). These programs include training or education about alcohol problems, the worksite EAPs, and the role of managers/supervisors in dealing with problem drinkers. Most studies lack an experimental design, therefore evidence is strongly suggestive. Results indicate that worksite interventions including core components of Employee Assistance Programs are effective in rehabilitating employees with alcohol problems. Additionally, it is concluded that worksite training affects the attitudes of supervisors and employees about the program and about taking actions toward problem drinkers.

The review of Roman and Blum (1996) reveals only one study that can be characterized as a Health Promotion Program and is primary preventive in nature. It concerns the study by Kishchuk, Peters, Towers, Sylvestre, Bourgault, and Richard (1994) that assessed the efficacy of a workplace-oriented educational program designed to alter drinking behaviors in healthy and socially responsible directions. Workers could volunteer to participate in two, half-hour sessions delivered by a health professional. The program provided information on the social and personal costs of alcohol, on strategies for promoting socially responsible drinking, and for the prevention of negative consequences of intoxication. Results show that despite a lack of interest in the topic, the program was effective in promoting socially responsible attitudes and reducing self-reported weekly consumption among participants. 
But some effects could be placebo-effects, because those receiving nutrition education also altered drinking behavior in the desired direction.

In general, worksite Health Promotion Programs exist of several programs on different lifestyle behaviors, for example nutrition, smoking, weight loss, stress, exercise, etcetera. Those programs usually have two phases. In the first phase employees receive a Health Risk Appraisal, a questionnaire that assesses the individual's risk. Based on this risk assessment the employee is advised to participate in one or more behavior change programs. Two well-known examples of these comprehensive Health Promotion Programs are those of the companies DuPont (Bertera; 1990a; 1990b) and Johnson and Johnson (Breslow, Fielding, Herrman, \& Wilbur; 1990). It remains unclear if alcohol is part of the Health Risk Appraisals and followup programs (e.g. nutrition) at DuPont and Johnson and Johnson. Studies on both programs do not report effects on alcohol drinking behavior.

We do not know of Dutch evaluation studies on worksite alcohol programs. We only have insight into the prevalence of worksite alcohol programs in the Netherlands from a representative study by Gründemann and Lourijsen (1991). This study shows that programs that might be classified as Quality of Work Life Programs (in terms of Sonnenstuhl, 1988) are more widespread in Dutch companies than social programs or health behavior programs. The study rates 5 types of activities: $57.6 \%$ of the companies implement activities on safety and ergonomics, $54.5 \%$ implement organizational change activities, $38.9 \%$ have periodic physical examinations, $23.7 \%$ conduct health behavior activities, and $21.6 \%$ carry out activities on well-being (i.e. social work including stress activities). One subtype of health behavior programs in Gründemann and Lourijsen's study is alcohol programs (in most cases alcohol policies) that are implemented in $15 \%$ of all companies.

To conclude, determinants of workers' drinking behaviors can be classified in three categories: 1) quality and organization of work (work stressors), 2) normative regulation of drinking (formal and informal social control, alcohol availability), and 3) individual factors (drinking history, attitudes, coping style). Worksite alcohol programs can be qualified as Employee Assistance Programs (treatment of problem drinkers), Health Promotion Programs (promoting healthy drinking behavior), or Quality of Work Life Programs (reduction of work stressors). Evaluation studies on Employee Assistance Programs show positive results. Only one evaluation study on a primary preventive Health Promotion Program is known that includes alcohol. Results suggest modest positive effects of this program. No study is known that evaluates the effects of a Quality of Work Life Program on alcohol outcomes. 


\subsection{Two field studies: Development and implementation of a primary and a secondary preventive worksite alcohol program}

Based on literature study and the existing ALCON program we developed global plans for a primary and secondary preventive worksite alcohol program. These plans considered content and planning of the programs. This section describes the operationalization of worksite participation in the project, the process of finding worksites to participate in the project, and the implementation of the two programs. The implementation is only described briefly here, because chapters 2 and 3 give all the details. Results are summarized in section 1.5.

\section{Participation principle}

The Health Promotion field has long recognized the importance of participation of the target group in fitting programs to their specific needs. But recent developments in community projects (Bracht, 1990) have stressed this principle and worked out new strategies to improve participation. Participation facilitates not only the use, but also the enlargement of existing capacities in the community, which will make people capable of solving their own problems in the future (empowerment).

In our project we operationalized participation via working groups in the worksites that participated in the project from the moment we entered the worksite. The working groups were in fact responsible for the programs. The ALCON Foundation and the University functioned as external advisors in the working groups.

\section{Finding worksites}

In a letter and by telephone we asked several worksites if they wanted to participate in the project. Their choice was restricted to a secondary preventive program or a primary preventive program. We had developed global plans for the two programs concerning possible goals and possible program components. The plan for an alcohol program was based on the existing ALCON programs. The overall, long-term goal was to reduce alcohol problems. Short-term goals were: 1) improvement of signaling and counseling skills of social medical workers and supervisors, 2) development of an assistance system including rules and procedures for alcohol problems, and 3) improvement of knowledge of all workers about the new policy and improvement of their awareness of their own drinking behavior.

The main goal in the plan for the Health Promotion Program was to improve health behavior including a healthy drinking behavior. The longer term goal was also to reduce alcohol problems. Health Promotion Programs usually have two phases: in the first phase the main goal is to improve people's awareness about their own health behaviors (a commonly used instrument for this is a Health Risk Appraisal), and based on the results of this first phase people can choose to participate in program activities most relevant for them. Because of their relationship with alcohol drinking behavior the following themes, besides alcohol, were proposed in our plan: smoking, diet behavior (including weight loss), exercise and stress. No concrete activities were 
mentioned in the plan, although we were preparing a workbook that would give an overview of existing programs offered by national and local organizations. For the first phase of the program we developed a Dutch version of a Health Risk Appraisal called a Health Profile, that gave feedback on the healthiness of four health behaviors (smoking, diet belhavior, alcohol drinking behavior, exercise behavior) and the Quetelet-Index (weight/height ratio).

We further proposed methods with respect to planning and organization of the project: ALCON and the University as external consultants would cooperate with an internal working group, a problem diagnosis would be conducted by the external consultants, external consultants and the working group would develop and implement an intervention based on the results of the diagnosis, and the external consultants would evaluate the effects of the intervention. The main instruments for diagnosis and evaluation would be interviews and written questionnaires.

\section{Implementation of the secondary preventive alcohol program}

A large pharmaceutical company ( 1600 workers) agreed to participate in the secondary preventive program that we called the alcohol program. The program would be part of their health policy that was aimed at promotion of health and well-being, and reduction of sickness absence. The alcohol program was the first project to operationalize their health policy. A social worker of the worksite was responsible for the development and implementation of the alcohol program. She composed a working group to assist her and she reported to the personnel and organization manager, who is a member of the top management team. It was agreed that ALCON would give practical advice and would implement some activities, and that the University would evaluate the program. The worksite did not agree on a control group, because of privacy reasons.

A diagnosis was conducted consisting of interviews and questionnaires. Based on this diagnosis an alcohol policy document was developed by the working group. The top management approved of this document and the program was implemented and evaluated.

In short (see chapter 2 for more details), the major focus of the program was the constructive confrontation skills of social medical workers and supervisors. A training was planned to improve these skills. In practice onlly social medicall workers received the training. Supervisors only received an informative letter and a brochure and could ask for individual assistance. Secondly, a policy with rules on alcohol drinking at work and procedures on assistance to problem drinkers was implemented. Information on this new policy was given in several mass-media channels to promote knowledge and a positive attitude on the policy. Thirdly, mass-media was also used to increase workers" awareness of their own drinking behavior and to promote behavioral change if necessary (i.e. in case of excessive drinking).

\section{Implementation of the primary preventive alcohol program}

A municipal department (the garbage collecting department) of a large city agreed to participate in the Health Promotion Program. This worksite had implemented an 
alcohol policy some years ago and now wanted to broaden their health activities to other lifestyle behaviors. A division manager was the internal project leader and a representative working group was formed. We also found a garbage collecting department of another municipality that wanted to serve as a waiting list control group.

After a diagnosis that was based on written questionnaires and interviews, workers from the experimental worksite were given personal feedback on the healthiness of their behawiors in a A4-booklet that we called the Health Profile. The major goal was to improve workers' awareness on the healthiness of their own behavior. In the meantime, the working group wrote a plan for the activities to follow on this Health Profile. But the top management did not agree on the proposed major focus on stress and working conditions. So, the project was stopped after the evaluation of the Health Profile.

\subsection{Evaluation of the two field studies}

This section first presents the results of the evaluation study on the effectiveness of the two worksite alcohol programs. Second, the evaluation study on the process of implementation is summarized. In the process evaluation study similarities and differences of the implementation process in the two worksites will be compared. The results will be discussed in the final section of this overview (1.7) together with the results of the theoretical study on the relation between work stress, alcohol and sickness absence (1.6).

\section{Effectiveness of the secondary preventive alcohol program}

Research questions on effectiveness of the secondary preventive alcohol program were worked out based on the goals and content of the program:

1) How effective is the alcohol program in improving the knowledge and attitudes of all. workers with regard to the alcohol policy and drinking in relation with work?

2) How effective is the alcohol program in improving the knowledge, attitudes and skills of social medical workers and supervisors with regard to assistance to problem drinkers?

3) How effective is the alcohol program in improving awareness of one's own drinking behavior and changing this behavior when necessary?

4) How effective is the alcohol program in the cessation of alcohol drinking during working hours and the promotion of non-alcoholic drinks at receptions?

5) How effective is the alcohol program in the assistance to problem drinkers?

Three subpopulations were used to examime the effects of the program: 1) a random sample (30\%) of the total work population, 2) all social medical workers, and 3) a random sample $(50 \%)$ of supervisors. They all received a pretest and a posttest questionnaire. So, the design was quasi-experimental with a pretest and a posttest 
and no control groups. The questionnaire for the social medical workers measured four subsets of variables: 1) knowledge about procedures, rules and cooperation, 2) attitudes about the importance of the policy and the content of their role (signaling and counseling), 3) perceived quality of cooperation among social medical workers, and between social medical workers and supervisors, and 4) self-efficacy about constructive confrontation skills necessary for assisting problem drinkers, and selfefficacy about informing supervisors and workers about the policy. The posittest questionnaire also contained questions about participation in the program (including the value they attached to the program). The supervisors' questionnaire contained the same four subsets of variables as the social medical workers' questionnaire, although not all the questions were the same. Their posttest questionnaire also contained questions about participation. The questionnaire for all workers contained six subsets of variables: 1) knowledge about procedures for the assistance of problem drinkers and the worksite resources for assistance, 2) attitudes toward the Alcohol Policy (importance of the policy, taking work into account when drinking, intention not to drink at work), 3) self-efficacy on constructive confrontation skills, 4) alcohol drinking behavior (weekly consumption based on quantity-frequency measures on weekdays and weekend days), 5) awareness of workers' own drinking behavior (measured by the interaction between actual drinking behavior and the subjective attitude towards drinking too much), and 6) intention to drink less. Again, the posttest questionnaire also contained questions about participation.

Out of 22 social medical workers 18 responded to the pretest and 11 out of 16 to the posttest, 10 respondents participated in both tests. Only these 10 respondents were used for the analyses. Among the supervisors, the response to the pretest was $71.6 \%$ $(\mathrm{n}=78)$ and to the posttest $52.5 \%(\mathrm{n}=63)$. With regard to all workers, the response to the pretest was $70.9 \%(n=319)$ and to the posttest $53.6 \%(n=267)$.

In the case of the social medical workers, paired T-tests were used to test the difference in outcome variables between pretest and posttest. Because of the clear expectations for all the variables to increase and because of the small group number, one-tailed T-tests were used. In the case of the supervisors, a multivariate variance analysis was used to test the differences between pretest and posttest outcome variables. Regarding all workers, univariate and multivariate covariance analyses and logistic regression analyses were used to assess the program effects. Age was used as a covariate because, due to reorganizations, the pretest and posttest samples differed with respect to age.

The program was partly effective. Knowledge about the Alcohol Policy (its rules and procedures) increased significantly for all three study groups. So, the information via mass media, workshop and work meetings was effective. The attitude towards the Alcohol Policy was positive for all three study groups. Because it was already posi= tive at the pretest, there was no attitudinal change. Two other attitudes of workers also did not change. One attitude concerns not drinking alcohol at work. Respondents scored positively on this attitude at the pretest and at the posttest. The other un- 
changed attitude concerns not taking work into account when drinking (e.g. the evening before a workday). Respondents were positive about this, but not as strongly positive as on the other two attitudes and it did not change. The attitude of social medical workers and supervisors about the importance of the Alcolhol Policy was also very positive at pretest and posttest, with social medical workers scoring higher than supervisors. Social medical workers and supervisors differed with respect to their attitude about the importance of their own role in the Alcohol Policy. Both groups scored positively, but the score of social medical workers was twice as high as that of supervisors. The attitudes of both did not change.

The same kind of difference between social medical workers and supervisors appears with regard to their self-efficacy on constructive confrontation skills. The self-efficacy of social medical workers increased significantly. So, the workshop was effective in reaching its goal. But the less intensive intervention for supervisors (letter, brochure, assistance) did not result in an improvement of their self-efficacy.

Social medical workers and supervisors also differ in their evaluation of the cooperation between social medical workers and supervisors. Neither group was very positive about this cooperation, but the opinion of social medical workers increased. significantly while that of supervisors did not change.

The third research question was concerned with the improvement of the awareness of the employees' own drinking behavior and with changing this behavior when necessary. The results indicated that 8 to $9 \%$ of the respondents were excessive drinkers and that about $20 \%$ of them were aware that they drank too much. The awareness increased between pretest and posttest, and the intention to change behavior decreased. Neither change was significant. So, the mass media alcohol education was not effective.

The fourth and the fifth research questions were difficult to answer. The fourth question concerned the cessation of drinking during working hours and the promotion of drinking non-alcoholic drinks at receptions. It was clear that the knowledge of the organizational rules on alcohol use had improved, but it was not possible to check whether no alcohol was used during working hours. At receptions non-alcoholic drinks were indeed promoted. They were the only drinks that were presented on trays, and alcoholic drinks had to be specially ordered at the bar. Whether this resulted in a net change in the use of alcohol at receptions is not known. The fifth research question was about the effectiveness of the assistance system for problem drinkers. Because of the short period after implementation of the Policy and the posttest, the system could not be evaluated.

To conclude, major positive effects of the program were improvement of constructive confrontation skills of social medical workers, and improvement of knowledge about the alcohol policy. Supervisors did not change their constructive confrontation skills. And workers did not become more aware of their own drinking habits, nor did they improve their intentions to change their behavior when necessary. 


\section{Effectiveness of the primary preventive alcohol program}

The implementation of the primary preventive Health Promotion Program was restricted to only the first phase, the personal Health Profile. Therefore, researcli questions were:

1) How effective is the Health Profile on the behavioral determinants awareness, attitudes, social support, self-efficacy and intention to change behavior?

2) Can the Health Profile achieve a) a stronger relationship between respondents' objective behavior scores and their subjective belief about the healthiness of their behavior (i.e. a greater awareness) and b) a stronger relationship between respondents' objective health behavior scores and their intention to change behavior?

3) How do respondents evaluate the content and lay-out of the Health Profile?

The study design was quasi-experimental with a pretest and a posttest (no control group). The study population was formed by the workers of a municipal garbage collecting department of a large city. A health questionnaire was used to diagnose workers' health behaviors. Workers were invited to join department-based, group sessions in the canteen where the questionnaire could be filled out. Within a few weeks respondents received the Health Profile at their home address. Within two months after the pretest (about two to four weeks after participants received the profile) a posttest was conducted. This was done by means of telephone interviews.

The questionnaire contained 48 questions about health behaviors and behavioral determinants. The questions on behavior were asked during the pretest only, because no changes were expected within a couple of weeks. The questions on behavioral determinants were asked during the pretest and the posttest. The posttest questionnaire additionally contained some evaluative questions about the content and lay-out of the Health Profile.

Analyses were done on the following themes: self-reported health, nutrition, alcohol, smoking, exercise, Quetelet index, behavior risk index score, awareness, attitudes, social support, self-efficacy, and intention to change behavior. Changes between pretest and posttest in awareness, attitudes, social support, self-efficacy, and intention for the whole group of workers were analyzed by paired T-tests. To test whether the behavioral feedback (i.e. the Behavior Risk Index score) affected respondents' subjective beliefs about the healthiness of their behaviors (i.e. a better awareness), a univariate covariance analysis (ANCOVA) was conducted in which prior individual differences in subjective beliefs were held constant (dependent variable: posttest subjective belief; independent variable: Behavior Risk Index score; covariate: pretest subjective belief). The same kind of analysis was done with respect to the intention to change behavior.

All workers $(\mathrm{N}=328)$ were invited to join the group sessions and to complete the pretest questionnaire. The response then was $47.9 \%(n=157)$. A Health Profile was sent to $91.7 \%(n=144)$ of the respondents. Only from 63 respondents could satisfactory posttest information be obtained (see chapter 3 ). Therefore the analyses include 63 respondents. 
About half of the respondents were overweight $(49.2 \%)$. The majority of the respondents ate too much fat $(84.1 \%)$. The excessive drinking rate was $6.4 \%(n=4)$. More than half of the respondents $(59.7 \%)$ did not do any sports activities. Most of the respondents (75.0\%) scored negatively on 2 or 3 health behaviors (medium Index score), $11.6 \%$ scored negatively on 4 or 5 behaviors (high Index score), and 13.4\% scored negatively on 1 or 0 behaviors (low Index score). Awareness of the healthiness of own lifestyle behaviors was measured by combining objective Index scores and subjective beliefs on the healthiness of own behaviors. Of the respondents with a high Risk Index score, $42.9 \%$ thought their behaviors were unhealthy, $6.7 \%$ of the respondents with a medium Risk Index score thought so, while none of the respondents with a low Risk Index score thought so.

Results indicate that the awareness of own health behaviors increased significantly. Additionally, the Health Profile did succeed in significantly influencing attitudes like locus of control and outcome expectancy. Other behavioral determinants like self-efficacy, social support, and intention to change health behaviors when necessary did not change.

\section{Process evaluation of two alcohol programs}

The project goal was not only to investigate the effectiveness of a primary and a secondary preventive program, but also to generate recommendations on the best ways to implement worksite alcohol programs. Therefore, we formulated the following research questions on the implementation process:

1) In which extent were the programs delivered as planned?

2) What was the site response?

3) What was the recipient response?

4) What was the practitioner response?

5) What were the competencies of the personnel?

Data collection for the process evaluation took place throughout all planning phases of the project. A mix of six data collection methods was used: 1) reading company reports, 2) semi-structured group and individual interviews with representatives of different organizational groups, 3) open-ended and closed questions in written questionnaires, 4) registration forms, 5) minutes of the working group meetings, and 6) writing process reports. Data were analyzed as follows. Summaries of company reports were incorporated in diagnostic reports. Minutes were kept of the semi-structured interviews. These were then categorized by topic and summarized. The same (categorizing and summarizing) was done with the open-ended questions in the questionnaires, the minutes of working group meetings and the process reports. The closed questions in written questionnaires were analyzed using the SPSS-X statistical computer package. Because of the low response the registration forms were not analyzed.

Results indicate that the two worksites differed greatly regarding the extent to which they had developed a vision of their own on project goals and felt the project was 
theirs. In the pharmaceutical company the program was part of an umbreila health policy, in contrast to the municipal department that had no policy basis for the project. This was of great influence on the implementation of the project. At the municipal department the project stopped after the first phase, the Health Profile. The management team could not approve of the content of the program plan that the working group developed. In the pharmaceutical company, the internal personnel took their own initiative much more and the program was to a large extent delivered. as planned. The role of the external consultant was inappropriate at the municipal department; she was too much the motor of the project. In the pharmaceutical company the external consultant's role was more appropriate; there was a balance between the coaching and expertise part of the role. In both worksites feedback about diagnostic results was restricted; several relevant persons and groups (especially lower and higher management) were confronted with a ready made intervention plan and could not participate in program development. This was of negative influence on the implementation of the programs. The organization of the project was better in the pharmaceutical company compared to the municipal company; there was more clarity on the division of tasks, responsibilities, communication and decision lines. Finally, at both worksites there was some resistance against the incorporation of research in the project; workers were especially concerned about confidentiality of the research data.

A discussion on the results of the field studies can be found in section 1.7 together with a discussion on the results of the theoretical study that will be described in the next section.

\subsection{A theoretical study on the effect of drinking to cope with stress on sickness absence}

As indicated in the introduction, we conducted a theoretical study on the relation between work stressors, perceived stress, alcohol consumption and sickness absence in addition to the field studies. This section summarizes the theoretical background, methods and results. This siudy can increase our knowledge on determinants and effects of workers' alcohol drinking behavior. Additionally, the results could give indications on how to improve the content of worksite alcohol programs.

\section{The hypothesized model}

The hypothesized model is based on social learning principles. Social learning theory (Abrams \& Niaura, 1987; Marlatt \& Gordon, 1985; Wills \& Shiffman, 1985) hypothesizes that high levels of stress will lead to excessive drinking when individuals lack other more adaptive coping responses. Drinking to cope with stress is considered maladaptive because it does not solve the problem, but instead increases the 
problem. For example it could result in sickness absence (Marmot, North, Feeney and Head, 1993; Van Deursen, Raat and Garretsen, 1989).

Based on literature study (see chapter 5 for details), we proposed an interactional model on the relations between work stressors (i.e. bad working conditions), perceived stress (i.e. negative emotions), alcohol consumption (i.e. number of glasses per week), and sickness absence (i.e. having been absent at least one time during the past 6 months). Figure 4 visualizes our hypotheses. We first hypothesized that work stressors would predict work stress (arrow a). Second we hypothesized that work stress would predict higher alcohol use (arrow b). Third work stress and alcohol use were hypothesized to interact in their effect on sickness absence (arrow c). We expected that the combination of stress and excessive alcohol use (reflecting drinking to cope) would result in higher sickness absence. Based on the studies of Marmot, North, Feeney and Head (1993) and Van Deursen, Raat and Garretsen (1989) we also expected an interaction effect of abstinence and work stress on sickness absence. Furthermore, we expected buffering effects of female gender and having a partner on the relation stress-alcohol (arrow d). Finally, we test whether work stressors have direct effects on alcohol use and sickness absence (arrows e) in addition to their supposed indirect influence via perceived stress (i.e. mediated by perceived stress).

Figure 4: Hypothesized model.

$e$

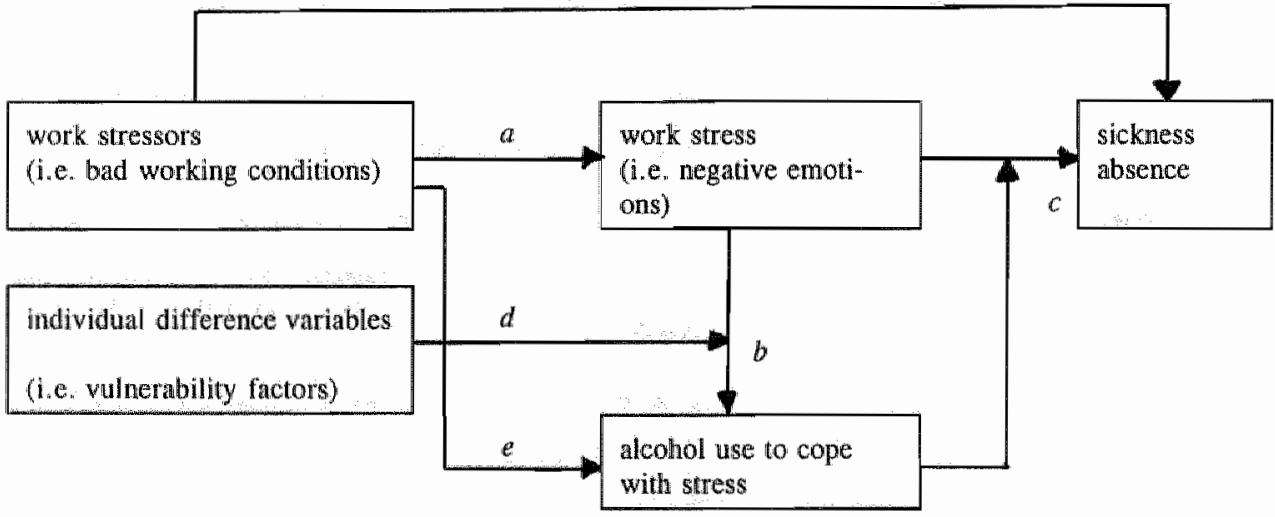

\section{Methods}

For this study we used data from three worksites (the pharmaceutical company, and the experimental and control municipal departments). Data were gathered via written health questionnaires in 1992 at the two municipal departments and in 1994 at the pharmaceutical company. The response was moderate: $47.7 \%(n=157)$ and $39.5 \%$ $(n=47)$ for the municipal departments and $53.6 \%(n=267)$ for the pharmaceutical company. The majority of the respondents from the municipal departments had a low levell of education ("blue-collar" workers) and were male. The respondents from the 
pharmaceutical company were highly educated ("white-collar" workers) and $63 \%$ was male. The total study population comprised 471 respondents.

Multiple linear regression analyses were used to predict stress and alcohol consurmption. Multiple logistic regression analysis was used to predict sickness absence. The moderating effect of individual difference variables on the stressor-alcohol relationship was tested by the interaction between gender with stress, and marital status (i.e. having a partner or not) with stress. Drinking to cope with stress was operationalized by the interaction of alcohol drinking with stress. The direct effects of stressors on alcohol use and on sickness absence were tested by adding them in the last step of the regression analyses. All analyses controlled for sociodemographic variables and type of worksite.

\section{Results}

Three major findings result from this study. First, in the presence of stress abstinence increased the risk of sickness absence compared with moderate drinking (see figure 5). We failed to find a significant relationship between excessive drinking and sickness absence although the relationship was in the predicted direction. The effect of abstinence could reflect medical problems of abstainers or a lack of skills to cope with stress. Abstinence was strongly related to a lower education. The nonsignificance of excessive drinking may have been due to lack of power because of the small groups. Alternatively it may only be present at levels well in excess of the threshold used in this study. Second, stress mediated the stressor-alcohol consumption and the stressor-sickness absence relationships, although stressors had also direct effects on sickness absence (especially the negative effects of work on private life). Third, no moderating effects of individual difference variables on the stress-alcohol consumption relation were found. To conclude, this study supports the hypothesis that workers' alcohol drinking behavior is related to work stress and sickness absence. The results suggest that moderate drinking has a buffering effect on the relation between stress and sickness absence and that abstinence is at least as unhealthy as excessive drinking. Future research should investigate if the effect of abstinence is due to medical problems, a lack of coping skills, or other factors. 
Figure 5: The interaction effect of stress and alcohol consumption on sickness absence.

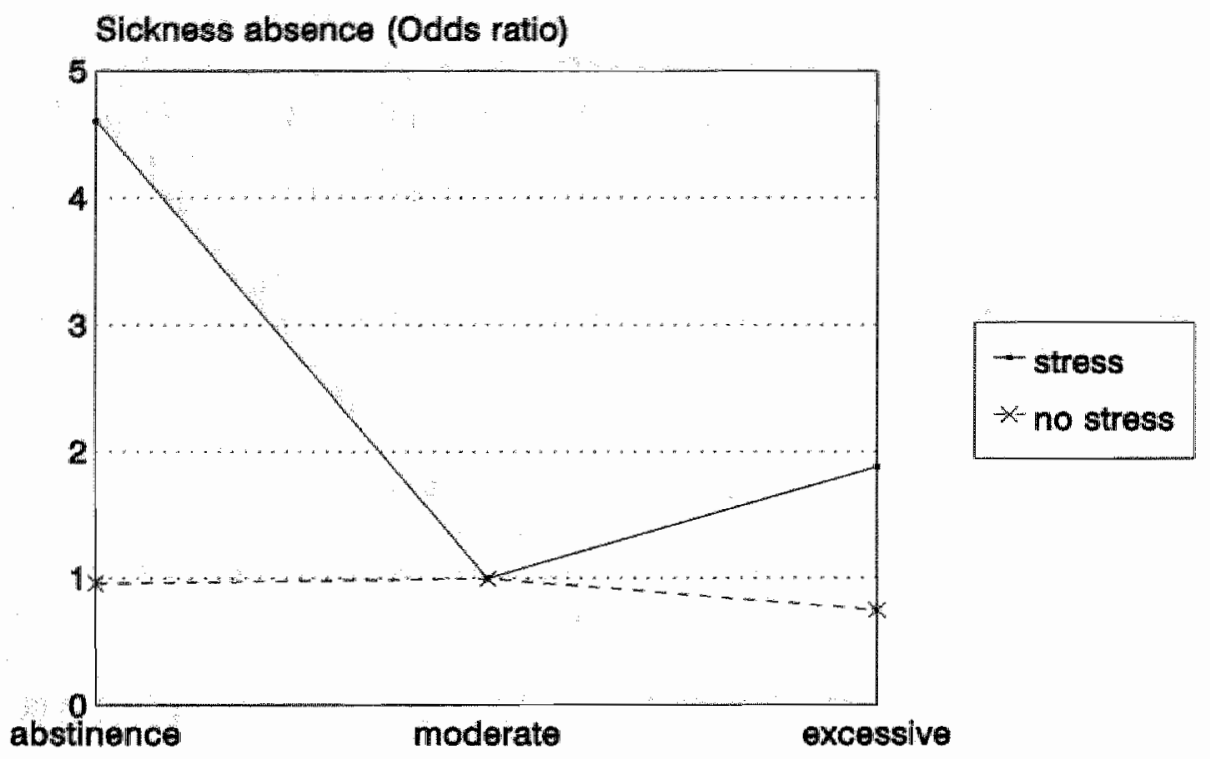

Alcohol consumption

\subsection{Discussion and conclusions}

The purpose of this research project was to assess the feasibility and effectiveness of two worksite health programs aimed at preventing alcohol problems. This final section discusses major learning points of the project and gives recommendations for practitioners as well as researchers who want to implement and evaluate worksite alcohol programs in the future.

\section{Content of secondary and primary preventive alcohol programs}

The long-term goal of both programs was the same, namely preventing alcohol problems, but the secondary and primary preventive programs had different short term goals and different program components. The secondary preventive program's major goal was to reduce and prevent alcohol problems. The program components were alcohol education, skills training for supervisors and social medical workers, and a policy with regulations and procedures for assistance to problem drinkers. The primary preventive program's major goal was increasing awareness of the individual's own health behavior (including alcohol drinking behavior) and improving intention to behavioral change when necessary. The program components were a 
Health Profile (implemented) and behavior change programs (not implemented). How could these components of both programs be improved?

\section{Alcohol education}

Alcohol education was given via mass media (company magazine and canteen campaign) in the pharmaceutical company and via the Health Profile in the municipality department. Results indicate that two major improvements can be made.

Firstly, global information on alcohol and its risks does not improve awareness of the risk of a person's own behavior. To break through the denial process with respect to one's own behavioral risks, the education must be more personalized and detailed. This could be done with a feedback method such as our Health Profile. Such a method can be offered to all workers (primary prevention), but it can also be used in (individual) counseling sessions with problem drinkers (secondary prevention).

Secondly, a major improvement of alcohol education at the worksite should be the incorporation of the drinking-to-cope concept. A short diagnostic questionnaire should be used to investigate to what extent workers drink to cope with (work) stress. This set of questions could be based on the existing "psychological dependence" scale (Calahan, 1976; see also Garretsen, 1983) and added to the questionnaire used for the Health Profile. The Health Profile itself then should include feedback about drinking to cope. Such a diagnostic instrument on stress and alcohol could also be used in stress management programs and in health promotion or lifestyle programs. The latter programs could also add smoking and eating as possible maladaptive coping responses, and so putting at the core the underlying coping and addiction mechanisms.

\section{Skills training on constructive confrontation}

The skills training on constructive confrontation skills was successfully implemented for the social medical workers at the pharmaceutical company. But we did not succeed in convincing management about the usefulness of skills training for supervisors. We have two recommendations to improve supervisors' participation in skills training.

Firstly, better participation of line management in developing the program could improve involvement with the content of the program. So, other planning strategies must be used, for example feedback sessions (see below).

Secondly, the training must be less intensive and more compatible with other programs for supervisors. The skills of constructive confrontation have much overlap with general social skills or communication skills. Therefore, alcohol problems could be added as a theme to existing courses on skills training for example courses on leadership style, social or communication skills, skills needed for appraisal talks with workers ("functioneringsgesprekken"). A short version of the one-day course in this project should be developed that focuses on the characteristics (signals) of alcohol problems and constructive confrontation skills. In addition, individual assistance of a social medical worker must be offered to supervisors who are confronted with problem-drinking subordinates. 


\section{Alcohol policy}

The altcohol policy at the pharmaceutical company was formulated in an Alcohol. Policy Document that contained the vision of the company towards responsibilities of the company and of the worker in case of alcohol problems (work performance or functioning/dysfunctioning formed the core in this vision), regulations (no alcohol during working hours, promotion of non-alcoholic drinks at receptions) and procedures for assistance to problem drinkers (roles and tasks of social medical workers and supervisors).

The project firstly reveals that careful explanation of the company's vision (why are we initiating this? what are the goals? what will it mean in practice?) in company magazines, work meetings, etcetera, improved knowledge and acceptance of the pollicy.

Secondly, except for supervisors, the project also succeeded in making clear roles and tasks relevant for assistance to problem drinkers.

With respect to the third component, regulations on drinking during working hours, we recommend making a more detailed analysis of drinking subcultures and formulating more detailed rules that better can be controlled. From a theoretical perspective, a better analysis of drinking subcultures could also give more insight into the effects of such subcultures (social influence) on individuals' drinking behavior. Such an analysis should be added to the qualitative part (interviewing individuals and groups) of the problem diagnosis at the start of the project.

\section{Health Promotion Program}

The primary preventive program, as implemented in this project, consisted of a Health Profile that gave workers feedback about the healthiness of their behaviors. This was only the first phase of a Health Promotion Program; originally a package of behavioral change programs was planned as a follow-up. So, we can give no specific recommendations on behavioral programs except to explicitly integrate the drinking-to-cope concept (see above).

Also we recommend composing a workbook with possible intervention programs (including goals, costs, etcetera) in an early stage of the project to facilitate adoption and implementation. Such a workbook might enable inexperienced working group members and higher managers to form concrete ideas about the program and indicate their own priorities.

The Health Profile itself was successfully implemented and effective in raising awareness about the healthiness of participants' own behaviors and in improving some attitudes. As indicated before, the instrument could be improved by adding the drinking-to-cope concept and other coping styles. In general, people are very interested in getting personalized, specific information about their own "state of art", and they are also interested in tailored follow-up programs in which they learn how they can change their unhealthy behaviors.

Confidentiality of the data is very important: a system should be developed so that neither the company nor the researchers can connect names and outcomes. Instead of, or in addition to, sending the results to the workers' home address, the company physician might be involved in communicating the results to the worker. In the Netherlands this could be integrated in the periodical health examinations ("perio- 
diek geneeskundig onderzoek") that are common in certain areas and for certain groups of workers.

\section{Planning of worksite alcohol programs}

\section{Use of planning models and the role of external advisors}

To plan the development, implementation and evaluation of the programs we used the PRECEDE-PROCEED model of Green and Kreuter (1991). As this model is primarily focused on solving the health problem, we were preoccupied by the content of the programs and were less prepared for the specific barriers within a worksite context regarding the implementation of the programs.

The first barrier we were confronted with was the project structure. This created a somewhat artificial situation because the ALCON Foundation and the university were the demanding party (we needed companies for our project), while normally companies ask the ALCON Foundation for help. We had had contact with a lot of other companies before the municipal garbage collecting department and the pharmaceutical company agreed to participate. There was a lot of interest but the emphasis on alcohol frightened some companies (they were afraid to be seen as a company with a lot of alcohol problems); most companies were interested in the Health Promotion Program but disliked the emphasis on alcohol in this program. Furthermore, in 1990 most companies were only starting to develop health policies in light of the new Dutch Work Environment Act ("Arbeidsomstandighedenwet") but were not yet ready to determine whether they needed (behavioral) intervention programs or what kind of programs they needed most. So, it was difficult to motivate companies in such a short period of time as was available in the project. These conditions probably have influenced the implementation of the Health Promotion Program in the municipal department because this department had not developed a vision of their own on what the project goals should be. The situation at the pharmaceutical company was more normal, because they indeed asked the ALCON Foundation for help during the period that we were looking for participants in the project.

The most important thing that we learned from this difficult start of the project was that it is essential to inventarize the vision of the company, their needs, their policy basis, etcetera, intensively, and that as an external consultant you should find a balance between a coaching and an expertise role. The company must want to implement the program to reach specific concrete goals and as an external consultant you have to guide company members to do most of the work themselves. The expertise role consists of offering insight into possible program components that have proven to be effective in reaching certain goals and perhaps in giving some courses yourself. Furthermore, the expertise role might consist of executing diagnostic and evaluative research; the external consultant might also be the one who writes diagnostic reports and proposals for interventions. It will differ from company to company, but agreement on the roles, responsibilities and concrete tasks is essential for a good start. 
Later on in the project, in addition to the PRECEDE-PROCEED model (Green and Kreuter, 1991), we used a model from the field of organization development and change: the General Model of Planned Change (Cummings and Worley, 1993). This latter model was very useful to interpret barriers from the worksite context (see chapter 4). Also for the start of a project (the entering and contracting phase in terms of Cummings and Worley), the book gives very useful recommendations. For future worksite health projects we therefore would advise practitioners and researchers to use the General Model of Planned Change in addition to the PRECEDE-PROCEED model.

\section{Participation}

For a successful program it is essential that company members participate in developing and implementing the program. As already indicated above, company members should give their vision and priorities on program goals, and they should be involved in developing and implementing the program as well. To attain this kind of participation it is very important to develop a good organizational structure for the project, to appoint the right people in the right functions and to create appropriate communication lines with higher management who decide on the project. Furthermore, in addition to a small group of direct executors and decision takers, a broad group of relevant company members (and at certain moments all personnel) should be involved in interpreting diagnostic results and giving priorities for program components. Company members can also be involved in the implementation and organization of actual programs.

Our project determined that supervisors are a very important group. They are relevant with respect to the content of the alcohol program (constructive confrontation strategy), but also with respect to communication about the project to their subordinates. If they think the program is not worthwhile, this will negatively influence the participation of "floor workers" in the program. They are also important key persons in explaining research topics like confidentiality.

So, based on our experiences we would advise trying to involve line management in all project phases. One way to do this is to organize feedback sessions for them about the diagnostic results and involve them in drawing conclusions and developing program goals and implementation plans. Additionally, the need for feedback to other groups or in other phases of the project (especially evaluation and continuation) must be assessed. Cummings and Worley again give useful recommendations for this.

\section{Institutionalization}

A final learning point from our project regarding planning concerns the institutionalization phase. A change project is only finished when agreements are made on continuation of certain program components or on initiating new components depending on the evaluation results. In our project institutionalization was only relevant in the pharmaceutical company. In the evaluation report some recommendations were formulated for institutionalization and in the final meeting with the project leader and the manager for Personnel and Organization, the latter introduced some ideas for future activities, but no concrete plans were written. So, we would recommend that 
future projects plan more carefully meetings with relevant persons in which institutionalization plans are developed.

\section{Methodollogical limitations}

\section{General limitations of field studies}

This project included two field studies in which priority was given to intensive participation of the worksites in developing and implementing the interventions. These interactions between intervention and worksite resulted in continuing adjustments of goals, content and implementation strategies. Consequently, some goals that were formulated at the start of the project became less important when the project proceeded, and other goals got more priority. Therefore, it is important to plan two kind of measurements: a global, overall measurement of the effects of the total intervention and more specific measurements of the effects of intervention components. Questionnaires for the latter type of evaluation can be developed when decisions are made about specific intervention goals. Evaluation of intervention components should take place within in a short period before and after the intervention. This resembles the situation at the pharmaceutical company in our study where samples of social medical workers and supervisors received additional pretests and posttests focused on their role and tasks in the alcohol policy.

That the interaction between intervention and worksite can have more extreme effects than the adjustment of measurement instruments, is illustrated by the decision of the municipal department to stop the project. In this case, the changes in priorities that were made by the working group were not accepted by the management.

Besides disadvantages, field studies also have advantages compared to experimental studies in which everything can be controlled. The problems that emerge during implementation offer insight into hindering and facilitating factors with great practical relevance. Consequently, the present study forms a good basis for implementation and evaluation of future worksite alcohol programs on a larger scale.

\section{Threats to internal validity of the field studies}

The quasi-experimental design without control groups is a major methodological limitation of the field studies. As described in section 1.4, the pharmaceutical company refused a control group for privacy reasons. For the municipal department a waiting-list control group was found, but not used in the evaluation study because the intervention was stopped. A quasi-experimental design can result in history and testing as possible threats to internal validity of the studies. A history effect can result from other activities that take place during the intervention period and that can influence the outcome variables. The period between pretests and posttests in most of our studies was very short which minimizes the chance of history effect (i.e. the studies with social medical workers and supervisors in the pharmaceutical company, and employees in the municipal department). Only the study with employees in the pharmaceutical company has a long period between pretest and posttest ( 2 years) and a history effect there cannot be excluded. We know that reorganizations took place in the pharmaceutical company during the project. The reorganizations resulted in a 
slightly different age distribution among employees, but we controlled for a confounding effect of age by addling age as a covariate to the analyses. We cannot think of other activities that could have influenced the findings.

A testing effect can result when pretests raise awareness and increase knowledge on themes that are being questioned. Subsequently, the pretest becomes an intervention in itself: A test effect is excluded in our studies with supervisors and employees at the pharmaceutical company because we used different random samples for pretests and posttests with these groups. A test effect cannot be excluded in the study with social medical workers at the pharmaceutical company and in the study with employees at the municipal department. We think a testing effect has little implications for generalization of the results to practice, because a diagnostic instrument like the questions in our pretest often are part of the intervention in practice. Especially in case of the Health Profile the pretest questionnaire in combination with feedback information is even meant to raise awareness.

\section{Generalizability}

In this study we used samples of the worksite population to evaluate the programs. The generalizability of the results to the total worksite population and to other worksites therefore depends on the representativeness of these samples. In the case of the studies with social medical workers and supervisors at the pharmaceutical company we have no background information on sociodemographic characteristics. Therefore we cannot exclude a selection bias; respondents in these studies could be a relatively high motivated group. With respect to the studies with employees at the pharmaceutical company and the municipal department we do have background information on sociodemographic variables. Both groups of respondents do not differ with respect to sociodemographic variables compared to the total worksite populations (see chapter 2 and 3 for more detaills). Thus, results seem to be generalizable to the total worksite population. But at the municipal department the situation is quite complex; only $34.7 \%$ of the respondents who received a Health Profile responded to the posttest and were included in the analyses. We have no indications that these group differs significantly from the total work population or from the respondents who only responded to the pretest with respect to sociodemographic variables or lifestyle behaviors (see chapter 3 ). The majority of the nonresponse to the posttest at the municipal department can be explained by logistic problems; telephone numbers of a large group of respondents were unknown at the personell department and another group could not be reached during evening hours within the research period. Only a group of 13 respondents refused to participate in the posttest and this group was included in the analyses using their pretest scores as posttest scores. So, selection bias at the municipal department seems to be limited but cannot be excluded totally.

Generalizability of results of the field studies to other worksites is debatable, because both worksites were not representative of the Dutch working population. The pharmaceutical company can be characterized as a typical white collar worksite, while the municipal department is a typical blue collar worksite. Therefore, intervention studies must be executed on a larger scale to learn more about the feasibility and effectiveness of worksite alcohol programs in different situations. 
The theoretical study on relations between stress, alcohol and sickness absence used data from the pharmaceutical company and mumicipal departments. Compared to the total Dutch working population this study contains relatively more male, middle aged workers with a low level of education (see chapter 5) although the differences are small. To conclude, generalizability of the results of the theoretical study to the total working population is limited. The same kind of study should therefore be repeated with a larger sample that is representative of the total Dutch working population.

\section{Cross-sectional design of the theoretical study}

With respect to the theoretical study on the relations between stress, alcohol and sickness absence, the major methodological limitation is the cross-sectional character. Therefore nothing can be said about cause and effect, only about associations. Future studies in this area must therefore be prospective and also explore feedback loops.

\section{Measurements}

Also with regard to the measurement of certain variables there are limitations. Especially improvements could be made in measuring stress, sickness absence, alcohol problems, and alcohol drinking behavior.

Stress was measured using the questionnaire on work and health ("Vragenlijst Arbeid en Gezondheid") of Dijkstra, Van der Grinten, Schlatmann and De Winter (1989). Four emotional feelings are measured dichotomously. A more detailed measurement and an interval scale would improve our measurement of stress.

Sickness absence was only measured subjectively and dichotomously (respondents themselves indicated if they had been absent one or more times during the past half year). More quantitative measurements are needed, for example company records on sickness absence. Also it would be relevant to inventarize the causes of sickness absence.

Alcohol problems were not measured properly. In the pretest measures we used the measurement method of Knibbe and Garretsen (inventarizing several possible problem areas in addition to alcohol drinking behavior itself, see for exanple Garretsen, 1983), but this did not work well. In our relatively small research groups only a very few respondents fell into the problem-drinking category and furthermore the measurements were not reliable; we received signals that people did not dare to fill out these kinds of questions honestly because they were afraid the company would misuse the information. Therefore, we did not measure alcohol problems in that way again in the posttests.

But we can estimate the percentage of problem drinkers based on the findings of Knibbe and Garretsen. They found that $60 \%$ of the excessive drinkers ( $>20$ glasses/week) were problem drinkers. In our study this would mean about $5.4 \%$ problem drinkers in the pharmaceutical company (white collar workers; $5.9 \%$ in the pretest and $4.9 \%$ in the posttest) and $9.1 \%$ for the two municipal departments (blue collar workers). These findings are in line with the findings of Gründemann (1989) for the total Dutch working population who used the same estimation method and found $7.3 \%$ problem drinkers. 
We would advise worksites to set up a registration system for problem drinkers and to consequently evaluate the quality and results of the assistance that is offered to them. This should be a task for the social medical team.

With respect to the measurement of alcohol drinking behavior also improvements can be made. We followed Knibbe and Garretsen, and measured 1) abstinence, 2) frequency and quantity of alcohol use during week days and weekend days, and 3) frequency of drinking 6 glasses or more per day. With these questions the average consumption can be calculated (number of glasses per day) and respondents can be categorized as abstainers, light, moderate or excessive drinkers. When we compare our measurement methods with those recommended by Swinkels (1991) based on a comparison of different measurement methods, prevalence findings and official per capita consumption figures (the amount of alcohol sold in the shops), we can conclude that two improvements could be made regarding our measurement methods.

The major improvement would be to measure abstinence in a more detailed way. We only asked if people considered themselves as abstainer (explaining that that was someone who never drank alcohol), people could answer yes or no. This resulted in a comparable abstinence rate for white collar workers (pharmaceutical company) and Gründemann's population and a much higher abstinence level among our blue collar workers (municipal departments) than the abstinence level in Gründemann's population. It would be more accurate to ask if people drank alcohol during the last 12 months and offering different alcohol drinks as answer categories including the possibility "I did not drink alcohol the last 12 months". This would discourage the group of drinkers who drink less than once a month to indicate that they are abstainers (Swinkels, 1991).

Secondly, according to Swinkels (1991), our measurements might be improved by using closed answer categories (e.g. 1-7 glasses, 8-14 glasses etcetera), instead of open ended items (e.g. ... glasses), for the questions about the quantity of alcohol use on a week day or weekend day. But the disadvantage would be that no exact average alcohol consumption could be computed then. When closed answering categories are used the mean number of glasses within a category is used to compute (estimate) the total number of glasses per week. As there are no strong indications that closed answering categories are better, we would recommended using open ended answering categories for practical reasons. The total alcohol consumption per week is in fact a very relevant measure for practical alcohol education. Educational recommendations are formulated in terms of number of glasses per week and per day; the Netherlands Bureau for Food and Nutrition ("Voorlichtingsbureau voor de Voeding") for example recommends drinking not more than 2 or 3 alcoholic drinks per day and not to drink every day. Using open ended answering categories has additional advantages for evaluation research because changes between pretest and posttest measures can be calculated more precisely. 


\section{Ethical limitations}

According to the Dutch Work Environment Act ("Arbeidsomstandighedenwet") employers and employees have a shared responsibility with respect to safety, health and well-being of employees. Worksite health programs are a means to promote safety, health and well-being. But, in practice, there is a lot of discussion about inappropriate interference in personal lives when these programs address lifestyle behaviors.

Therefore the Dutch minister of Social Affairs and Employment asked the Dutch Work Foundation ("Stichting van de Arbeid") for advice on further policy required concerning alcohol and work. This resulted in a report describing the visions of both employers and employees (Stichting van de Arbeid, 1993). Employers and employees agree that social policy forms the structure for an alcohol policy. An alcohol policy must contain prevention, assistance, correction/sanctions and evaluation. But employers and employees disagree about whether employers might use control instruments. Employers think total alcohol bans and alcoliol tests are acceptable in certain risk functions. While employees think alcohol tests are unnecessary and undesirable because they are in conflict with the respect for personal privacy (article 10 of the Dutch constitution) and the inviolability of the human body (article 11 of the Dutch constitution). Employees think alcohol tests would only create a climate of distrust that would be counterproductive for a successful alcohol policy. From this report it can be concluded that the limits of an worksite alcohol policy seem to lie at blood testing because blood tests threaten workers' personal privacy and physical integrity.

A similar conclusion can be drawn from the Dutch juridical \iterature on testing employees on alcohol and drugs (see Dute (1994) for a review). Geers and Gevers (1992) formulate three criteria for blood testing: relevance, proportionality and subsidiarity. The testing must be relevant with respect to the goal, it must not be out of all proportion, and no less drastic alternative may exist. Only in functions with a high safety and health risk may blood testing be allowed. But employers must have valid reasons based on dysfunctioning. The Dutch government too views dysfunctioning a necessary condition for alcohol tests (Tweede Kamer 1993-1994).

Subsequently, we would advise planners not to include alcohol tests in worksite alcohol programs. Tests should only be used in individual cases where continuing dysfunctioning brings increased safety and health risks. Evidence from an alcohol test could then be the start of an assistance program for a denying and unmotivated problem drinker. As we explained in the training on constructive confrontation skills, for each problem worker a good registration system must be set up with concrete examples of dysfunctioning. In the assistance program the problem employee, a social medical worker and, if necessary, an external assistance organization are involved. Goals must be formulated with regard to work performance along with sanctions if no progress occurs.

Not only specific alcohol programs but also broader Health Promotion Programs interfere with personal lives. Employees fear negative consequences if their lifestyle behaviors become known to the management. Especially Health Risk Appraisals or Health Profiles collect concrete personal data. Confidentiality must then 
be guaranteed. Data must be reported to the management anonymously and at group level. Employees themselves (e.g. the Union) must be asked for advice on a confidential diagnostic and feedback system at individual level.

\section{Conclusions and implications}

This study is the first Dutch evaluation study on worksite alcohol programs. Despite the methodological limitations, it therefore provides valuable knowledge on the possibilities and difficulties of implementing worksite alcohol programs in the Netherlands, and the effectiveness of different program components. Therefore, this project can be the basis for improving worksite alcohol programs and implementing them on a larger scale. The theoretical study on the determinants and effects of workers' drinking behaviors is rather unique at international level. The results support the theoretically hypothesized coping function of workers' alcohol consumption, and its negative consequences in terms of sickness absence.

The final section of this overview formulates concrete implications with respect to development and implementation of worksite alcohol programs, future research studies, and tasks of practitioners.

\section{Implications for development and implementation of worksite alcohol programs}

Concerning the original worksite alcohol program that the ALCON Foundation offered to worksites, we would recommend improving that program by:

- developing a shortened module for supervisors on constructive confrontation and promoting integration of this module as a theme in existing training programs for supervisors

- $\quad$ improving the alcohol education component by giving personalized feedback on the individual's risk behavior, and integrating a diagnosis of the extent to which alcohol use functions as a coping response to stress

- improving the involvement of managers and supervisors especially at the start of the project by giving feedback sessions on the content and progress of the program

- stimulating a clear vision and formulation of concrete, realistic program goals at the start of the program.

\section{Implications for researchers}

With respect to future research we would recommend the following studies:

- a prospective, large scale study on determinants and effects of workers' alcohol drinking behavior (including abstinence) to retest and refine our findings an experimental, large scale study on the effectiveness of an improved Health Profile (including education on drinking to cope with stress)

- a prospective study on the effectiveness of treatment offered to problem drinkers, not only the work performance and drinking behavior of the problem drinker, but also the quality of the assistance (e.g. constructive confrontation skills) given by supervisors and social medical workers must be evaluated. 


\section{Implications for practitioners}

Practitioners who work as external advisors should find a balance between their coaching and expertise roles. Internal program leaders should decide on an organizational structure for a worksite alcohol program and on a division of tasks. Internal and external project members could best work together if they agree on basic steps in planning the project. Therefore this overview is closed by presenting four practical planning steps for implementation of a worksite alcohol program based on the experiences of our project. These recommendations are worked out in more detail in a practical handbook that can be ordered from the ALCON Foundation (Kroodsma \& Bouwer, 1995). These recommendations are written for internal project leaders, for example a social worker or personnel officer.

1 The start: the orientation phase. Whatever may be the reason for initiating an alcohol policy, a concrete alcohol problem or a health policy or something else, the way to develop an alcohol policy remains the same. A basic assumption is that real and lasting changes can occur only when key persons within the company give their total support. It is also essential that certain basic conditions for a successful implementation of a project are fulfilled. Basic conditions in this stage are commitment to an alcohol policy, an effective project organization, and a decisional structure.

To detail the commitment of relevant people in the company you need to organize meetings with them. Relevant key persons are high and middle managers, personnel officers, health/social/safety workers, and union members. These meetings can give you, as a project leader, insight into the existing situation and enable you to explain project goals and motivate others for the project. Questions you can put to key persons are, for example: Do you recognize the problem? What are your experiences? Do you think our company must pay attention to alcohol and work? Which policy could serve as a framework (e.g. social policy/working conditions policy/personnel policy/safety policy/quality policy/health policy)? What role do you see for yourself? What roles would others have? What are your suggestions for the project?

After these orienting activities it is necessary to develop an effective project organization. You can initiate a working group with relevant key persons that will be responsible for the total process of development, implementation and evaluation of the project. You must make an inventory of the possibilities and facilities you have, whether external consultants should be used, how much time you have, etcetera. At this stage it is important to define the problem and a desired end goal with which all relevant persons can agree. The tasks of the working group are policy development, organization of educational and counseling activities, and communication. To maintain the commitment for the project continuing communication is necessary. Therefore you must develop a communication plan in which you make an inventory of which communication channels you can use to give information about the project (e.g. work meetings, union meetings, management meetings, company magazine, personal letters, etcetera).

Before you go on with developing detailed plans, it is important to define the necessary boundary conditions that you need and to obtain the agreement of top management. Otherwise you might do a lot of work for nothing or realize later that 
your facilities are too limited. You should make a global budget in which you include secretarial support and costs of educational activities and communication. Later you can specify these costs. To obtain managerial agreement on your (global) plan, it is important to formulate clear goals and a time schedule.

To check if you can go on to the next phase see if you can answer the next questions. Why is an alcohol policy important for your company? What will be your working methods and to whom will you report? What are your goals? In what time you want to realize these goals? What do you expect from others, especially from working group members? What are the global costs?

2 A good preparation: the diagnostic phase. After the top management has given permission to start the project, you and your working group can begin to work out a detailed policy plan. But before you can write the policy plan, you must systematically diagnose the situation by collecting information, draw conclusions and then develop goals and intervention plans. You can do all this by yourself or put out certain parts to an external (research) bureau. The specific information about the company's situation will motivate managers and others for the project and will be the basis for the evaluation.

The collecting of information can be done by holding individual or group interviews and by written questionnaires. Additionally, existing information sources like sickness absence registration, existing reports on health and other relevant matters should be consulted. The questions can be categorized as follows:

1 Alcohol consumption: How much alcohol do workers drink in general? Do they drink during working hours? How much and when? What do workers think about their own drinking habits? What do they know about the working of alcohol and its consequences?

2 Alcohol culture: Is alcohol available at work? What are formal and informal drinking rules? In what situations is alcohol used? What is the attitude of management, supervisors and workers about drinking at work?

3 Risk factors: Which working conditions stimulate the use of alcohol? Are there situations that create safety problems when alcohol is used?

4 Work performance: What is the prevalence of work performance problems that are related to alcohol use? Do managers, supervisors and social medical workers have the skills to signal alcohol problems at an early stage? What are the formal and informal procedures for assistance to problem drinkers? Are these procedures well known and do they function well?

5 Assistance to problem drinkers: What experiences does the company have with assistance to problem drinkers? What are the contacts with external consultancy organizations like?

6 Regulations: What regulations exist regarding alcohol use? Are the regulations well known? How are they controlled?

7 Need for educational activities: Is there a need for educational activities (e.g. alcohol education, skills training)? Who intend to participate?

8 Need for alcohol policy: Is there a need and commitment to sharpen alcohol regulations? Is there a need and commitment for additional procedures regarding assistance to problem drinkers? 
After the diagnosis is made, the results must be set down in a report. Then the results must be fed back to the working group and other relevant persons (e.g. management, supervisors, social and health workers, union). Depending on how large your company is, you could decide to organize special feedback sessions. The reactions you get to the results are a very important help for drawing conclusions and developing detailed goals and interventions.

The last activity in this developing stage is writing a policy plan jointly with the working group. In the policy plan you must make explicit what the problem is and what possible solutions are. This includes specific goals connected to specific intervention plans. It must be clear what kind of interventions will be implemented, how many people will participate, who will implement the activities, when, what the costs are, etcetera. Also, the policy plan must include plans for the evaluation of the project; how will the effects of the project be assessed? To end the diagnostic phase the top management and the union must agree with the policy plan. Besides a solid plan, a clear presentation of the plan too can stimulate a positive decision.

3 Introduction of the new policy: the implementation phase. After a formal agreement with the policy plan, the new policy can come into force and the educational activities can be implemented (e.g. skills training, mass media campaign). In the policy plan all these activities are mentioned. The actual implementation requires thorough preparation, supervision and, if necessary, adjustment.

The preparation consists of making a detailed time schedule for all activities including the preparing activities like writing an announcement for the company"s magazine. You should also talk to key persons personally. You can organize special instruction meetings for this so that the project really comes alive. For a large project with many persons involved it is convenient to write a detailed scenario. Make clear who is responsible for which part and what is actually expected.

The supervision of the implementation requires you to follow the activities, stay in contact with the executive personnel and be open for their reactions. If some things turn out differently from what was expected, you need to adjust the plan. Express how much you appreciate everybody's work and keep motivating them for example by feeding back positive results that you already observe.

4 Lasting attention: the continuation phase. After an intensive developing and implementation period, the danger exists that the attention for the alcohol policy fades away. Special activities aimed at evaluation and continuation can prevent this.

The evaluation of the project is aimed at both the effects as well as the process. The main questions are: to what extent have we reached our goals? and is the project delivered as we planned? Whether you are able to evaluate your goals properly depends on how thoroughly you executed the developing and diagnostic phase. If you have not formulated a clear problem and specific goals, you cannot evaluate them. And if you did not describe the situation before the project, you cannot say if the situation improved or not. So, it is important to take comparable measurements in the diagnostic and continuation phase. Ideally, you must use the same questionnaires. The process evaluation concerns an evaluation of the quality of the project organization, the working group, the communication, the decisional structure, the evalution 
of the different intervention activities, the participation level, etcetera. This should result in recommendations for future projects; what should we do differently or in the same way the next time we want to implement a comparable project? The evaluation results are specified in an evaluation report. You include conclusions and recommendations for continuation or adjustment.

To stimulate continuation of the policy you should organize feedback meetings about the evaluation results and stimulate others to make recommendations for future activities. You should make a continuation plan that is agreed by management and union. In that plan you should try to integrate the alcohol policy in other (umbrella) policies or projects, ask for periodic evaluations of the policy, for example in yearly social reports or at certain meetings, and propose to include the policy rules and procedures in personnel handbooks, general company information books, and so on. Finally, if necessary, the policy should be adjusted to new or changing problems. In that case you should follow all four planning phases (developing, diagnostic "implementation and continuation phase) again. 


\section{Effectiveness of a worksite alcohol program}

A shortened version of this chapter will be resubmitted to the Journal of Studies on Alcohol as a brief report.

Authors: R.M. Vasse, F.J.N. Nijhuis, G. Kok and A.T. Kroodsma

\subsection{Abstract}

Objective: Excessive alcohol drinking create serious health and social problems for workers. Furthermore, alcohol problems result in substantial costs for companies and society as a whole. This study evaluated the effectiveness of a worksite alcohol program in a large pharmaceutical company ( $\mathrm{N}=1600$ ).

Method: The study design was quasi-experimental (no control group, no randomization). Three study groups received written questionnaires before and after the intervention. Group and individual interviews gave background information. The three study groups consisted of: all social medical workers $(n=10)$, a sample of supervisors (pretest: $n=78$, posttest: $n=63$ ), and a sample of all workers (pretest: $n=319$, posttest: $\mathrm{n}=267$ ). The most important intervention elements were an Alcohol Policy, a skills training for social medicall workers and supervisors, and educational activities for all workers.

Results: The Alcohol Policy was well known and accepted. The training on constructive confrontation skills was effective for social medical workers, but not for supervisors. The educational activities were not effective in improving awareness and intention to change excessive drinking behavior.

Conclusions: Worksite alcohol programs are useful. The theme must be carefully approached because of its sensitiveness. In future projects much more effort must be made to involve managers and supervisors in the program. Health education activities on alcohol should emphasis "healthy drinking" in stead of "problem drinking". The education should be more tailored to the individual worker. To prevent alcohol problems the theme alcohol can be integrated with other health educational activities. In addition, work stressors related to problematic alcohol use should be reduced. 


\subsection{Introduction}

An increasing number of Dutch companies are developing Health Programs in order to promote the health of their workers. This tendency is strongly related to the high costs resulting from absenteeism and disability. The Dutch Government bears most of these costs, but new laws resulted in more responsibilities and costs for the companies themselves.

The costs of alcohol abuse related to work has been studied by the Dutch Economic Institute (Meijer \& Tjioe, 1990), whose study shows that about 30\% (HFL 588 million) of the total costs related to alcohol abuse (HFL 2000 million) is workrelated. The largest part (95.7\%) of these work related costs is caused by extra sickness absence of excessive drinkers compared mith moderate drinkers.

Empirical studies confirm the relationship between alcohol and absenteeism. Both excessive drinking and abstinence result in an increased sickness absence rate compared with light and moderate drinkers (Marmot et al., 1993; Van Deursen et al., 1988; Vasse et al., submitted). From a social learning perspective alcohol drinking is considered a maladaptive coping response with regard to stress (see Abrams \& Niaura, 1987; Marlatt \& Gordon, 1985), and stress is one of the most important causes of absenteeism and disability. Part of this stress might be related to alcohol abuse. The literature confirms the existence of stress related drinking (see Cooper et al. (1990) for a review of literature on workstress and alcohol drinking). So the prevalence of alcohol problems may be underestimated when absenteeism diagnoses are used because alcohol problems might be diagnosed as stress.

In the United States there is a long tradition of Employee Assistance Programs that deal with the counseling of problem drinkers. In Europe the interest in these kind of programs has been growing since 1970 (for an overview of the content of these kind of programs see Ames, 1993; Berridge and Cooper, 1993; Brody, 1988; Pratt and Tucker, 1989; Trice and Beyer, 1984; Trice and Sonnenstuhl, 1990; and Sonnenstuhl, 1988). A representative study among Dutch companies shows that in $199115 \%$ of the Dutch companies with more than 100 employees had some kind of alcohol policy or program (Gründemann \& Lourijsen, 1991). The Dutch Alcohol Consultancy Foundation (ALCON) has a lot of experience in assisting companies to develop Alcohol Programs, which resemble the American Employee Assistance Programs. The main focus in Dutch alcohol programs is on developing a Alcohol Policy with rules on alcohol consumption at work and procedures for the assistance of problem drinkers. Furthermore, social medical workers and supervisors are trained in constructive confrontation skills so that they can signal alcohol problems in an early stage and assist the worker in solving his or her problems.

Although there is some experience with worksite alcohol programs in the Netherlands, the effectiveness of these programs has never been evaluated. On international scale program evaluations are also rare. The present article tries to fill this gap. It describes the effectiveness evaluation of a worksite alcohol program implemented by the ALCON Foundation in a large Dutch pharmaceutical company $(\mathrm{N}=1600)$. First, a short overview is given of the theoretical background and program goals. Second, the effectiveness of the program is presented for three groups: social medical workers, a sample of supervisors, and a sample of workers. 


\section{Theoretical background and program goals}

Several theoretical models were used in our project. One of the planning models we used throughout the whole project was the PRECEDE-PROCEED Model for Health Promotion Planning and Evaluation (Green \& Kreuter, 1991). The process evaluation of the planning and implementation of the project will be described elsewhere. This article is restricted to the content of the program and its effectiveness. Because the PRECEDE-PROCEED Model was not only used for the planning of the project, but also for the development of the content of the program, it will be discussed here in more detail.

The PRECEDE-PROCEED model is commonly used in the Health Education and Promotion field for the development, implementation and evaluation of programs concerned with health problems. On the basis of the diagnosis of behavioral and environmental determinants of health problems, educational and environmental programs are developed. Thereby a distinction is made between predisposing factors, reinforcing factors, and enabling factors. Influencing these factors is the main goal of a program that is aimed at behavioral change. In the field of health education environmental changes are mostly considered as supportive of the behavioral goals, although environmental changes can be separate goals. Different (social-psychological) theories can be used to develop detailed activities that fit within the three categories of determinants mentioned.

Predisposing factors include a person's or population's knowledge, attitudes, beliefs, values, and perceptions that facilitate or hinder motivation to change. Reinforcing factors are formed by attitudes and behavior, of the individuals themselves or of other people, that give the individual feedback and rewards after behavioral change. This may encourage or discourage continuation of the behavior. Enabling factors are those skills, resources, or barriers that can help or hinder the desired behavioral changes as well as environmental changes. Enabling factors are created mainly by societal forces or systems. For example, facilities and personal or community resources may be ample or inadequate, and laws and statutes may be supportive or restrictive.

Our case involved a pharmaceutical company $(\mathrm{N}=1600)$ that contacted the ALCON Foundation in 1991. The question was whether the ALCON Foundation would assist the company in developing and implementing an alcohol program. After a few meetings between organizational members and members of ALCON and the university it became clear that the program would be part of a broader company health program. Earlier in 1991 the health department and the social work department of the company (both part of the personnel and organization department) wrote a policy document about health. The main goal of the health policy was to promote health, well-being and safety and to reduce absenteeism. The alcohol program was one of the first programs they started with. A social worker was responsible for the development and implementation of the alcohol program. It was agreed that ALCON would give practical advice and would implement some activities and that the university would evaluate the program. The social worker composed a working group to assist her and she reported to the manager personnel and organization, who is a member of the top management team. A diagnosis was conducted consisting of 
interviews and questionnaires. Based on this diagnosis an alcohol policy document was developed by the working group. In October 1993 the top management team approved this document. From Nowember 1993 till May 1994 the program activities were implemented.

The main goals of the alcohol program (as written down in the policy document) were to reduce work performance problems related to alcohol abuse and to reduce the usse of alcohol during working time. To reach these goals the following subgoals and activities were developed. Firstly, with regard to the predisposing factors the following subgoals were developed: 1) increasing knowledge of and a positive attitude towards the new policy, 2) increasing awareness about the workers' own alcohol drinking behavior, 3) increasing a positive attitude about teh incompatability of alcohol and work, and 4) increasing a healthy (i.e. moderate) drinking behavior. To gain attention for the messages and to reach the mostly attitudinal goals mass-media educational activities were developed (McGuire, 1985). These activities included an information market in the canteen, articles in the company"s magazine, information given by the supervisor at a work meeting, and the opportunity to read the policy document or a summary of it.

Secondly, the reinforcing factors were translated into subgoals to increase the skills of social medical workers and supervisors with regard to constructive confrontation strategy. The core of constructive confrontation strategy is formed by a combination of progressive, positive discipline with provisions to assist problem-drinking employees to rehabilitate themselves (see Trice and Beyer, 1984; Trice and Sonnenstuhl, 1990). To use this constructive confrontation strategy social medical workers and supervisors need to be able to signal alcohol problems in an early stage, to confront problem drinkers with their dysfunctioning and the relationship with alcohol problems, and provide assistance during the recovery period. The best way to improve the self-efficacy on these behaviors is to practice the necessary skills (Bandura, 1986). Empirical research indicates that such skills-training can be effective (Trice and Beyer, 1984; Gerstein et al., 1989). The study by Gerstein et al. (1989) shows that a constructive confrontation training on how to identify, confront and refer troubled workers, indeed increased the familiarity of supervisors with behaviors related to workers' problems. The study by Trice and Beyer (1984) with more than 600 managers indicates that oral discussions between supervisor and employee containing both constructive and confrontational topics were positively associated with employees accepting help and with better work performance following intervention. However, more severe forms of discipline (written warnings, suspensions or discharges) were negatively associated with work performance following intervention. The authors conclude that these results suggest that: 1) the strategy is most effective when repeated discussions balance both constructive and confrontational elements, and 2) the presence of the alcohol policy encouraged supervisors to take more actions with problem drinkers, legitimated those actions and made the threat of discipline more credible. These results indicate that it is effective to combine an alcohol policy with superwisory training. Therefore, in our project a one-day skillstraining in the form of a workshop was held for social medical workers (i.e. social workers, personnel workers, physician, nurse). The workshop was aimed at improving knowledge about the company's policy, the rules and procedures (including own 
role and responsibilities), and self-efficacy with regard to the constructive confrontation strategy. The methods used in the workshop were: lectures, videotapes, a case with a manager who had had alcohol problems himself, discussions in small groups, and role-playing exercises.

Unfortunately with regard to supervisors it was only possible to conduct less intensive activities than the working group originally intended. Supervisors received a letter from the managing director with a copy of the alcohol policy document and information about their specific roles and tasks. Furthermore the assistance of a personnel officer was offered to them. The personnel officer could give some background information about alcohol problems and the tasks of the supervisor.

Thirdly, the subgoals with regard to the enabling factors were formed by rules and procedures. The rules are: 1) no alcohol use during working hours at the worksites, and 2) the drinking of non-alcoholic drinks at receptions after working hours must be promoted and the use of alcohol drinking must be discouraged. The procedure for the assistance of problem-drinking employees detaills responsibilities and tasks. It is the responsibility of supervisors to point out problems related to alcohol early. It is the supervisor's task then to offer help, thus following the constructiveconfrontation strategy. And it is the responsibility of the social medical team to assist the supervisor and the employee. The rules and procedures were described in detail in the policy document together with the vision and the basic assumptions of the alcohol policy. The policy came into effect on January 1, 1994. Table 1 summarizes the program components.

Table 1: Overwiew of program components.

\begin{tabular}{|c|c|c|c|c|}
\hline \multirow[t]{2}{*}{ Program goals } & \multicolumn{3}{|c|}{ Educational activities } & \multirow{2}{*}{$\begin{array}{l}\text { Environmental } \\
\text { activities: } \\
\text { total worksite }\end{array}$} \\
\hline & all workers & social medical team & supervisors & \\
\hline $\begin{array}{l}\text { predisposing factors: } \\
\text {-knowledge } \\
\text {-attimdes } \\
\text {-awareness } \\
\text {-behawior }\end{array}$ & $\begin{array}{l}\text { articles } \\
\text { info market } \\
\text { policy document } \\
\text { work meeting }\end{array}$ & & & \\
\hline $\begin{array}{l}\text { meinforcing factors: } \\
\text {-skills of social medical } \\
\text { workers and supervisors }\end{array}$ & & $\begin{array}{l}\text { skills-training } \\
\text { (wotkshop) }\end{array}$ & $\begin{array}{l}\text { letter } \\
\text { brochures } \\
\text { assistance }\end{array}$ & \\
\hline $\begin{array}{l}\text { enabling factors: } \\
\text {-vision } \\
\text {-rules } \\
\text {-procedures }\end{array}$ & & & & policy document \\
\hline
\end{tabular}

In summary, the research questions in this study were:

1) How effective is the program in improving knowledge and attitudes of all workers with regard to the alcohol policy and drinking in relation with work?

2) How effective is the program in improving knowledge, attitudes and skills of social medical workers and supervisors with regard to assistance to problem drinkers? 
3) How effective is the program in improving the awareness of own drinking behavior and changing this behavior when necessary?

4) How effective is the program in the cessation of alcohol drinking during working hours and the promotion of non-alcoholic drinks at receptions?

5) How effective is the program in the assistance to problem drinkers?

\subsection{Methods}

\section{Design and samples}

Three subpopulations were used to examine the effects of the program: 1) a random sample (30\%) of the total work population, 2) all social medical workers, and 3) a random sample (50\%) of supervisors. They all received a pretest and a posttest questionnaire. The pretest for all workers took place in May 1992 and the pretest for supervisors and social medical workers in October 1993. All three posttests took place in May 1994. So, the design was quasi-experimental with a pretest and a posttest and no control groups. The random selection of workers and supervisors was made with help of the persomel administration of the company. Different samples were drawn for the pretests and posttests in order not to place too much load on the respondents and to avoid a test-effect. All the social medical workers received a pretest and a posttest questionnaire because of their small number (about 20). Additionally, during the pretest and posttest periods, group and individual interviews too were held with the primary goals to obtain background information. The interviews were held with representatives of the company's union, the top management, social medical personnel, three main groups of workers (administrative, research and production workers), and the project's working group. We also wanted to talk with supervisors, but the project leader did not succeed in finding supervisors who were willing to participate because of the heavy work loads of the supervisors.

\section{Questionnaires}

The questionnaire for the social medical workers measured four subsets of variables. The first variable was knowledge about procedures, rules and cooperation as described in the Policy Document ( 3 questions, alpha at pretest 0.97 ). The second subset of variables contained attitudes about the importance of the policy ( 1 question) and the content of their role (signaling and counseling) (3 questions, alpha 0.81 ). The third subset of variables concerned perceived quality of cooperation among social medical workers ( 1 question), and between social medical workers and supervisors (1 question). The last subset of variables concerned self-efficacy about constructive confrontation skills necessary for assisting problem drinkers (6 questions, alpha 0.67), and self-efficacy about informing supervisors and workers about the policy ( 2 questions, alpha 0.90 ). The minimum score on all these variables was -2 and the maximum score was +2 . The posttest questionnaire also contained questions about participation in the program (including the value they attached to the program).

The supervisors' questionnaire contained the same four subsets of variables as the social medical workers' questionnaire, although not all the questions were the same. The first subset of variables contained three questions about knowledge (proce- 
dures, rules, cooperation, alpha 0.93). The second subset was about attitudes: importance of policy (1 question) and own role (two questions about signaling and counseling, alpha 0.67 ). The third subset concerned the cooperation with social medical workers ( 1 question), and the last subset was about selfefficacy on constructive confrontation skills (6 questions, alpha 0.80 ). The minimum score on all the variables was -2 and the maximum score was +2 . The posttest questionnaire also contained questions about participation.

The questionnaire for all workers contained six subsets of variables. The first variable was knowledge about procedures for the assistance of problem drinkers and the worksite resources for assistance ( 2 questions, alpha 0.49 ). The second subset of variables concerned attitudes toward the Alcohol Policy (importance of the policy, taking work into account when drinking, intention not to drink at work). The third variable was self-efficacy on constructive confrontation skills (3 questions, alpha 0.59). The fourth subset of variables was the alcohol drinking behavior (weekly consumption based on quantity-frequency measures on weekdays and weekend days). The fifth variable was the awareness of own drinking behavior (measured by the the subjective attitude towards drinking too much). The final variable concerned the intention to drink less ( 1 question). The minimum score on all the variables (except alcohol drinking behavior) was -2 and the maximum score was +2 . Again, the posttest questionnaire also contained questions about participation.

\section{Group and individual interviews}

In addition to the written questionnaires 5 group and several individual interviews were held during the pretest and posttest period. These interviews gave valuable background information and helped us to interpret the results.

\section{Analyses}

In the case of the social medical workers, frequency tables were computed to describe the sociodemographic characteristics of the population and to describe the participation in the program. Paired T-tests were used to test the difference in outcome variables between pretest and posttest. Because of the clear expectations for all the variables to increase and because of the small group number, one-tailed T-tests were used.

In the case of the supervisors, chisquare tests and univariate variance analyses were used to compare the sociodemographic characteristics of the pretest and posttest samples. Frequency tables were computed to describe the participation rate in the program. Finally, a multivariate variance analysis was used to test the differences between pre and posttest outcome variables.

Regarding all workers, chisquare tests and univariate variance analyses were used to compare the sociodemographic characteristics of the pretest and posttest sample. Frequency tables were computed to describe the program participation. Univariate and multivariate covariance analyses and logistic regression analyses (all with the continuous variable age as a covariate) were used to assess the program effects. 


\subsection{Results}

\section{Response and sociodemographic characteristics}

Eighteen social medical workers out of 22 responded to the pretest and 11 out of 16 to teh posttest. Ten respondents participated in both tests. Only these ten respondents were used for the analyses. We could not check how well the samples represented the total population of social medical workers, because no information was available on sociodemographic characteristics of the total group of social medical workers. Seven of the ten respondents were men; the mean age was 36 years. Six respondents were personnel workers, two were social workers, one was a physician, and one was a nurse. The mean number of years of service was 6 .

Among the supervisors, the response to the pretest was $71.6 \%(n=78)$ and to the posttest $52.5 \%(n=63)$. Again, we could not check the representativeness of the samples, because there was no information available on sociodemographic characteristics of this subgroup. The majority $(93.5 \%$ at pretest) of the respondents were men, and the mean age was about 44 years. The mean number of years of service was about 13, and the mean number of years of experience as a supervisor was about 9.5.

With regard to all workers, the response to the pretest was $70.9 \%(n=319)$ and to the posttest $53.6 \%(\mathrm{n}=267)$. Only for this subpopulation could we check how well the sample represented the total work population. The comparison between samples (pretest/posttest) of all employees and the total work population (in 1992 and 1994) showed that the samples were representative with respect to all relevant variables (gender, age, education, sector, years of service). Although the pretest and posttest samples represented the actual work populations well, they differed from each other with regard to age. In 1994 there were relatively fewer middle aged workers and more younger and older workers. This difference can be explained by a reorganization that had taken place. The mean age of the samples did not differ significantly. We corrected for age differences in all analyses concerning the sample of all workers by using age as a covariate (see analyses). About two-thirds of the respondents were men. The mean age was about 39 years. Most respondents were highly educated. The mean number of years of service was about 11 , and about $25 \%$ of the respondents had supervising responsibilities.

\section{Participation and evaluation of program components}

Table 2 shows how many respondents participated in the program and how they valued the different activities. The activities aimed at skills training proved to be more successful for the social medical workers than for the supervisors. All social medical workers who filled out the pretest and posttest questionnaires joined the workshop. Also the registration of attendance at the workshop showed that almost all social medical workers joined the workshop. Most of the participants rated the workshop as good or very good, while $40 \%$ judged it as not good/not bad. Some participants had critical remarks that there was an overlap with other skills training activities in the past. Most of the supervisors who filled out the posttest questionnaire read the letter from the Top Manager, but only a very few read the special brochure for supervisors, asked for personal assistance of a personnel officer, or saw the 
special videotape for supervisors. Paradoxically, about half of the supervisors who filled out the questionnaire found that they did not receive sufficient education and support. In contrast eight out of ten social medical workers found that the education and support they received was sufficient. The summary of the Policy Document was read by a majority of social medical workers, supervisors, and all workers. The Policy Document itself was read by all social workers and about $40 \%$ of the supervisors and workers. Both documents were judged rather good. The rules that were described in the policy (no alcohol during working time and the discouraging of alcohol at receptions after working time) were rated as good by a large majority of all three study groups. The procedures about the assistance of problem drinkers were seen as good by a large majority of social medical workers and the sample of all workers. The supervisors were somewhat less enthusiastic; $60.3 \%$ of them rated the procedures as good. The articles in the company's magazine were read by more than three-quarters of all workers that filled out the questionnaire and most of them judged the articles as good. Only $23 \%$ of the respondents were informed by their supervisors about the new policy. The last way in which the workers could get information about the policy and about alcohol was the canteen campaign including an information market. Most of the respondents noticed the activities in the canteen, and $57 \%$ of those who saw the activities judged them as good. Although they saw the activities, only a very few respondents actively joined them. Only $4 \%$ watched the videotape, $23 \%$ looked at the posters, $10.5 \%$ took one or more brochures and read them, and $14 \%$ tried out the computer program. The specific activities were rated as good by their participants, except for the computer program which they found too complex. In summary, most respondents noted the information about the policy and they judged the rules and procedures as good. The social medical workers participated in the skills training activities, but the supervisors did so to much lesser extent. The articles in the company's magazine were read widely, but only a few respondents actively participated in the activities during the canteen campaign.

\section{Effects on social medical workers}

Table 3 shows the results of the paired T-tests (one-tailed). Knowledge about procedures, rules and cooperation as described in the Policy Document increased significantly. The perceived quality of cooperation with supervisors also increased significantly, and the self-efficacy on constructive confrontation skills increased significantly too. The other variables showed no significant change. In three cases this is not unexpected because the mean scores on the pretest were already very positive; that is, attitude about the importance of the Alcohol Policy, the rolle of social medical workers, and the self- efficacy on informing supervisors and workers about the Alcohol Policy. The increase of attitude towards the cooperation among social medical workers was marginally significant $(\mathrm{P}<0.10)$. 
Table 2: Participation and evaluation of program components

\begin{tabular}{|c|c|c|c|c|c|c|}
\hline \multirow[t]{2}{*}{ Prograim } & \multicolumn{2}{|c|}{$\begin{array}{l}\text { Soeial medical work- } \\
\text { ery }\end{array}$} & \multicolumn{2}{|c|}{ Supervisors } & \multicolumn{2}{|c|}{ All workers } \\
\hline & $\begin{array}{l}\text { partici- } \\
\text { pation } \\
(N=10)\end{array}$ & $\begin{array}{l}\text { w partice } \\
\text { pants who } \\
\text { rated it as } \\
\text { good" }\end{array}$ & $\begin{array}{l}\text { partici- } \\
\text { pation } \\
(\mathrm{N}=63)\end{array}$ & $\begin{array}{l}\text { partici- } \\
\text { pants who } \\
\text { rated it as } \\
\text { "good" }\end{array}$ & $\begin{array}{l}\text { partict- } \\
\text { pation } \\
(\mathrm{N}=267)\end{array}$ & $\begin{array}{l}\text { \% partici- } \\
\text { pants who } \\
\text { rated it as } \\
\text { "good" }\end{array}$ \\
\hline & $\%$ & $\%$ & $\%$ & \% & $\%$ & $\%$ \\
\hline Workshop & 1000 & 60.0 & & & & \\
\hline Letter & & & 69.8 & 73.2 & & \\
\hline Brochure & & & 14.3 & 66.7 & & \\
\hline Assistance & & & 6.3 & 75.0 & & \\
\hline Videotape & & & 3.2 & 50.0 & & \\
\hline Policy Document & 100.0 & 900 & 44.4 & 57.1 & 42.6 & 68.8 \\
\hline Summary P.D. & 90.0 & 100.0 & 81.0 & 74.5 & 57.6 & 70.7 \\
\hline Articles & & & & & 77.4 & 58.7 \\
\hline Info by supervisor & & & & & 22.9 & 51.7 \\
\hline Canteen campaign & & & & & 61.9 & 57.1 \\
\hline -videotape & & & & & 4.1 & 100.0 \\
\hline -posters & & & & & 22.9 & 68.9 \\
\hline wbrochures & & & & & 10.5 & 78.6 \\
\hline computer program & & & & & 14.2 & 42.1 \\
\hline Rules & & 100,0 & & 81.0 & & 83.9 \\
\hline Procedures & & 100.0 & & 60.3 & & 86.3 \\
\hline $\begin{array}{l}\text { Education was } \\
\text { sufficient }\end{array}$ & & 80.0 .0 & & 58.3 & & \\
\hline
\end{tabular}

Table 3: Program effects on social medical workers $(\mathbb{N}=10)$.

\begin{tabular}{lcc|cc|cc}
\hline & Pretest & \multicolumn{2}{l|}{ Posttest } & \multicolumn{2}{l|}{ Test } \\
\cline { 2 - 7 } Variables (scores from -2 to +2) & mean & s.d. & mean & s.d. & T & df \\
\hline $\begin{array}{l}\text { Knowledge about policy } \\
\text { (rules, procedures, cooperation) }\end{array}$ & 0.97 & 1.23 & 1.70 & 0.48 & $-2.70^{\circ}$ & 9 \\
Autitudes & & & & & & \\
-importance of policy & & & & & & \\
-importance of own role & 1.70 & 0.68 & 1.70 & 0.48 & 0.00 & 9 \\
Cooperation & 1.13 & 0.95 & 1.33 & 0.79 & -0.69 & 9 \\
-SMT & & & & & & \\
-supervisors & 0.00 & 0.47 & 0.40 & 0.52 & -1.81 & 9 \\
Self-efficacy & -0.10 & 0.88 & 0.50 & 0.53 & $-1.96^{*}$ & 9 \\
-inform supervisors and workers & & & & & & \\
-constructive confrontation & 1.30 & 0.72 & 1.30 & 0.95 & 0.00 & 9 \\
\hline
\end{tabular}

$* \mathrm{P}<0.05$ 


\section{Effects on supervisors}

Table 4 shows the results of multivariate variance analysis. There was only one significant effect. The knowledge of rules about drinking at the worksite, procedures on assistance of problem drinkers, and desired cooperation increased significanty. The other variables did not change significantly. Regarding attitude about the importance of the Alcohol Policy this is not unexpeeted, because the mean score on this variable is very positive both in the pretest and in the posttest.

Table 4: Program effects on supervisors.

\begin{tabular}{|c|c|c|c|c|c|c|}
\hline \multirow[b]{2}{*}{ Variables (scores from -2 to +2 ) } & \multicolumn{2}{|c|}{ Pretest $(N=69)$} & \multicolumn{2}{|c|}{ Postest $(N=50)$} & \multicolumn{2}{|c|}{ Test } \\
\hline & mean & s.d. & mean & $\mathrm{s} d \mathrm{~d}$ & $\mathrm{~F}$ & $d f$ \\
\hline $\begin{array}{l}\text { Knowledge about policy } \\
\text { (rules, procedures, cooperation) }\end{array}$ & -.28 & 1.21 & 0.55 & 1.03 & $15.33^{* * *}$ & $1 / 117$ \\
\hline $\begin{array}{l}\text { Attitude } \\
\text {-importance of policy } \\
\text {-importance of own role }\end{array}$ & $\begin{array}{l}1.32 \\
0.67\end{array}$ & $\begin{array}{l}0.78 \\
0.96\end{array}$ & $\begin{array}{l}1.26 \\
0.64\end{array}$ & $\begin{array}{l}0.97 \\
0.96\end{array}$ & $\begin{array}{l}0.14 \\
0.04\end{array}$ & $\begin{array}{l}1 / 117 \\
1 / 117\end{array}$ \\
\hline Cooperation with SMT & 0.12 & 0.61 & 0.06 & $0.7 \pi$ & 0.21 & $1 / 117$ \\
\hline $\begin{array}{l}\text { Self-efficacy on constructive confron- } \\
\text { tation }\end{array}$ & 0.65 & 0.57 & 0.71 & 0.70 & 0.25 & $1 / 117$ \\
\hline
\end{tabular}

$\therefore \mathrm{P}<0,001$

\section{Effects on workers}

In all analyses concerning the workers we used age as a covariate because of the difference in age between the pretest and the posttest samples mentioned above. Table 5 shows the results of the multivariate covariance analysis regarding to knowledge, attitudes and self-efficacy. Only knowledge on procedures and assistance resources increased significantly. Attifudes towards the importance of the policy and towards not using alcohol at work were already very positive at the pretest. Selfefficacy on constructive confrontation skills is remarkably negative. Respondents do not feel able to signal alcohol problems among their colleagues and to help them.

Table 5: Program effects on workers (knowledge, attitudes and self-efficacy).

\begin{tabular}{lll|ll|ll}
\hline & \multicolumn{2}{l|}{ Pretest $(\mathrm{N}=278)$} & \multicolumn{2}{l|}{ Posttest $(\mathrm{N}=224)$} & \multicolumn{2}{l}{ Test } \\
\cline { 2 - 8 } Variables (scores from -2 to +2$)$ & mean & s.d. & mean & s.d. & F & df \\
\hline Knowledge on procedures \& assistance & -.13 & 1.17 & 0.20 & 1.16 & $9.92 *$ & $1 / 499$ \\
resources & & & & & & \\
A.titudes & & & & & & \\
-importance of policy & 1.08 & 1.19 & 1.05 & 1.04 & 0.09 & $1 / 499$ \\
-take work into account when drinking & 0.68 & 1.64 & 0.80 & 1.57 & 0.64 & $1 / 499$ \\
-no alcohol at work & 1.66 & 0.77 & 1.69 & 0.85 & 0.13 & $1 / 499$ \\
Self-efficacy consitructive confrontation & -.65 & 0.85 & -.62 & 0.98 & 0.10 & $1 / 499$ \\
\hline
\end{tabular}

$\cdots \mathrm{P}<0.01$ 
An univariate covariance analysis was used to test if mean alcohol consumption per week changed. The mean number of glasses per week was 8.3 at the pretest and 7.2 at the posttest. This difference is not statistically significant $(F=2.10$, n.s.). Table 6 shows the prevalence of abstinence, light, moderate and excessive drinking. The excessive drinking was $9.9 \%$ in 1992 and $8.1 \%$ in 1994 . This does not differ from other Dutch companies (see Gründemann, 1989). A logistic regression analysis (with age as a covariate) was ased to test if the distribution of drinker groups changed between pretest and posttest. Abstinence and light drinking was coded as 0 in this logistic regression analysis, and moderate and excessive drinking as 1 . The results (not shown) indicate that the distribution of drinker groups did not change significantly. So, based on these two analyses we can conclude that the alcohol drinking behavior did not change.

Table 6: Program effects on workers (alcohol drinking behavior).

\begin{tabular}{lll}
\hline Variable & Pretest $(\mathrm{N}=314)$ & Postrest $(\mathrm{N}=259)$ \\
\hline & $\%$ & $\%$ \\
Abstainer (no alcohol) & 5.7 & 7.3 \\
Light drinker ( $\leq 13$ glasses /week) & 72.6 & 74.9 \\
Moderate drinker (14-20 glasses/week) & 11.8 & 9.7 \\
Excessive drinker $(\geq 21$ glasses/week) & 9.9 & 8.1 \\
\hline
\end{tabular}

Finally, a multivariate covariance analysis was used to test whether the awareness about respondents' own alcohol consumption ("I drink too much") and their intention to change had increased. Age was included as a covariate. Because we hypothesized that the change over time in both variables would depend on the number of glasses that respondents drank, we added the interaction between alcohol behavior ( 3 subgroups) and time of measurement (pretest, posttest) to the analysis. We hypothesized that the change would be positively related to the alcohol behavior, i.e. excessive drinkers would increase their awareness and intention to change drinking behavior more. The means in table 7 show that indeed respondents with a higher alcohol consumption were more conscious that they drank too much and had a higher intention to lower their consumption. Also the significant effects of "group" give further indication of this relation between awareness and alcohol drinking behavior and between intention to change and alcohol drinking behavior. But there was no significant effect of time and no significant interaction effect. So there is no change over time for the population as a whole, nor is there a difference in change over time between the subgroups (light, moderate, excessive drinkers). It is noteworthy that awareness increased and that intention to lower drinking behavior decreased for all drinker groups.

Additional information was gained from chi square analyses (not shown). These analyses showed that about $20 \%$ of the excessive drinkers were aware of their own behavior (i.e. thought that they drank too much), and about $30 \%$ of the excessive drinkers intended to drink less. 
Table 7: Program effects on workers (awarentess and intention).

\begin{tabular}{llll|lll|lll}
\hline & \multicolumn{3}{c|}{ Pretest } & \multicolumn{3}{c|}{ Posttest } & \multicolumn{3}{c}{ Univariate F-tests } \\
\cline { 2 - 10 } $\begin{array}{l}\text { Variables } \\
\text { (scores:-2 to +2) }\end{array}$ & n & mean & s.d. & n & mean & s.d. & $\begin{array}{l}\text { Tirne: } \\
\text { F(d) }\end{array}$ & $\begin{array}{l}\text { Group: } \\
\text { F(d) }\end{array}$ & Interaction: \\
\hline Awareness: & & & & & & & & & \\
-light drinker & 218 & -1.81 & 0.58 & 186 & -1.74 & 0.68 & 0.22 & $85.7^{* . *}$ & 0.04 \\
-moderate drinker & 35 & -1.06 & 1.03 & 25 & -1.04 & 0.94 & $(1 / 509)$ & $(2 / 509)$ & $(2 / 509)$ \\
-excessive drinker & 31 & -0.42 & 1.21 & 21 & -0.33 & 1.15 & & & \\
Intention: & & & & & & & & & \\
-light drinker & 218 & -0.75 & 1.27 & 186 & -1.12 & 1.22 & 3.2 & $8.4^{* * *}$ & 0.28 \\
-moderate drinker & 35 & -0.26 & 1.25 & 25 & -0.64 & 1.04 & $(1 / 509)$ & $(2 / 509)$ & $(2 / 509)$ \\
-excessiwe drinker & 31 & -0.16 & 1.24 & 21 & -0.79 & 1.17 & & & \\
\hline
\end{tabular}

… $P<0.001$

\subsection{Discussion}

The purpose of the present study was to assess the effectiveness of a worksite alcohol program on several predisposing, reinforcing and enabling factors with regard to problematic alcohol use. The research questions, as described in the introduction, will be discussed below.

Knowledge about the Alcohol Policy (its rules and procedures) increased significantly for all three study groups (social medical workers, a sample of supervisors, and a sample of all workers). So, the information via mass media, workshop and work meetings was effective.

Attitude towards the Alcohol Policy was positive for the three study groups. Because it was already positive at the pretest, there was no attitudinal change. Respondents supported the basic assumptions of the Alcohol Policy that workers whose functioning is inhibited by heavy alcohol use are confronted with this fact. But at the same time workers are afraid that the company will interfere with private affairs. So, the line between a sensible policy and paternalistic behavior is very thin. This makes a worksite Alcohol Policy a very sensitive subject. Two quotations from participants in the posttest interviews illustrate this: "The danger of this approach is that it becomes paternalistic and that people's self discipline is forgotten. Of course it is important that people with problems can get help", and "Only the functioning of an employee is important for the company and the supervisors. Supervisors have to be reserved with regard to the private life of employees. There are lots of problems that can be the reason for dysfunctioning; there is no need to pay extra attention to alcohol." Two other attitudes also did not change. One attitude concerns not drinking alcohol at work. Respondents scored positively on this attitude at the pretest and at the posttest. The other unchanged attitude concerns not taking work into account when drinking (e.g. the evening before a workday). Respondents were positive about this, but not as strongly positive as on the other two attitudes and it did not change. Again, this can be explained by the fact that workers do not want the company to interfere with private behaviors like alcohol drinking in free time. 
The attitude of social medical workers and supervisors about the importance of the Alcohol Policy was also very positive at pretest and posttest, with social medical workers scoring higher than supervisors. Social medical workers and supervisors differed with respect to their attitude about the importance of their own role in the Alcohol Policy. Both groups scored positive, but the score of social medical workers was twice as high as that of supervisors. The attitudes of both did not change. The relatively low involvement of supervisors represents a major problem. The problems with implementing skills training for supervisors also shows the low involvement of top and line management with alcohol problems. Managers are in the first place concerned with the production process. Social skills are considered of minor importance. This contrasts with the crucial role of supervisors in implementing a Policy aimed at constructive confrontation.

The same kind of difference between social medical workers and supervisors appears with regard to their self-efficacy on constructive confrontation skills. The self-efficacy of social medical workers increased significantly. So, the workshop was effective in reaching its goal. But the less intensive intervention for supervisors (letter, brochure, assistance) did not result in an improvement of their self-efficacy.

Social medical workers and supervisors also differ in their evaluation of the cooperation between social medical workers and supervisors. Neither group is very positive about this cooperation, but the opinion of social medical workers increased significantly while that of supervisors did not change. It is unclear whether the opinion of social medical workers reflects their actual experience in working together with supervisors or whether it reflects the fact that they know better what kind of cooperation is asked of them. The latter is more likely, because of the short period between implementation of the Policy and the posttest.

This structural difference in effects between the groups of social medical workers and supervisors implies that in future projects far greater effort must be made to involve and motivate managers and "floor" supervisors for their role in signaling and assisting problem workers. Policies and procedures can never be effective without supervisors being aware of their role and being able to use the necessary skills. To make supervisors aware of their signaling and assisting role, it is necessary to make them realize that workers' dysfunctioning can be related to alcohol problems. Furthermore, alcohol problems should be made discussible, and it should be made clear what supervisors can do to prevent alcohol problems and their escalation. When supervisors are better aware of their role they can be trained in constructive confrontation skills. In our case, the Manager of Personnel and Organization ( $\mathrm{P \& O}$ ) should have played a more active role in motivating the management for the project. The P\&O manager described the less well developed social part of a manager's task in general as a structural problem. In the posttest interview he said he realized that the social skills of most supervisors were underdeveloped. In his opinion the company lost twice if they promoted a technician to a supervision function: they lost a good technician and they did not have a good supervisor. Our experience is fully consistent with the experience of Ames and Delaney (1992). They discuss the first-line supervisor's role in the minimization of workplace alcohol problems. Minimization is defined as "the values, beliefs, and practices that reduce the awareness, acknowledgement, assessment of the occurrence, and concrete effects of drinking and 
alcohol-related problems". They conclude that this minimization process is not by volition but that it occurs in concert with social action that is designed to meet the primary goals of the workplace organization.

The third research question was concerned with the improvement of the awareness of teh employees' own drinking behavior and with changing this behavior when necessary. The results indicated that 8 to $9 \%$ of the respondents were excessive drinkers and that about $20 \%$ of them were aware that they drank too much. The awareness increased between pretest and posttest, and the intention to change behavior decreased. Neither change was significant. The decrease in intention to change drinking behavior is probably a reflection of the resistance against interference of the company with private (drinking) behavior. So, the mass media alcohol education was not effective. More personal, tailored education with the emphasis on "healthy drinking" might be more effective. As the experience of Towers, Kishuk, Sylvestre, Peters and Bourgault (1994) also points out, the emphasis on problem drinking is confusing for the workers. No one considers himself or herself as a problem drinker. Problem drinking is associated with alcoholism. People do not want to be approached as potential problem drinkers, but they are interested in how healthy their (drinking) behavior is. Therefore, integration of alcohol in a general Health Risk Appraisal might be a method for primary prevention of alcohol problems. Primary prevention of alcohol problems also should imply reduction and prevention of work stressors that are related to problematic alcohol use. Secondary prevention of alcohol problems might be accomplished by integrating alcohol in stress management programs for workers where the danger of alcohol drinking as a coping behavior for stress is discussed. In addition, secondary prevention can be stimulated by training supervisors in signaling and assisting workers with problems. If special training is not possible, the subject of alcohol problems can be integrated in other supervisory courses, such as courses on periodical evaluation talks with workers about their functioning, or courses on general social or communication skills.

The fourth and the fifth research questions are difficult to answer. The fourth question concerned the cessation of drinking during working hours and the promotion of drinking non-alcoholic drinks at receptions. It was clear that the knowledge of the organizational rules on alcohol use had improved, but it was not possible to check if no alcohol was used during working hours. At receptions non-alcoholic drinks were indeed promoted. They were the only drinks that were presented on trays, and alcoholic drinks had to be specialiy ordered at the bar. Whether this resulted in a net change in the use of alcohol at receptions is not known.

The fifth research question was about the effectiveness of the assistance system for problem drinkers. Because of the short period after implementation of the Policy and the posttest, the system could not be evaluated. It was agreed that the system should be periodically evaluated in the Social Report of the company and in the meetings of the Social Medical Teams. In the posttest interviews several new cases were reported, but it was unclear whether there were more cases cases than normal. It was also reported that some drug problems were handled in the same way as 
alcohol problems. So, the rules and procedures of alcohol problems appeared to be applicable to other addictive behaviors.

We think that our project is a realistic example of what a workplace alcohol program can accomplish and what kind of difficulties appear during the implementation of such projects. But the project has its weaknesses. The major weakness is the nonexperimental design. Future projects should include control groups and preferably randomization too. At the start of our project the desirability of control groups was discussed with company representatives. The only acceptable form of control groups for the company would have been a branch of the same company in another town, but this was not possible because of internal company reorganizations. The company did not want the involvement of another company in the project, because of the sensitivity of the subject. They wanted to prevent the company becoming known as a place where a lot of alcohol problems were prevalent, even if there were not.

Other improvements can be made by adding follow-up measures, especially with regard to the functioning of assistance systems. Also, indicators of health, wellbeing and absenteeism should be added to pretest and posttests, because only then can the longer term goals of an alcohol program be evaluated.

In conclusion, we think that worksite alcohol programs are useful because alcohol problems do exist among workers. These are serious problems with negative consequences for the workers themselves (e.g. alcohol addiction, illnesses, job loss) and the company (e.g. absenteeism, lack of safety). Prevention of alcohol problems is a very sensitive subject within companies and should be carefully approached. The line between acceptable and unacceptable interference by management with personal behavior is very thin. Workers should be carefully informed about the goals and basic assumptions of an alcohol policy. For the secondary and tertiary prevention of alcohol problems a well-designed assistance and referral system is needed. Furthermore, supervisors and social medical workers need to be able to master constructive confrontation skills. The group most in need of training in these skills, supervisors, are the most difficult group to reach. Training activities on alcohol might be integrated in other supervisory courses. Other methods for secondary prevention of alcohol problems are stress management courses for workers. Primary prevention can imply integration of alcohol in health education activities, and reduction or prevention of work stressors that are related to problematic alcohol use. 


\title{
3 Effectiveness of a personalized Health Profile for blue-collar workers
}

\author{
Authors: R.M. Vasse, F.J.N. Nijhuis, and G.Kok \\ This chapter is accepted for publication as an article in the \\ Joumal of Occupational and Environmental Medicine.
}

\subsection{Abstract}

This article describes a study on the effectiveness of a Health Profile that was offered to blue-collar workers. The major goal of the Health Profile was to improve workers' awareness of own health behaviors and their intentions to change unhealthy behaviors. Additional goals were improvements in attitudes, self-efficacy and social support.

The Health Profile consisted of a booklet in A4-format in which tailored information was given on health behaviors. The study design was quasi-experimental with a pretest and posttest (no control group). The study group was formed by blue-collar workers who completed a Health Questionnaire as part of a worksite Health Promotion Program ( $N=63)$.

The results showed a significant improvement of awareness. Significant attitudinal changes were achieved too. There were no changes in social support and selfefficacy, nor was there a change in the intention to change behaviors.

These results suggest that a personalized health profile is a promising means to make workers aware of their personal risk behaviors. Future Health Profiles should contain more specific information on how to change unhealthy behaviors. Furthermore, more opportunities should be created to discuss and compare results with colleagues and partners.

\subsection{Introduction}

Dutch work organizations are stimulated by high costs related to sickness absence and disability to develop organizational health policies and intervention programs. The long term goal of these policies and programs is to promote health and to reduce 
and prevent absenteeism and disability. In the short term two main goals of health policies and programs can be distinguished. The first is to improve the working environment and the second is to promote workers" health behaviors in order to improve their coping capacities against stress and illnesses.

A recent review on the prevalence of health programs at Dutch companies (Gründemann \& Lourijsen, 1991) reveals that companies give most priority to improvement of the working environment (for example safety and ergonomics or organization change). About $55 \%$ of the companies studied reported having such programs. Health behavior programs, on the other hand, are implemented by $23.7 \%$ of the companies, and within these programs smoking cessation is the most popular.

The planning of worksite health programs concerns four basic stages: 1) diagnosis and feedback of data on the status quo, 2) development of program, 3) implementation of the program, and 4) evaluation and institutionalization of the program (Cummings and Worley, 1993; Green and Kreuter, 1991).

An instrument that is commonly used for giving feedback on individual health behavior is the Health Risk Appraisal. Most Health Risk Appraisals (HRAs) are computerized and calculate the mortality-risk of an individual. ("risk-age") based on age, sex, family history, personal health habits, and direct assessment of health risk indicators (Fielding, 1989; Dunton; 1992). Some HRAs also include an assessment of morbidity risks by giving feedback on mental health, occupational risks and health habits like nutrition, exercise, personal safety, etcetera. This kind of feedback is usually given in (low, medium, high) risk terms or in an narrative statement (Dunton, 1992). The results of an HRA are returned to the individual in a personal conficlential report, usually a computer printout or a letter. Sometimes HRAs are accompanied by health education counseling sessions.

A recent review by Dunton (1992) reveals that findings about the effectiveness of Health Risk Appraisals are ambiguous and mixed. Most studies employ a weak research design. Nevertheless, the well-designed studies show positive changes for a large variety of outcomes, most frequently for exercise, weight reduction, smoking cessation or reduction, increase in seat belt use, breast self-examination, risk-age improvement, and decreased blood pressure, cholesterol, and alcohol intake, absenteeism, among others. Because the studies use different intervention mixes (mortality risk and/or morbidity risk and/or counseling and/or health examinations, etcetera), it is difficult to conclude which components are the most effective.

In the present study a Dutch version of a Health Risk Appraisal was developed within a Health Promotion Program at a Municipal Garbage Collecting Department in a large city. Because the validity of individual mortality risk estimates is very debatable (see Schoenbach, 1987 for example), the information in our instrument is restricted to the semi-quantitative assessment of four health behaviors and the Quetelet-Index. Individual results were compared to (Dutch) medical standards, the average Dutch man/woman, and colleagues. Additionally, the workers received advice on how to improve their health habits. The instrument was named the "Health Profile". This article describes the effectiveness of the Health Profile on several behavioral determinants. It also describes how the content and lay-out of the Health Profile was evaluated by the workers. But first, the next section gives some back- 
ground information on the theoretical basis and intervention goals of the Health Profile.

\section{Theoretical basis and goals of the Health Profile}

The theoretical basis for the development of the Health Profile was formed by the Transtheoretical Model of Stages of Change (Prochaska and DiClimente, 1984). This model distinguishes four stages in behavioral change: 1) precontemplation (unaware of a problem), 2) contemplation (thinking about making a change), 3) preparation and action (initial attempts to change), and 4) maintenance (long-term change), This model has found to be applicable to twelve health behaviors (Prochaska, et al, 1994). Our Health Profille was restricted to five health behaviors: exercise, fat consumption, alcohol consumption, smoking and being overweight (Quetelet Index). The term "transtheoretical" indicates that at different stages different (more specific) sociopsychological theories can be applied. These theories can be used to develop detailed educational goals. People at different stages of change need different information. In our Health Profile we addressed five behavioral determinants: awareness, attitudes, social support, self-efficacy and intention to change behavior (McGuire, 1985; Fishbein and Ajzen, 1975; Ajzen, 1988; Bandura, 1986). The major goal of the Health Profile was improvement of awareness of own health behaviors. We tried to motivate people in the precontemplation stage to consider behavioral change. To improve awareness it is important that the message is interesting, comprehensible, and credible (McGuire, 1985). Interesting information for people who have not considered behavioral change before is information that influences their risk perception. Most people tend towards an unrealistic optimism i.e. they underestimate their personal risks in comparison with others (Weinstein, 1989). We tried to stimulate a realistic risk perception by giving personal health behavior scores and comparing them with (Dutch) medical standards, the scores of the average Dutch man and woman, and with scores of their own colleagues (worksite scores). To further motivate people in the precontemplation stage we gave attitudinal information that emphasized that people can influence their own health (internal locus of control) and we explained what relationships exist between health behaviors and health (outcome expectancy). Indirectly, we tried to stimulate social support by sending the Health Profile to the home address where we hoped it would be discussed with family and friends, and by giving comparisons with the scores of the total worksite that may stimulate discussions with colleagues. We addressed self-efficacy by giving personalized information on how to change the health behavior that turned out to be unhealthy. For example, we gave feedback about the food products that contributed in a large extent to the total fat intake. But this kind of information was very limited because it is less relevant for our target group. Self-efficacy information is more interesting for people at the contemplating stage. As stated earlier, the Health Profile aimed at motivating people for behavioral change. To measure this motivation we used the concept of intention to change behavior. The workers were informed that the Health Profile was followed by a Health Promotion Program. In this Health Promotion Program people could join thematic workshops that were aimed at improving self-efficacy by teaching people specific skills. These skills could enable them really to change their behavior. 


\section{Technical background of the Health Profile}

A Turbo Pascal computer program was developed that could combine two sets of data. One (SPSS) dataset contained the individual health scores and the other (WP) dataset contained educational information in the form of texts, graphics and illustrations. All respondents had a research number. For each individual the program selected the relevant educational information and put individual scores into standard texts. The result was a 6-page black and white printout from a laserprinter with texts, graphics and illustrations. The pages were stapled into a booklet on A4-format.

\section{Research questions}

The research questions of the present study were:

1) How effective is the Health Profile on the behavioral determinants awareness, attitudes, social support, self-efficacy and intention to change behavior?

2) Can the Health Profile achieve a) a stronger relationship between respondents' objective behavior scores and their subjective belief about the healthiness of their behavior (i.e. a greater awareness) and b) a stronger relationship between respondents' objective health behavior scores and their intention to change behavior?

3) How do respondents evaluate the content and lay-out of the Health Profile?

\subsection{Methods}

\section{Study population and procedure}

The study design was quasi-experimental with a pretest and a posttest (no control group). The study population was formed by workers of a Municipal Garbage Collecting Department of a large city. In 1991 this worksite joined a Health Promotion Project that was financed by the Dutch Ministry of Welfare, Health and Cultural Affairs, and implemented by the Dutch Alcohol Consultancy Foundation (ALCON) and the Maastricht University. The worksite had implemented an Alcohol Policy some years ago and now wanted to broaden their health activities to other lifestyle behaviors. In 1992 a working group with representatives from the different parts of the worksite was formed.

In May 1992 a Health Questionnaire was used to diagnose workers' health behaviors and their wishes for change. Workers were invited to join departmentbased, group sessions in the canteen where the questionnaire could be filled out. Within a few weeks respondents received the Health Profile on their home address. The addresses were provided by the Persomnel Department. Within two months after the pretest (about two to four weeks after participants received the profile) a posttest was conducted. This was done by means of telephone interviews. The posttest questionnaire contained the same questions about behaviors and behavioral determinants as the pretest did, but additionally some evaluative questions were asked about the content and lay-out of the Health Profile. 


\section{Measures}

The questionnaire contained 48 questions about health behaviors and behavioral determinants. The questions on behavior were asked during the pretest only, because no changes were expected within a couple of weeks. The questions on behavioral determinants were asked during the pretest and the posttest.

Self-reported health. One question about respondents' subjective health in general (5point Likert scale from very healthy (1) to very unhealthy (5)).

Nutrition. Twenty-five items of a validated food frequency questionnaire on fat consumption (Van Assema, et al, 1992). These items were used to compute a fat score. This fat score was used to categorize respondents' fat consumption as "healthy" $(<23)$, "too much fat" (23-31) or "much too much fat" $(\geq 31)$. Additionally, one question was asked about respondents' own belief on the healthiness of their diet regarding the use of fat (5-point Likert scale from very fat (1) to very meager (5)).

Alcohol. Six questions about abstinence, the frequency and quantity of alcohol consumption during weekdays and weekend days, and about binge drinking (frequency of drinking six or more glasses on one day). These questions were used to categorize respondents in one of four categories (Garretsen, 1983): abstainer, light drinker, excessive drinker, or very excessive drinker. An excessive drinker was defined as: drinking 3-4 days per week 6 or more glasses, or drinking 9-20 days per month 6 or more glasses, or drinking 21 days per month 4 or 5 glasses. Additionally, one question was asked about the respondents' own belief about the healthiness of their drinking behavior (i.e. drinking too much) (5-point Likert scale from totally disagree (1) to totally agree (5)).

Smoking. One question about whether the respondent had smoked at least once during the last seven days (yes/no).

Exercise. Two questions about the frequency and quantity of the respondents' sporting behavior. These questions were used to categorize respondents in one of four categories (Manders and Kropman, 1987): no sports/too low exercise level (less than 30 minutes per week), medium exercise level ( 1 day per week 30 minutes or more; or $\leq 2$ days per week less than 30 minutes), high exercise level (2 days per week 30 minutes or more), and very high exercise level ( $\geq 3$ days per week 30 minutes or more). Additionally, one question was asked about the respondents" own belief about the healthiness of their exercizing behavior (i.e. is it enough?) (5-point Likert scale from totally disagree (1) to totally agree (5)).

Quetelet index. The Quetelet Index was computed by using information about weight and height (two open-ended questions, $\mathrm{QI}=$ weight/height ${ }^{2}$ ).

Behavior Risk Index score. The 5 measures described above on health behavior were used to compute a Health Risk Index score that gave respondents a quick overview on how many of the 5 behaviors were rated "unhealthy". The Behavior Risk Index score was computed as follows: if respondents scored "unhealthy" on a behavior they received the score " 1 " on that behavior, otherwise they received a " 0 ". "Unhealthy" was defined as follows for the different behaviors: fat score $\geq 23, Q I \geq 25$, alcohol use: excessive or very excessive drinker, smoking: smoker, and exercise: no sports (less than 30 minutes per week). The five scores were added up. Consequently, the minimum total Index score was 0 and the maximum total Index score was 5 (al- 
pha $=0.2$ ). Finally, the Index scores were qualified as low (0 or 1), medium ( 2 or 3 ) or high (4 or 5 ).

Awareness. Two measures were used to assess respondents' awareness of the healthiness of their own health behaviors. One measure was the Behavior Risk Index score. The other measure was the subjective belief of repondents on the healthiness of their own behaviors. The question was: how healthy do you find your awn health behaviors? (5-point Likert scale from very unhealthy (1) to very healthy (5)).

Attitudes. Two questions towards respondents" attitudes towards health behaviors. One question concerned the locus of control: how much influence do you feel you have on your health? (5-point Likert scale from very little (1) to very much (5)). The other question was about outcome expectancy: how much influence do you think health behaviors have on health? (5-point Likert scale from very little (1) to very much (5)).

Social support. Two questions were asked on the amount of support the respondents expected from their partner and colleagues during behavior change (5-point Likert scales from much resistance (1) to much support (5)).

Self-efficacy. One question was included about how difficult respondents thought it was to change their health behaviors (5-point Likert scale from very difficult (1) to very easy (5)).

Intention to change behavior. One question about the respondents' intention to change their health behaviors (5-point Likert scale from certainly untrue (1) to certainly true (5)).

Unfortunately, four questions (social support from partner and colleagues, selfefficacy and intention to change) were formulated slightly differently in the pretest and posttest. Therefore $\mathrm{Z}$-scores were computed to make the pre- and posttest scores comparable. Higher Z-scores on social support, self-efficacy and intention to change behavior mean, respectively, more support, easier, and a more positive intention.

In addition to the questions on behavioral determinants, the posttest questionnaire contained 14 questions about the content and lay-out of the Health Profile:

1 Did you read the booklet? (no, partly, totally)

2. How curefully edited do you think the booklet is? (5 point Likert scale from very carefully edited (1) to very carelessly adited (5))

3 How interesting do you think the booklet is to read? (5-point Likert scale from very boring (1) to very nituresting $(5)$ )

4 What did you find the most interesting part(s)? (open-ended quastion)

5 How personal do you think the writing style of the booklet is? (5 point Likert scale from very impetsonal (1) to very personal (5))

6 Do you think the amount of information in the booklet is enough? (5-point Likert scale from too much (1) to too litile (5))

7 How well do you think the information is ordered? (5-point Likert scalle from wery pootly ordered (1) to very well ordered (5))

8 How comprehensible do you find the information? (5-point Likert scale from very poorly comprehersible (1) to very comprehensible (5))

9 How credible do you find the information? (5-point Likert scale from very poorly credible (1) to very credible $(5))$

10 Did you read much new information? (5-point Likert scale from no mew information (1) to very much new information (5))

11 Which information was new for you? (open-ended question)

12 What report mark should you give to this booklet (1 to 10 ) 


\section{Analyses}

Frequency tables were computed to assess the response and the prevalence of health behaviors, Behavior Risk Index scores, subjective beliefs on healthiness of behavior, and self-reported health. Cross-tables were computed to assess the awareness of own behavior at the moment of pretesting (i.e. subjective belief $X$ objective score). This was done for each behavior separately and for the Behavior Risk Index score.

A study on correlations between the Behavior Risk Index and behavioral determinants revealed significant correlations for the attitudes subjective belief on healthiness of own behavior $(r=-.45, p<0.01)$, and locus of control $(r=-.34, p<0.01)$ and for self-efficacy $(\mathrm{r}=-.31, \mathrm{p}<0.05)$. Changes between pretest and positest determinants were analysed with paired T-tests. To test whether the score on the Behawior Risk Index affected respondents' subjective beliefs about the healthiness of their behaviors (i.e. a better awareness) a univariate covariance analysis (ANCOVA) was conducted in which prior individual differences in subjective beliefs were held constant (dependent variable: posttest subjective belief; independent variable: Behavior Risk Index score; covariate: pretest subjective belief). The same kind of analysis was done with respect to the intention to change behavior.

\subsection{Results}

\section{Response}

All workers $(\mathrm{N}=328)$ were invited to join the group sessions and to complete the pretest questionnaire. The response then was $47.9 \%(n=157)$. This population was representative of the total population with regard to gender, age, sector, and job tenure.

It was not possible to compute a Health Profile for all respondents because some questionnaires were incomplete. A Profile was sent to $91.7 \%(n=144)$ of the respondents. The posttest took place by telephone, but not all. the telephone numbers of the respondents were known to the Personnel Department. We had the numbers of 107 of the respondents who received a Profile. After several weeks of telephone sessions during evening hours, we succeeded in contacting 69 respondents. Six of them could not be interviewed, because they did not receive the Health Profile or did not speak Dutch very well (we used an interpreter during the pretest sessions). In 13 cases the interview was incomplete because the respondents said they had not read the Profile or did not want to participate. Because it could not be excluded that the refusal to participate was connected with the intervention (e.g. refusers could have had a higher Risk Index score), these 13 respondents were included in the analyses. We computed conservative estimates for their posttest scores; their posttest scores were regarded as the same as their pretest scores.

A complete interview was held with 50 respondents. This is $34.7 \%$ of the respondents who received a Health Profile and $72.5 \%$ of the respondents we were 
able to contact by telephone. Together with the 13 incomplete interviews this resulted in a sample of 63 respondents. The demographic characteristics of these respondents are shown in table 1. Chisquare tests reveal that this subgroup of 63 respondents do not significantly differ from the respondents that did participate in the pretest but not in the posttest $(\mathrm{n}=94)$ with respect to sociodemographic variables and health behavior scores (not shown).

Table 1: Demographic characteristics $(N=63)$

\begin{tabular}{llll}
\hline Variable & $\%$ & Variable & $\%$ \\
\hline Gender & \multicolumn{3}{c}{ Age } \\
-man & 84.1 & $-\leq 34$ years & 49.2 \\
- Woman & 15.9 & -3549 years & 41.3 \\
& & $-\geq 50$ years & 9.5 \\
Marital Status & & Education & \\
-partner & 78.7 & -lower & 70.0 \\
-diworced & 4.9 & -middle & 15.0 \\
other & 16.4 & -higher & 15.0 \\
\hline
\end{tabular}

Prevalence of health behaviors, Behavior Risk Index scores, subjective beliefs on healthiness of behavior, and self-reported health

As background information, table 2 shows the prevalence of health behaviors, the Behavior Risk Index scores, the subjective beliefs on the healthiness of own behavior and self-reported health during the pretest.

About half of the respondents were overweight (49.2\%). Of these $76.7 \%$ thought themselves to be too heavy (not shown in the table). The majority of the respondents eat too much fat $(84.1 \%)$. Only $28.3 \%$ of those who eat too fat, are aware of their high fat intake. The excessive drinking rate is $6.4 \%(n=4)$; most of the excessive drinkers are aware of the fact that they drink too much $(75.0 \%, n=3)$. More than half of the respondents $(59.7 \%)$ do not do any sports activities. Of these, $40.5 \%$ think they get too little exercise.

Most of the respondents $(75.0 \%)$ scored negatively on 2 or 3 health behaviors (medium Index score), $11.6 \%$ scored negatively on 4 or 5 behaviors (high Index score), and $13.4 \%$ scored negatively on 1 or 0 behaviors (low Index score). With respect to the subjective beliefs on the healthiness of their own behavior, $10.0 \%$ of all respondents think their behaviors are unhealthy, $45.0 \%$ think they are neutral, and $45.0 \%$ think they are healthy. Of the respondents with a high Risk Index score, $42.9 \%$ think their behaviors are unhealthy, $6.7 \%$ of the respondents with a medium Risk Index score think so, while none of the respondents with a low Risk Index score think so.

The self-evaluation of respondents' own health is more positive than the selfevaluation of their own health behavior. A great majority $(90.2 \%)$ of the respondents evaluate their health positively (healthy). 
Table 2: Prewalence of health behaviors, the Behavior Risk Index score, subjective belief on healthiness of own behaviors, and self-reported health during pretest $(N=63)$

\begin{tabular}{|c|c|c|c|}
\hline Varialble & $\%$ & Variable & 荋 \\
\hline $\begin{array}{l}\text { Quetelet Index } \\
\text {-not overweight }(Q I<25) \\
\text {-overweight }(Q I \geq 25)\end{array}$ & $\begin{array}{l}50.8 \\
49.2\end{array}$ & $\begin{array}{l}\text { Fxercise } \\
\text { - Ho sports } \\
\text {-sports }\end{array}$ & $\begin{array}{l}59.7 \\
40.3\end{array}$ \\
\hline $\begin{array}{l}\text { Fat score } \\
\text {-not too much fat }(<23) \\
\text {-too much fat }(\geq 23)\end{array}$ & $\begin{array}{l}15.9 \\
84.1\end{array}$ & $\begin{array}{l}\text { Behavior Risk Index score } \\
-0-1 \\
-2-3 \\
-4-5\end{array}$ & $\begin{array}{l}13.4 \\
75.0 \\
11.6\end{array}$ \\
\hline $\begin{array}{l}\text { Alcohol consumption } \\
\text {-abstainer } \\
\text {-moderate drinker } \\
\text {-excessive drinker }\end{array}$ & $\begin{array}{l}32.3 \\
61.3 \\
6.4\end{array}$ & $\begin{array}{l}\text { Subjective belief on behavior } \\
\text {-lhealthy } \\
\text {-neutral } \\
\text {-unhealthy }\end{array}$ & $\begin{array}{l}45.0 \\
45.0 \\
10.0\end{array}$ \\
\hline $\begin{array}{l}\text { Smoking } \\
\text {-non-smoker } \\
\text {-smoker }\end{array}$ & $\begin{array}{l}46.8 \\
53.2\end{array}$ & $\begin{array}{l}\text { Self-reported health } \\
\text {-healthy } \\
\text {-neutral } \\
\text {-unheal thy }\end{array}$ & $\begin{array}{l}90.2 \\
8.2 \\
1.6\end{array}$ \\
\hline
\end{tabular}

\section{Effects on behavioral determinants}

Research question 1 is answered in table 3, which shows the effects of the Health Profile on the behavioral determinants. The effects were tested with paired T-tests. Two attitudes significantly increased, namely locus of control and outcome expectancy. At the posttest respondents fell more confident about their own influence on their health and about the influence of their health behaviors on health. These are two closely related findings. The other determinants did not change significantly.

Table 3: Effects of the Health Profile on behavioral determinants

\begin{tabular}{|c|c|c|c|c|c|c|}
\hline Variable (range) & n & $\begin{array}{l}\text { pretest } \\
\text { mean }\end{array}$ & s.d. & $\begin{array}{l}\text { posttest } \\
\text { mean }\end{array}$ & s.d. & T" \\
\hline Awareness (subj. belief) (1-5) & 63 & 3.48 & 0.93 & 3.54 & 1.09 & -0.55 \\
\hline $\begin{array}{l}\text { Attitudes }(1-5) \\
\text {-locus of control } \\
\text {-outcome expectancy }\end{array}$ & $\begin{array}{l}62 \\
61\end{array}$ & $\begin{array}{l}3.74 \\
3.80\end{array}$ & $\begin{array}{l}1.17 \\
1.08\end{array}$ & $\begin{array}{l}4.16 \\
4.20\end{array}$ & $\begin{array}{l}0.94 \\
0.98\end{array}$ & $\begin{array}{l}-2.76^{\circ} \\
-2.53^{\circ}\end{array}$ \\
\hline $\begin{array}{l}\text { Social support (z-scores) } \\
\text {-partner } \\
\text {-colleagues }\end{array}$ & $\begin{array}{l}37 \\
45\end{array}$ & $\begin{array}{l}0.22 \\
-0.03\end{array}$ & $\begin{array}{l}1.00 \\
1.06\end{array}$ & $\begin{array}{l}0.01 \\
0.00\end{array}$ & $\begin{array}{l}1.01 \\
1.01\end{array}$ & $\begin{array}{l}0.97 \\
-0.14\end{array}$ \\
\hline Self-efficacy (Zwscores) & 62 & 0.00 & 1.00 & -.03 & 0.97 & 0.25 \\
\hline Intention to change ( $\mathrm{z}$-scores) & 62 & 0.00 & 1.00 & 0.02 & 1.01 & -0.20 \\
\hline
\end{tabular}

$\therefore \mathrm{P}<0.01, \quad \mathrm{P}<0.05$ 
Relation between Behavior Risk Index score and a) subjective belief (i.e. awareness) and b) intention to change behavior

The next step (research question 2) was to test whether the different feedback respondents received (higher or lower Behavior Risk Index scores) affected their subjective belief on the healthiness of their behavior (i.e. awareness) and/or their intention to change behavior after individual differences in subjective beliefs and in intentions were held constant. In other words, did the Health Profile achieve a stronger relationship between respondents' objective health behavior scores and their subjective beliefs about the healthiness of their behavior or their intention to change behavior? Respondents with a higher Behavior Risk Index score (indicating unhealthy behaviors) were expected to have lower scores on subjective beliefs (indicating "unhealthier" subjective belief) and/or higher scores on intention (indicating a higher intention to change). Table 4 shows the results of the two analyses of covariance (see analyses section), indicating that respondents with higher objective scores indeed had lower scores on the subjective belief about the healthiness of their behavior. The significant effect of the Behavior Risk Index score $(F=5.06, p<0.05)$ indicates that the relation between the Behavior Risk Index score and the subjective belief had become significantly stronger between pretest and posttest. In other words, the feedback in the Health Profile increased the awareness in the right direction. Crosstabulations (not shown) of the subjective belief on the healthiness of own behavior by the objective Behavior Risk Index score strengthen this conclusion. At the posttest $71.4 \%$ of the respondents with a high Risk Index score thought their health behaviors were unhealthy $(42.9 \%$ at the pretest), $17.7 \%$ of the respondents with a medium Risk Index score thought their health Behaviors were unhealthy $(6.7 \%$ at the pretest), while none of the respondents with a low Risk Index score thought likewise (identical with the pretest).

Finally, table 4 shows that the Behavior Risk Index score had no significant effect on the intention to change behavior.

Table 4: Covariance analyses to test the relation between Behavior Risk Index score and a) subjective bellief (awareness) and b) intention to change behavior.

\begin{tabular}{|c|c|c|c|c|c|}
\hline & Behavion & isk Index score & & & \\
\hline Variable (range) & $\begin{array}{l}\text { low }(0,1) \\
(n=8)\end{array}$ & $\begin{array}{l}\text { medium }(2,3) \\
(n=45)\end{array}$ & $\begin{array}{l}\text { high }(4,5) \\
(n=7)\end{array}$ & $\begin{array}{l}\text { F(Index } \\
\text { score })^{2}\end{array}$ & $\mathrm{~F}(\text { covariate })^{3}$ \\
\hline $\begin{array}{l}\text { Subjective belief (awareness) } \\
\text {-pretest mean }(1-5)^{4} \\
\text {-posttest mean }\end{array}$ & $\begin{array}{l}3.48 \\
4.50\end{array}$ & $\begin{array}{l}4.13 \\
3.58\end{array}$ & $\begin{array}{l}2.71 \\
2.29\end{array}$ & $5.06^{\circ}$ & $15.60^{* * *}$ \\
\hline $\begin{array}{l}\text { Intention to change } \\
\text {-pretest mean }(-2.7-1.4)^{*} \\
\text {-posttest mean }\end{array}$ & $\begin{array}{l}0.12 \\
0.12\end{array}$ & $\begin{array}{l}0.07 \\
0.03\end{array}$ & $\begin{array}{l}-.69 \\
-.35\end{array}$ & 0.12 & $33.40^{*+*}$ \\
\hline
\end{tabular}

\footnotetext{
i higher score means a higher risk

2 intervention effect

${ }^{3}$ covariate is the pretest score

4a higher score means a healthier self-evaluation

s a higher score means a higher intention to change

${ }^{* * *} \mathrm{P}<0.001,{ }^{* *} \mathrm{P}<0.01, * \mathrm{P}<0.05$
} 


\section{Evaluation of the Health Profile}

The information on how respondents evaluated the different aspects of the Health Profile (research question 3 ) can help us to interpret the effects. Table 5 shows the answers on the questions about content and lay-out for respondents with a low, medium and high Behavior Risk Index score. On average the Health Profile is well evaluated. The writing-style was criticized most. As the answers on the open-ended questions indicate too, respondents would like a more personal, less businesslike writing style. Other lay-out improvements could be made by adding more graphics and colors. When we compare respondents with low, medium and high behavior Risk Index scores, we see that the respondents with a medium score are the most satisfied with the Health Profile. Respondents with a low Risk Index score scored relatively low on the amount of new information received. Respondents with low or medium Risk Index scores scored relatively low on the question whether they received enough information. From the open-ended questions it becomes clear that they want more specific information about how to change unhealthy behaviors (self-efficacy information). The respondents with high risk-scores indicate that they had enough information that was new for them, but they score relatively low on aspects such as credibility and comprehensibility. The latter could perhaps be explained by the fact that they also score relatively low on the items "carefully edited" and "well-ordered".

Table 5: Evaluation of content and lay-out of Health Profile (percentages represent positive answers).

\begin{tabular}{|c|c|c|c|c|c|c|c|}
\hline \multirow[b]{2}{*}{ Variable } & \multicolumn{3}{|c|}{ Behavior Risk Index scoret } & \multirow[b]{2}{*}{ Variable } & \multicolumn{3}{|c|}{ Behavior Risk Index score } \\
\hline & $\begin{array}{c}\text { low } \\
(\mathbf{n}=8)\end{array}$ & $\begin{array}{l}\text { medium } \\
(\mathrm{n}=34)\end{array}$ & $\begin{array}{l}\text { high } \\
(n=6)\end{array}$ & & $\begin{array}{l}\text { low } \\
(\mathrm{n}=8)\end{array}$ & $\begin{array}{l}\text { medium } \\
(n=34)\end{array}$ & $\begin{array}{l}\text { high } \\
(n=6)\end{array}$ \\
\hline & $\not$ & $\%$ & $\%$ & & $\%$ & $\%$ & $\%$ \\
\hline read it & 100 & 89.5 & 85.7 & well-ordered & 100 & 88.2 & 83.3 \\
\hline carefully edited & 87.5 & 94.1 & 66.7 & comprehensible & 87.5 & 94.1 & 83.3 \\
\hline interesting & 75.0 & 88.2 & 83.3 & credible & 100 & 85.3 & 66.7 \\
\hline writing-style & 50.0 & 70.6 & 66.7 & new information & 62.5 & 97.1 & 83.3 \\
\hline enough information & 75.0 & 79.4 & 83.3 & $\begin{array}{l}\text { report mark } \\
\text { (mean) }\end{array}$ & 7.3 & 7.3 & 6.5 \\
\hline
\end{tabular}

\subsection{Discussion}

The purpose of this study was to assess the effectiveness of a personalized Health Profile on several behavioral determinants. The major goal of the Health Profile was achieved because the awareness of own health behaviors increased significantly. So, it can be concluded that information on personal health behaviors and the possibility to compare behavior scores with medical norms, the average man or woman, and colleagues can improve behavioral awareness. In addition to the effects on awareness, the Health Profile did succeed in influencing attitudes like locus of control and 
outcome expectancy. A second major goal of the Health Profile, to improve the intention to change health behavior when necessary, was not achieved. This can be explained by the fact that some important behavioral determinants like self-efficacy and social support clid not change either. These results indicate that future Health Proffles should contain more specific information on how to change behaviors. This specific, thematic information could be added to the general Health Profile or could be given separately. Research on the effectiveness of tailored feedback on separate themes shows positive behavioral effects, for example for fat consumption (Brug, et al. (accepted for publication); Bowen, et al., 1994; Campbell, et al, 1994) and smoking (Prochaska, et al, 1993; Strecher, et al, 1994). Also, a counseling session with a health worker (e.g. the company physician) could be a means to give this kind of tailored information (Dunton, 1992). Social support could be increased by giving feedback in group sessions and including partners or friends in the program.

So, we can conclude that the Health Profile was effective in changing attitudes, but that it did not succeed in motivating persons with high risk scores to initiate behavioral change. Future Health Profiles should have additional supplements on specific behaviors and/or should be combined with counseling sessions. In the Netherlands, Health Profiles could be incorporated in periodic health examinations that are common at the worksite. Those examinations contain a physical examination, a questionnaire and a talk with the company physician.

\section{Acknowledgements}

We thank Deo Hoen (Department of Health Education and Promotion, Maastricht University) for his technical assistance; he developed the Turbo Pascal program that combined the pretest data with the appropriate educational texts. We also thank Gerard van Breukelen (Department of Methodology and Statistics, Maastricht University) for his statistical advice. 


\section{Process evaluation of two worksite alcohol programs}

Authors: R.M. Vasse, F.J.N. Nijhuis, G. Kok, and A.T. Kroodsma

\subsection{Abstract}

This article describes the process evaluation of two worksite programs aimed at preventing workers' alcohol problems. One program was a primary preventive, health promotion program and the other was a secondary preventive, employee assistance program. The process evaluation focused on the feasibility of implementing these programs. Therefore five factors were investigated: 1) program implementation, 2) site response, 3) recipient response, 4) practitioner response, and 5) competencies of personnel. The results of both programs are discussed and compared with each other. Recommendations are made on the use of planning models, the role of external consultants, participation of the worksite, incorporation of research, the content of the programs and integration with other programs.

\subsection{Introduction}

Problematic alcohol use is a major health problem. It has great negative consequences for drinkers themselves and their environment. Main physical problems related to chronic excessive alcohol drinking are disorders of the stomach, liver, pancreas and brains. Alcohol problems furthermore often create great financial problems and social isolation. Work is one of the environments that is affected by excessive alcohol use because it might result in decreased work performance, unsafe work situations, increased sickness absence and extra costs. Approximately $12 \%$ of the Dutch working population drinks excessively (13.6\% for men, $2.5 \%$ for women) (Gründemann, 1988; Gründemann, 1989a; 1989b) and thus has an increased risk on alcohol problems. A study of the Dutch Economic Institute (Meijer \& Tjioe, 1990) shows that $30 \%$ (HFL 588 million) of the total costs of alcohol abuse are workrelated. Of these work-related costs the major part $(95.7 \%)$ is caused by extra sickness absence of excessive drinkers compared to moderate drinkers. Because of these reasons companies are more and more interested in worksite programs aimed at 
preventing alcohol problems. From a health worker"s view the workplace is a interesting setting because the majority of the working population still exists of male adults who are difficult to reach with other health education activities.

This article reports on the feasibility of implementing two types of worksite alcohol programs namely a primary and a secondary preventive program. Therefore an extensive process evaluation was conducted. Both programs were aimed at preventing allcohol problems on the long term, but had other short term goals. The major goals of the secondary preventive program was to improve the early detection of and assistance to problem drinkers. The major goal of the primary preventive program was to improve awareness of own drinking behavior and to change this behavior when necessary. The project was financed by the Dutch Ministry of Welfare, Health and Cultural Affairs and implemented by the Alcohol Consultancy Foundation. (AL$\mathrm{CON})$ and the Maastricht University.

\section{Programs: plans, theoretical basis and effectiveness}

Before companies were asked to participate in the primary or secondary preventive program, global program plans regarding the content of the programs and their planning and organization were worked out with the help of several theoretical models.

\section{Behavior change models \& content of the programs}

For the development of program components several behavior change models were integrated: the Transtheoretical Model of Stages of Change (Prochaska \& DiClimente, 1984) and the Behavior Change Model (McGuire, 1985; Kok \& De Vries, 1989). Both modells give a framework in which other sociopsychological theories can be used to work out details. The Transtheoretical Model of Behavior Change distinguishes four stages in behavioral change: 1) precontemplation (unaware of a problem), 2) contemplation (thinking about making a change), 3) preparation and action (initial attempts to change), and 4) maintenance (long-term change). The Model of Behavior Change integrates several of those sociopsychological theories (McGuire, 1985; Fishbein \& Ajzen, 1975; Bandura, 1986). This resulted in five determinants of beliavior change that were used for program development: awareness, attitudes, social influence, self-efficacy, and barriers.

The main goal of the secondary preventive program was the early detection of and assistance to problem drinkers. The content of the program closely resembled that of american Employee Assistance Programs in which constructive confrontation and counseling are central concepts. Three central goals of our program were: 1) improvement of signaling, constructive confrontation and counseling skills of social medical workers and supervisors, 2) development of an alcohol policy including rules about alcohol use at work and procedures for assistance to alcohol problems, and 3) improvement of knowledge of all workers about the new policy and improvement of their awareness of own drinking behavior. The ALCON Foundation was experienced in implementing alcohol policies and skills training programs. 
The main goal of the primary preventive program was the promotion of health behaviors including a healthy alcohol drinking behavior. These kind of programs are called Health promotion Programs. Health promotion programs usually have two phases: in the first phase the central goal is improvement of people's awareness about their own health behaviors (a commonly used instrument for this is a Health Risk Appraisal) and based on the results of this first phase people can clioose to participate in program activities most relevant for them. Because of their relationship with alcohol drinking behavior the following themes besides alcohol were proposed in our plan: smoking, diet behavior (including weight loss), exercise and stress. No concrete activities were mentioned in the plan, although we were preparing a workbook that would give an overview of existing programs offered by national and local organizations. For the first phase of the program we developed a Dutch version of a Health Risk Appraisal namely a Health Profile, that gave feedback on the healthiness of four health behaviors (smoking, diet behavior, alcohol drinking behavior, exercise behavior) and the Quetelet-Index (weight/height ratio).

\section{PRECEDE-PROCEED Model \& organizational plan}

For the planning and organization of the programs the PRECEDE-PROCEED Model (Green \& Kreuter, 1991) was used. This model is commonly used in the Health Education and Promotion field for the development, implementation and evaluation of programs concerned with health problems. The model has nine phases: 1) social diagnosis, 2) epidemiological diagnosis, 3) behavioral and environmental diagnosis, 4) educational and organizational diagnosis, 5) administrative and policy diagnosis, 6) implementation, 7) process evaluation, 8) impact evaluation, and 9) outcome evaluation.

Basic activities included in the plan that was presented to companies regarding planning and organization were: the ALCON Foundation and the University as external consultants would cooperate with an internal working group, a problem diagnosis would be conducted by the external consultants, external consultants and the working group would develop and implement an intervention based on the results of the diagnosis, and the external consultants would evaluate the effects of the intervention. Main instruments for diagnosis and evaluation would be interviews and written questionnaires.

\section{Program implementation and effectiveness}

Two companies participated in the project. A pharmaceutical company $(\mathbb{N}=1600)$ participated in the secondary preventive program. The main goals, as finally formulated in the company's plan, were to reduce work performance problems related to alcohol abuse and to reduce the use of alcohol during working time. The final program closely resembled the original plan; it contained three major components: rules and procedures for assistance to problem drinkers, skills training for social medical workers and supervisors, and alcohol education for all workers. The program was partly effective; the knowledge about company rules and procedures improved, the attitude about the policy was positive, the training for social medical workers was effective in improving their skills, supervisors' skills did not improve, nor did the 
mass media education influence drinking behavior and behavioral determinants of workers.

A Municipal Garbage Collecting Department $(\mathrm{N}=328)$ participated in the primary preventive program. Only the first phase of the original plan was implemented namely the Health Profile. This intervention was effective in raising workers' awareness about the healthiness of their behaviors, but did not affect other behavioral determinants.

\subsection{Methods}

\section{Process evaluation}

Process evaluation is a form of formative evaluation that provides diagnostic feedback about the implementation and the quality of the program (Green \& Lewis, 1986). It includes feedback on five factors: 1) program implementation, 2) site response, 3) recipient response, 4) practitioner response, and 5) competencies of personnel. These five factors, that are strongly interdependent, will structure this article.

The evaluation of the program implementation documents the extent to which a program is delivered as planned. What activities actually occurred? Is the program offered as developed by the program planners or are (in)appropriate adjustments being made in its content or in the methods of delivery? (Green \& Lewis, 1986). The next factor, site response, is the response from people from the intervention site on the program. Programs are seldom implemented in a benign or apolitical environment (Green \& Lewis, 1986). What responses from staff or competing programs might have set up obstacles? What do relevant groups think about the program? Recipient response addresses the quality of the recruitment and progress of participants through the program (Green \& Lewis, 1986). It is judged from three perspectives: the participants' actual program participation, the quality of their progression (comprehension, skills improvement etcetera), and their level of satisfaction with program components. Practitioner response is the response of field personnel that implements the program. Their insights and feedback can contribute to refinement and improvement of the program (Green \& Lewis, 1986). In our case, we'll describe the response of the external consultant from the ALCON-Foundation on the program components and on her own role in assisting company members. The last factor, competencies of personnel, concerns the level of knowledge, skills and attitudinal performance of various professionals and nonprofessionals who deliver the programs (Green \& Lewis, 1986). Especially the performance of the working group and the project leader will be discussed.

In most studies process evaluation is limited to the implementation of (behavioral) programs, but we include the total research project thus not only the implemental but also the diagnostic, developmental and evaluative stages of the project. Recently, the term context evaluation is proposed to evaluate the needs assessment or diagnostic phase (Israel, Cummings, Dignan, et al, 1995). Context evaluation might consider the needs of targeted individuals as well as cultural, political, social, economic, or geographic factors that may influence project activities or outcomes (Isra- 
el, Cummings, Dignan et al, 1995). We'll discuss these context factors within the sections "program implementation" and "site response".

\section{General Model of Planned Change}

To describe the influence of our context, worksites, we used a planning model that stems from the field of organization development and change that indicates which worksite factors are important in the different planning stages of a project. The model is called the General Model of Planned Change (Cummings \& Worley, 1993). It is usually concerned with the development, implementation and evaluation of programs aimed at four categories of organizational issues: human process, technology and structure, human resource, and strategic issues. The General Model of Planned Change contains four stages (Cummings \& Worley, 1993). The first stage is concerned with entering and contracting activities. The second stage involves a careful diagnosis of the problems facing the organization, including their causes and consequences. In the third stage, the planning and implementing stage, organization. members and external consultants jointly plan and implement program components. The fourth stage involves evaluating the impact of the program and managing the institutionalization of successful program components. Compared with the PRECEDE-PROCEED Model, the General Model of Planned Change gives more specific information about important factors within the worksite that influence the progress of project implementation.

\section{Data collection}

Data collection for the process evaluation took place throughout all planning phases of the project. A mix of data collection methods was used (see also table 1).

The first data collection method in the process evaluation was reading company reports. This was primarily done to analyze the context of our project and to learn more about the organization. Main research questions were: What links existed with other projects? What kind of policy basis existed for our project? What was the number of registered problems (sickness absence, health problems, alcohol problems)? What was the organizational and decisional structure? How many workers worked at what kind of levels? What types of work could be distinguished? At the Municipal Garbage Collecting Department two major sources were read: social reports and brochures with information about the Department. At the pharmaceutical company three major sources were used: social reports, the health policy document, and general information about the company.

Secondly, semi-structured group and individual interviews with representatives of different organizational groups were held. During the behavioral and environmental diagnosis phase these interviews mainly addressed interviewees' attitudes about the project (importance, feasibility, obstacles, etcetera) and their specific needs (priorities). During the evaiuation phase interviewees gave their opinion about the content and ways of implementation of the project and the effects they observed. So, the interviews were mainly used to assess site response and recipients response. At the Municipal Garbage Collecting Department 11 individual and 2 group interviews were held during the diagnostic phase and 1 group and 2 individual interviews during 
the evaluation phase. At the pharmaceutical company 5 group interviews were held during the diagnostic phase and 4 during the evaluation phase.

Thirdly, open ended and closed questions were used in written questionnaires during the (educational and organizational) diagnosis phase and the (impact) evaluation phase to assess additional information about respondents" attitudes towards the project and to assess participation rate and evaluation of program components. So, the questionnaires were mainly used to assess recipient response. At the Municipal Garbage Collecting Department a pretest and a posttest questionnaire was sent to all workers (pretest response $47.9 \%$; posttest response $34.7 \%$ of pretest participants). At the pharmaceutical company a pretest and posttest questionnaire was sent to all social medical workers (pretest response 18 out of 22 ; posttest response 11 out of 16 ), a sample of supervisors (pretest response $71.6 \%$; posttest response $52.5 \%$ ), and a sample of all workers (pretest response $70.9 \%$; posttest response $53.6 \%$ ). In addition to these questionnaires, a written questionnaire was sent to all working group members during the (impact) evaluation phase to assess their evaluation of the working group's functioning (practitioner response and competencies of personnel). Finally, the social medical workers who participated in the workshop (skills training) filled out a form to evaluate the different components of the workshop (recipient response).

Fourthly, at the pharmaceutical company registration forms were used to assess the frequency at which supervisors contacted social medical workers for assistance, also the type of questions (content) and follow up contacts were included in the form. So, the forms were mainly used to assess program implementation and recipients response. Unfortunately, social medical workers did not consequently use the registration forms because it costed them too much time. So, we do not have much insight in the quality of the assistance from social medical workers to supervisors. Quantitative information (frequency of pleas for assistance) was gained from the written posttest questionnaire to supervisors (see above).

Fifthly, minutes were kept of the working group meetings to assess the process of project development and implementation (who did what and when) and the decisional structure. So, the minutes were used to assess program implementation, practitioner response and the competencies of personnel. At the Municipal Garbage Collecting Company the external consultant kept minutes and at the pharmaceutical company the secretary of the social work department kept minutes.

Finally, the external consultant from the ALCON Foundation wrote process reports throughout all phases of the project to document what she and others did, why and when, and how she evaluated the progress of the project. So, the process reports were used to gain information about all five process evaluation factors. 
Table 1: Research methods

\begin{tabular}{|c|c|c|}
\hline \multirow[t]{2}{*}{ Research method } & \multicolumn{2}{|c|}{ Program } \\
\hline & $\begin{array}{l}\text { Primary preventive program } \\
\text { research group }\end{array}$ & $\begin{array}{l}\text { Secondary preventive pro- } \\
\text { gram } \\
\text { research group }\end{array}$ \\
\hline 1. reading company reports & does not apply & does not apply \\
\hline 2 group and individual interviews & $\begin{array}{l}\text { workers ( } 2 \text { groups), } \\
\text { middle managers, } \\
\text { physician, } \\
\text { canteen personnel }\end{array}$ & $\begin{array}{l}\text { top management team, } \\
\text { workers ( } 3 \text { groups), } \\
\text { social nuedical workers, } \\
\text { union }\end{array}$ \\
\hline $\begin{array}{l}3 \text { open and closed questions in } \\
\text { written questionnaires }\end{array}$ & all workers & $\begin{array}{l}\text { sample of workers, } \\
\text { all social medical workers, } \\
\text { sample of supervisors, } \\
\text { all working group members } \\
\text { (only at evaluation phase) }\end{array}$ \\
\hline 4 registration forms & - & social medical workers \\
\hline $\begin{array}{l}5 \text { keeping minutes of working } \\
\text { group meetings }\end{array}$ & does not apply & does not apply \\
\hline 6 writing process reports & does not apply & does not apply \\
\hline
\end{tabular}

\section{Data analyses}

Summaries of company reports were incorporated in diagnostic reports. Minutes were kept of the semi-structured interviews. These were then categorized by topic and summarized. The same (categorizing and summarizing) was done with the open ended questions in the questionnaires, the minutes of working group meetings and the process reports. The closed questions in written questionnaires were analyzed with the SPSS-X statistical computer package. Because of the low response the registration forms regarding the quality of assistance to supervisors were not analyzed.

\subsection{Results}

The presentation of the results is based on the five factors of Green and Lewis (Green \& Lewis, 1986): program implementation (in our case project implementation), site response, recipient response, practitioner response, and competencies of personnel.

\section{Project implementation}

Strong and weak points within all stages of the planning process are summarized in table 2. Compared to the theoretical model, the entering and contracting phase was not very well executed in the Municipal Garbage Collecting Department. The major reason was that the department had not presented a problem itself. They were asked by the ALCON Foundation whether they were interested in participating in the 
project. The umbrella health department of the Municipality had suggested ALCON to contact the Garbage Collecting Department because there had been an alcohol project some years ago and the department might be interested in broadening the alcohol project into a health promotion project. The department had no objections, but did not have concrete ideas about a possible content of the project either. Out of his coordinating function regarding the new Dutch Work Environment Act, the internal project leader was a Division Manager. The external consultant from ALCON and the project leader set up a working group existing of representatives of the personnel office, the union, the municipal physician, other division managers, and workers who had shown former interest in health. In this stage mutual expectations were not clarified extensively. ALCON had presented a global plan for activities on five health themes (alcohol, stress, smoking, nutrition (including weight loss), and exercise) with which the department agreed. Regarding time, resources and a working relationship no specific agreements were made other than that the external consultant would be present at the department for one day a week and that based on the diagnosis a plan would be developed containing proposals for activities and costs. In practice it was the external consultant who was the motor of the project and there were no strong feelings of ownership within the department.

On the contrary, the entering and contracting phase at the pharmaceutical company went much better. The situation was different here in that it was the company itself that contacted the ALCON Foundation with a specific request for help with developing and implementing an Alcohol Policy. The company had developed a general health policy a year ago and wanted to start several health projects like, among others, an alcohol program. Their major focus was on how to deal with problem drinkers. The project leader here was a social worker out of her function that included assistance to problem workers. She had to report to the manager of the Personnel and Organization Department (P\&O) who was a member of the Management Team. A working group was set up consisting of representatives of the union, the department of internal and external communication, the personnel department, the internal training department, middle management, and the company physician. Mutual expectations, necessary time and resources, and the working relationship were thoroughly discussed. Especially with regard to the research part of the project the company wanted assurances about requested time and confidentiality. The external consultant had a far more advising role compared to the situation in the Municipal Department. 
Table 2: Evaluation of project implementation

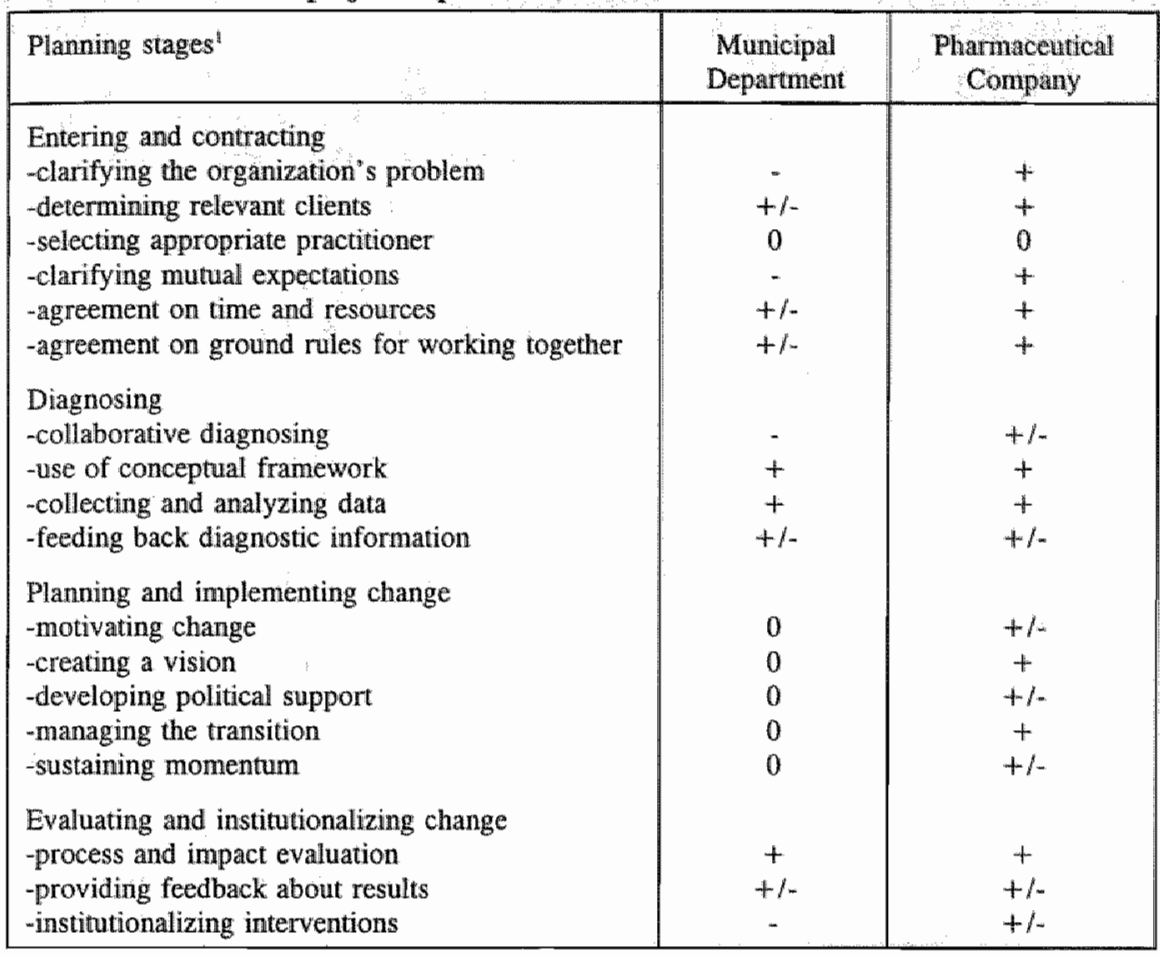

I Stages of the General Model of Planned Change (Cummings and Worley, 1993)

$+\quad$ means "well executed"

- means "badly executed"

$+/$ - means "moderately executed"

0 means "does not apply"

The diagnosing phase went moderately at the Municipal Department. The external consultants solely determined the content of the questions for the group and individual interviews. The division manager suggested the people for these interviews. Additionally, a written questionnaire was sent to all workers (response $47.9 \%$ ) that included a needs assessment. The external consultants wrote a report on the results of the diagnosis and presented it to the working group.

At the pharmaceutical company the diagnosing phase went moderately till good. Compared to the municipal department, in this case the project leader was more involved in determining the content of the diagnosis; first of all she had a vision on the project's goals and furthermore she gave comments and suggestions on the diagnostic interviews and questionnaires. The response to the questionnaires was: 18 out of 22 social medical workers at the pretest and 11 out of 16 at the posttest; $71.6 \%$ for supervisors at the pretest and $52.5 \%$ at the posttest; $70.9 \%$ for all workers at the pretest and $53.6 \%$ at the posttest. The working group received a report on the diagnosis. 
In the planning and implementing phase at the Municipal Department the working group, stimulated by the diagnosis report, thoroughly discussed goals and means for the project. This resulted in a plan that emphasized the need to develop activities on workstress (especially regarding internal communication) and sports on the short term. The management team did not agree with the plan and the project was stopped. So, the implementation was restricted to the Health Profile, an instrument that gave all workers who responded to the health questionnaire, feedback on the healthiness of their behaviors. The profile was sent to the home address of $91.7 \%$ of the respondents. This was done before the management team took the decision to stop the project. Reviewing the process afterwards, the weakest point in the first two stages at the Municipal Department was that the department did not have a vision itself about the content of the project. Before going on with a diagnosis the external consultants should have stimulated the department more to define the problem and goals for the project, especially the general director should have been personally involved as his personal approvement turned out to be very important. Another appropriate moment for involving the general director and others, would have been the moment of feeding back diagnostic information. As the General Model of Planned Change indicates, besides an appropriate content of the feedback, it is also important to organize an appropriate process for the feedback. Feedback meetings are important means to stimulate feelings of ownership by providing a forum for discussing the data, drawing relevant conclusions, and devising preliminary actions plans. Besides this, there were two other reasons for the discontinuation of the project that could not be influenced by project members. These reasons were reorganizations within the municipality and a police investigation because of supposed malversation within the department.

At the pharmaceutical company, based on the diagnosis report, the working group developed an Alcohol Policy including rules and procedures for assistance to problem drinkers, skills training for social medical workers and supervisors, and educational activities for all workers about the policy and alcohol in general. The concept plan was presented to the management team and to the union. Because of financial problems the skills training for supervisors was reduced to written information and the optional possibility to consult a personnel officer who could give more information. This meant a serious weakening of the original plan that gave high priority to skills training of supervisors. Also in this company, more energy should have been given to involve relevant clients (in this case managers and supervisors) in developing the plan. Feedback sessions on diagnostic results could have been organized for this group to make them aware of the need for skills training for supervisors. In this case, the manager Personnel and Organization (P\&O) should have played a more active role in involving management. The final plan was implemented as intended.

In the evaluating and institutionalizing phase at the Municipal Department the Health Profile was evaluated with a quasi-experimental design (pretest, posttest, no control group). The posttest questionnaire additionally contained questions to evaluate the content and lay-out of the Profile (process evaluation). Furthermore, two individual interviews (division manager and general manager) and one group interview (work- 
ing group) were held to evaluate the process of the project. No plans for institutionalization of the project were made besides that the division manager would try to incorporate some of the ideas from this project into his work as a coordinator of the Working Conditions Policy.

In the pharmaceutical company the effectiveness of the program was evaluated with a quasi-experimental design (pretest, posttest, no control group). The posttest questionnaires also contained process evaluation questions. Additionally, four group interviews were held to obtain process information. The working group and the manager Personnel and Organization received an evaluation report. Based on this report preliminary institutionalization plans were made. Because other projects litad had comparable difficulties with social skills training for supervisors, the manager $\mathrm{P} \& \mathrm{O}$ indicated that activities in the near future should be focused on social skills of supervisors in general. Problem drinking could be one of the themes in such a program. Furthermore, the alcohol policy would be regularly evaluated in meetings of social medical teams and in the yearly Social report.

\section{Site response}

The response on the project from members of the Municipal Garbage Collecting Department was mixed. The personal motives of the project leader (a division manager) for a Health Promotion Program were the chances he saw for improvement of the department's flexibility and readiness to change. He thought the department was rigid, old-fashioned and hierarchical. As the result of a recent Organizational Change Project the department was trying to change the management style from top-down to participative, but these changes went very slowly. The attitude of the department manager turned out to be less positive. He was not explicitly a champion of the project, but he was not against it either and liked to do some "nice things" for his workers like weight loss programs. Middle managers and "floor" workers did not know what to think of the project. This can be explained by the fact that is was unclear what the goals of the project were and what concrete activities would take place. People did not get a clear picture of the project. Furthermore, workers were concerned about the confidentiality of things they declared at interviews or in the written questionnaire. They were afraid the company would use the information against them, although a system of research numbers was set up so that nor the company nor the university could combine names with outcomes.

The response at the pharmaceutical company was also mixed but much more positive on the whole. People closely involved with the project (manager P\&O, social worker, working group members) were convinced of the importance of the project and knew what they wanted to achieve. They also could repeatedly convince the top management team. Other workers had more mixed feelings. These concerned mostly the extent at which the company would interfere with private affairs like alcohol consumption. The company made very clear in the policy document and in the mass media campaign that dysfunctioning of a worker was the only legitimation for interference and that was accepted by the personnel. As in the Municipal Department, workers had also here some difficulties with the confidentiality of the research data, but in a far less extent. Partly this can probably be explained by the higher education level at the pharmaceutical company and partly by the fact that the goals of 
the program were clearer. Because of their great relevancy for the project, more attention should have been paid to managers and supervisors in an early stage of the project to check and influence their motivation. As said above, these groups should have received more feedback about diagnosis results and should have been involved in developing program plans.

\section{Recipient response}

At the Municipal Garbage Collecting Department the response to the pretest questionnaire was moderate $(47.9 \%, n=157)$. To $91.7 \%$ of them a Health Profile was sent $(n=144)$ and with 63 respondents who got the Profile a posttest questionnaire was completed. The Health Profile was evaluated rather good. The major improvement could be made by giving more specific information about how to change health behaviors that turned out to be unhealthy. But this would have been the goal for follow up interventions that unfortunately did not take place. More information about the Health Profile can be found in Vasse, Nijhuis and Kok (submitted).

At the pharmaceutical company the participation on and evaluation of program components were mixed. In general, the participation on the program components was moderate till good and program components were well judged by their participants. Relatively well evaluated were the skills training for social medical workers and the information about the policy in the company's magazine and the special policy document: Judged as minor components were the canteen campaign and the information/education for supervisors. The relatively poor evaluation of the canteen campaign can be explained by workers" hesitancy about company"s interference with their behavior and by the emphasis on problem drinking. The goals of the mass media campaign on improvement of awareness and changing peoples' drinking behavior were not achieved. Alcohol education would perhaps attract more workers when the term health drinking is used and the emphasis is laid on the assessment of the healthiness of own drinking behavior (see also Towers, Kishcuk, Sylvestre et al, 1994). More tailored, personalized feedback is needed for that. The paradoxical situation that supervisors did not make use of the assistance that was offered to them, but nevertheless judged the education/assistance as insufficient once again shows that new strategies should be developed to reach supervisors. If a special skills training on constructive confrontation skills needed for the assistance to problem drinkers is not possible, ways should be found to incorporate these skills in other supervisory courses such as courses on periodical evaluation talks with workers about their functioning, or courses on general social or communication skills. Alcohol can be used as a theme then.

\section{Practitioner response}

This section evaluates the external consultant's role. At the Municipal Garbage Collecting Department the external consultant was the moving spirit behind the project. Nearly everything happened at her initiative. Everybody, including herself, held her responsible for the continuation of the project. After some time she realized this was not workable. The internal project members should feel more responsible for the project. This change occurred after the diagnosis; the project leader and the 
working group showed more and more involvement with the project, but it turned out to be too late:

At the pharmaceutical company the situation was different. The project leader and the working group felt responsible from the very beginning and took own initiatives. The external consultant fulfilled an advising role in stead of a initiating role. But nevertheless the external help was vital. One major reason concerned the skills of the project leader (see next section). Another reason was that the attention of company members was distracted from the project by other important things like reorganizations. An external force was needed to motivate them again and again. The company members said afterwards that they felt a responsibility towards the external consultant to accomplish the agreed tasks. So it can be concluded that the external consultant played a very important role in the project at both companies.

\section{Competencies of personnel}

At the Municipal Garbage Collecting Department the project leader"s background had nothing to do with physical or mental health; he was the head of a division within the department. So he had no experience with implementing these kind of projects in the organization. Other working group members who might theoretically have had more affinity with this kind of projects (the personnel worker and the company physician) did not play the champion role either. The personnel worker was too busy with his own refresher course and with reorganizations. The company physician was not very familiar with the department. It was a relatively new job for him, and the department was only one of many he had to serve. Also, he seemed not convinced that health education could change blue collar workers" health behaviors.

At the pharmaceutical company the project leader, a social worker, was very involved with the subject. The manager $\mathrm{P} \& \mathrm{O}$ who was responsible for the health and social policy of the company also felt responsible for the project. But involvement is not the only ingredient for a successful project. The reason why the external consultant's help was vital here, was that the project leader was unexperienced in leading a project. As a social worker she was experienced in the field of individual counselling, but her organizing skills were less well developed. She had never led a big project or had been responsible for setting up a policy.

So, it can be concluded that internal personnel need to have a mix of competencies. They have to be involved with the subject, but also need to be able to organize and plan. Our recommendation on basis of these two cases would be to appoint a person from the health or social field who has organizing experience. But it will also depend on the competencies of other working group members who might complement the project leader.

\subsection{Discussion and conclusions}

The purpose of this article was to evaluate the process of development, implementation and evaluation of two worksite programs aimed at preventing alcohol problems. The two programs had different goals (primary and secondary prevention) and were implemented in different kind of worksites (blue-collar and white-collar), but never- 
theless the comparison between the two worksites gives important insight in which components of project planning and organization are most effective. This discussion focuses on some major topics found important for a successful implementation process in general namely the use of planning models, the role of an external consultant, participation of the worksite, and the incorporation of research. Additionally, some specific remarks will be made on the two programs" content.

\section{The use of planning models}

Being health education professionals, the project members from the ALCON Foundation and the Maastricht University were most familiar with the PRECEDE-PROCEED planning model (Green \& Kreuter, 1991). As this model concentrates on the unraveling of a health problem, the focus was on the content of the programs and as external consultants they were less prepared for how the working relationship with worksite members could best be filled in. During the project it became clear that there were great differences between the two worksites regarding the working relationships and their effectiveness. In an effort to explain these differences an additional planning model specialized in change processes in organizations was sought and found in the General Model of Planned Change (Cummings \& Worley, 1993). The surplus walue of this model was especially linked to the emphasis on 1) the entering and contracting phase, 2) the feedback process of diagnostic data, and 3) the activities contributing to effective change management. A major difference between the two worksites in the entering and contracting phase was the extent in which worksite members presented the problem themselves, had a vision on the desired future state and developed specific goals for the project themselves. In both worksites the process of feeding back diagnostic data could have been improved which might have stimulated worksite members' feelings of ownership and actual participation in program development. Besides the working group other relevant groups (e.g. higher and lower management, union, health and social workers) should have received diagnostic feedback. Cummings and Worley (1993) sum up 5 basic activities for effective change management (see table 2 under "planning and implementing change"). This makes explicit what activities internal and external change agents must do during planning and implementing interventions independent from their content. Although most of these things were done intuitively in the pharmaceutical company, explicit planning of these activities would have improved the implementation process. To conclude, we recommend health educators who want to implement worksite health programs to use a planning model for organizational change like the general Model of Planned Change in addition to the PRECEDE-PROCEED model.

\section{The role of external consultants}

Although already slightly interwoven in the previous section, the role of the external consultant is discussed separately because of its importance. The project revealed the importance of the "coaching" component of the external consultants" role besides their expertise on the program's content. The change management activities as indicated by Cummings and Worley (1993) make clear what the coaching role should be. We would like to emphasize here how delicate the balance is between the "coaching" and expertise part of the external consultants' role. On the one hand, external 
consultants should coach worksite members so that they participate maximally in the development and implementation of the program, but on the other hand external consultants are expected to pass solutions and fully worked-out intervention programs. In the pharmaceutical company clear agreements were made on what was expected from the external consultant and because of the ALCON Foundation's experience with secondary preventive alcohol prograrns there were no major problems regarding the external consultant's role. On the contrary, the external consultant's role was less well executed at the Municipal Department because of the lack of clear agreements, the greater complexity of the program and the lack of experience of the ALCON Foundation with worksite health promotion programs. A practical recommendation for future external consultants on worksite health promotion programs is to develop a workbook that gives an overview of possible, ready-made programs or activities that could be used to reach certain goals. Empirical research indicates that such kind of workbooks are very useful (Assema Van, Steenbakkers, Eriksen et al, 1994-95). The workbook should explicitly indicate what program components had proven to be effective in reaching what kind of goals. Descriptions of national, regional and local programs should be included as well as contact persons from offering organizations, costs etcetera. It is then the task of the external consultant to assist company members in choosing between alternative programs so that the end product is a comprehensive program with a high potency of effectiveness. To conclude, it is important to make clear agreements on the coaching and expertise components of the external consultant's role and a workbook with an overview of alternative programs could be an effective means to assist worksite members in composing their own program.

\section{Participation of the worksite}

The importance of worksite participation in the planning process is widely acknowledged in the health promotion field. At both the municipal department and the pharmaceutical company the organizational structure of a working group was the major way in which participation was given form. The working groups were the main communication partners for the external consultants. In the pharmaceutical company because of the organizational structure of the health department there was a natural communication line between the internal project leader and the manager Personnel and Organization. But other working group members who represented certain segments of the company rarely communicated with their parties about the progress of the project. In the municipal department the internal project leader was a member of the management team but there was no tradition in communication about health projects between this division manager and the department manager or management team. Once more, this lack of communication within the worksites about the project emphasizes the need for clear agreements in an early stage of the project about responsibilities, tasks, organizational and decisional structures. Furthermore, in between decisional moments other ways to improve participation should be made use of. Two major improvements for our project would have been: 1) determining more carefully relevant clients during the entering and contracting phase, and 2) feeding back diagnostic data to a broader group of people and involving them in the development of the program. Explicitly determining relevant clients (i.e. those organizational 
members who can directly impact the change issue) and trying to gain their commitment might have prevented the "ignorance" of middle managers in the pharmaceutical company and the department manager in the municipal department. Additionally, as mentioned above, well planned feedback sessions with relevant groups within the organizations might have improved feelings of ownership regarding the project within those groups (e.g. supervisors, higher management, workers). To conclude, participation of worksite members is very important for a successful implementation of the project and can be given form by shaping organizational and decisional structures (representative working group, communication lines with higher management) and by carefully determining other relevant clients within the organization and improving their commitment through feedback sessions in which visions and program goals are worked out too.

\section{Incorporation of research}

The incorporation of research within change projects is necessary for tailoring the interventions to companies' specific needs and for making adjustments during the implementation process when necessary. But the incorporation of research is not very common in practice and can generate resistance as we saw in both worksites. The management is primarily concerned about necessary time, costs and publicity outside the company, while the workers are primarily concerned about the confidentiality of research data. In the municipal clepartment no specific agreements were made regarding the research part of the project nor was the necessity of it properly communicated to the workers. This resulted in quite a lot of resistance when the meetings for filling out the pretest questionnaires were organized. By setting up a system of research numbers and repeatedly explaining the procedures the response was moderately in the end. In the pharmaceutical company the situation was slightly different because respondents did not receive personalized feedback like in the municipal department so their names were not necessary and two different samples could be used for the pretest and posttest. But, the communication about the project and the need for the research was much better than in the municipal department. Also, these workers were higher educated. This resulted in less resistance against research activities. In both worksites the usefulness of both the diagnostic and evaluative data was greatly acknowledged by worksite members afterwards. To conclude, external consultants must be aware of the resistance that might exist within companies against research. The need for it should be carefully explained and confidentiality should be assured. Furthermore, workers should be informed of the research procedures carefully.

\section{Content of primary and secondary preventive programs}

Besides general factors also factors linked to the specific content of the two programs might have influenced their implementation. The sections site and recipient response gave some insight in this.

The program components of the secondary preventive program at the pharmaceutical company that were received relatively good were the policy itself with its vision statement, regulations and procedures, and the skills training for social medical workers. The policy was explained well in company mass media messages and 
the interference of the company was accepted towards dysfunctioning, problem drinking workers. This resulted in an improvement of knowledge and attitudes towards the policy. Social medical workers were involved with the subject and motivated for the skills training although for some there was overlap with former skills training. The skills training was effective in improving constructive confrontation skills. Relatively minor components were the skills training for supervisors and the health education about alcohol. Supervisors and higher managers were less involved with the subject and gave low priority to the skills training. The alcohol education generated resistance for two reasons namely the unacceptability of interference of the company with private (drinking) behavior and because of the emphasis on problem drinking, a term people think not applicable to their selves. The result was no improvement in supervisors' skills nor in workers' awareness of the healthiness of their own drinking behavior or their intention to drink less. Therefore, in future secondary preventive alcohol programs in the entering and contracting phase and during the feeding back of diagnostic results more emphasis should be laid on the importance of supervisors' role and the need for skills training. The alcohol education should be made more attractive which could be done by emphasizing healthy drinking in stead of problem drinking. Personalized feedback on the healthiness of their drinking behavior might be found interesting like the results of the Health Profile in the municipal department indicate.

In the municipal department only one program component was implemented namely the Health Profile. This instrument was well evaluated and effective in raising awareness about the healthiness of health behaviors. The discontinuance of intervention programs was partly due to content factors. A broad health promotion program would have included stress, but a program that would interfere with working conditions linked to stress (e.g. internal communication) was not acceptable for the department manager. Earlier involvement of the management team (in the entering and contracting phase and during feeding back diagnostic results) might have convinced them of the need for such components in a broad health promotion program. Or they might have indicated other short term goals and delayed stress programs for a later moment.

\section{Integration with other programs}

For both type of programs it is important that they are imbedded as much as possible within other policies or programs. This improves the acceptability and the institutionalization of the program. In the pharmaceuticall company the alcohol program was part of the company's health policy which facilitated the implementation. On the contrary, at the municipal department there was no clear link between the health promotion program and an umbrella (health) policy although there had been other programs (e.g. on sickness absence, management styles, alcohol) that could have formed a basis for an integrative (health) policy. After realizing this, the external consultants should have emphasized the need to develop a broad vision on health policy before working out a health promotion program. In general it can be said that programs aimed at the preventing alcohol problem have major links with 3 other programs: 1) stress management programs (alcohol as a coping behavior for stress), 2) health behavior or life style programs (healthy drinking behavior), and 3) social 
skills training for supervisors and social medical workers (constructive confrontation strategy). For the acceptability of behavioral programs for workers and for their long term effectiveness it is important that in addition to behavioral programs also improvements are made in the area of working conditions (e.g. work stressors) and that this integrative policy is well communicated to the workers. 


\title{
5 Associations between work stress, alcohol consumption and sickness absence.
}

\author{
Authors: R.M. Vasse, F.J.N. Nijhuis, and G. Kok
}

This chapter is accepted for publication as an article in the journal Addictions.

\subsection{Abstract}

This chapter tests an interactional model on the associations between work stressors, perceived stress, alcohol consumption and sickness absence in a working population $(\mathrm{N}=471)$. Regression analyses result in three major findings. First, in the presence of stress both abstinence and excessive drinking increased the risk of sickness absence compared with moderate drinking, although the effect of excessive drinking was not significant. The effect of abstinence could reflect medical problems of abstainers or a lack of skills to cope with stress. Abstinence was strongly related to a lower educational level. The failure to find a significant detrimental effect of excessive drinking may have been due to use of a low threshold for excessive drinking and/or low power. Second, stress mediated the association between stressors and alcohol consumption and between stressors and sickness absence, although stressors also had direct effects on sickness absence. Third, no moderating effects of individual difference variables on the association between stress and alcohol consumption were found. Recommendations for future research and practical interventions are given.

\subsection{Introduction}

Although in the workplace the number of people with alcohol problems is relatively small (about 5\% of workers in the Netherlands (Bijl \& Ziekemeyer, 1990), the problems themselves are severe and result in substantial costs for employers. The extra sickness absence of excessive drinkers compared with moderate drinkers costs about 563 million Dutch guilders per year (Meyer \& Tjioe, 1990). Therefore employers initiate policy and intervention programs to prevent alcohol problems. To im- 
prove the content of these programs, this study investigated the nature of workers" alcohol problems.

That people drink alcohol to cope with stress is a widely-held belief. Theoretically, drinking to cope is maladaptive and leads to more severe problems, for example alcohol abuse and sickness absence. Nevertheless, to our knowledge, there is no empirical evidence of the association between drinking to cope with work stress and sickness absence. Therefore this study proposes and tests an interactional model which states that work stress and alcohol drinking behavior interact in predicting sickness absence.

\section{Theoretical background}

Social learning theory provides the theoretical basis for this interactional model. According to a social learning perspective on alcohol consumption (Abrams \& Niaura, 1987; Bandura, 1986; Marlatt \& Gordon, 1985; Wills \& Shiffman, 1985), people drink alcohol to cope with negative emotions when they lack other more adaptive coping responses. Drinking to cope is considered maladaptive because it can result in more severe alcohol-related problems on the longer term (e.g. sickness absence). Lazarus and Folkman (1984) present a comparable view on alcohol use in their transactional model of stress, appraisal and coping. They consider alcohol use as an emotion-focused or palliative coping strategy.

A review of existing work stress-alcohol studies (Cooper, Russell and Frone, 1990) reveals that despite widespread acceptance of the belief that work stress promotes problematic alcohol use, existing research fails to provide an adequate test of work stress-induced drinking. According to Cooper and colleagues (1990), these studies have largely ignored the mediating role of negative emotions (i.e. stress) and the moderating effects of coping and alcohol expectancies on the hypothesized negative emotion-alcohol link. Furthermore, few studies have included adequate sociodemographic and psychosocial controls that might confound the association between work stress and alcohol consumption. In their own study Cooper and colleagues (1990) found no main effect for work stress on alcohol drinking behavior, but they found three interaction effects for work stress with coping styles, coping responses and alcohol expectancies in the prediction of drinking to cope. In their later work Cooper and colleagues define these three moderators and others (e.g. gender, social support) as "individual difference variables" (Cooper, Russell, Skinner, Frone and Mudar, 1992; Peirce, Frone, Russell, and Cooper, 1996). These variables reflect a person's vulnerability for inadequate coping with stress. In our study we measured gender and social support. Gender is thought to moderate the association between stress and allcohol consumption because men have been socialized to externalize stress and may be more likely to use alcohol as a result of exposure to stress, while women have been socialized to internalize stress and may be more prone to effects such as depression. Social support is thought to buffer the effects of stress. We used marital status (having a partner or not) as an indicator of social support.

Two empirical studies have tested the association between alcohol consumption and sickness absence (Marmot, North, Feeney \& Head, 1993; Van Deursen, Raat \& Garretsen, 1989). Both studies found a U-shaped relationship indicating that both excessive drinking and abstinence increase the risk on sickness absence. The associa- 
tion between excessive drinking and sickness absence is easy to understand. Excessive drinking increases the risk of health problems and accidents that result in sickness absence. The finding that excessive drinkers score higher on sickness absence diagnoses such as influenza, accidents and musculoskeletal complaints confirms these assumptions (Van Deursen, Raat and Garretsen, 1989). The association between abstinence and sickness absence is more difficult to understand. Abstainers might not drink because they have medical problems that are responsible for a higher sickness absence. Another explanation might be that abstinence has negative effects on health in contrast with moderate drinking that is supposed to protect against health problems (Van Deursen et al., 1989). In the social learning perspective on alcohol use, moderate alcohol use could be considered an adaptive coping response that has the adequate buffering effect on stress. So, abstainers who have no adequate alternative coping response, instead of moderate drinking might have a higher risk of sickness absence. Van Deursen et al (1989) found that the abstainers' increased rate of sickness absence was related only to the diagnosis influenza. This might indeed reflect an increased vulnerability.

\section{Definitions and the hypothesized model}

Figure 1 shows the hypothesized associations between work stressors, work stress, alcohol use and sickness absence. We defined work stressors as working conditions that are negatively evaluated by workers (e.g. high work pressure or bad relationships with supervisor). Work stress was defined as a state of negative emotional feelings (i.e. feeling tense, nervous, hurried, or down-hearted). Alcohol use was defined as the number of glasses that are drunk per week. The line between moderate and excessive drinking was set at 14 glasses per week for women and 21 for men (Anderson, 1986; McDonaid, 1982; Neve, Knibbe and Swinkels, 1994). Drinking to cope with stress was indirectly measured by computing an interaction between stress and alcohol consumption. So, feeling stressed and drinking alcohol at the same time is thought to reflect drinking to cope with stress. Sickness absence was defined as having been absent one or more times during the last six months.

At all times controlling for influences of sociodemographic variables and type of worksite (i.e. blue or white collar), firstly, we hypothesized that work stressors would predict work stress (arrow a). Secondly, we hypothesized that work stress would predict higher alcohol use (arrow b). Thirdly, work stress and alcohol use were hypothesized to interact in their prediction of sickness absence (arrow c). We expected that the combination of stress and excessive alcohol use would be associated with higher sickness absence. Based on the studies of Marmot et al (1993) and Van Deursen et al (1989), we also expected abstinence and work stress to be associated with higher sickness absence. Furthermore, we expected buffering effects of female gender and having a partner on the association between stress and alcohol consumption (arrow d). Finally, we aimed to test whether work stressors directly predict alcohol use and sickness absence (arrows e) in addition to their supposed indirect association via perceived stress (i.e. mediated by perceived stress). We found no indications in the literature which stressors would have a direct association and which would have an indirect association with alcohol consumption and sickness absence; so we did not formulate hypotheses. 


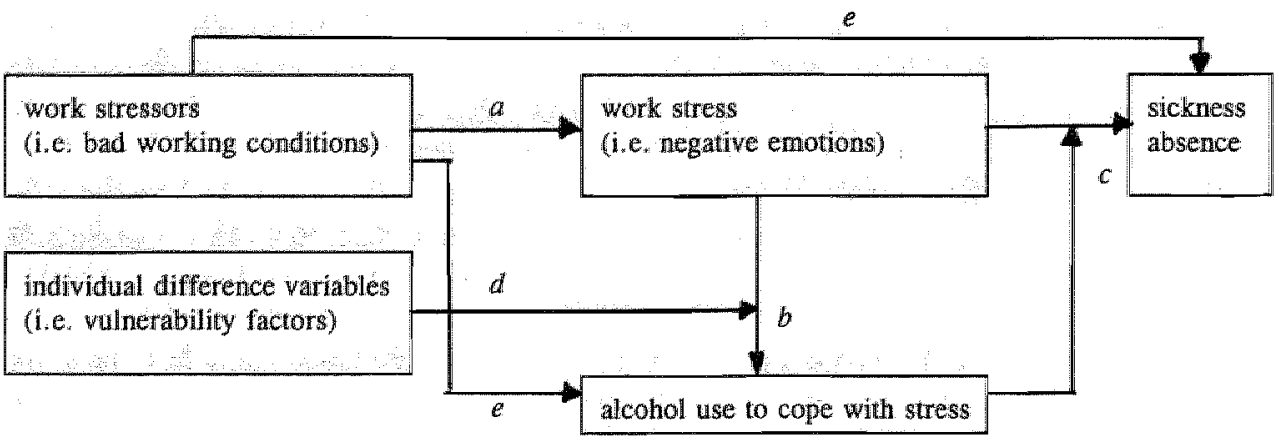

\subsection{Methods}

\section{Study population}

The study population comprised workers in three different work settings. All three work settings participated in a Worksite Health Project financed by the Dutch Ministry of Welfare, Health, and Cultural Affairs. The goal of that project was to develop, implement and evaluate worksite health programs aimed at primary and secondary prevention of alcohol problems. The primary preventive program could be characterized as a Health Promotion Program. It contained different lifestyle behayiors including alcohol drinking, diet behavior, smoking, stress, and exercise. The main goal was raising the consciousness of workers about their own health behaviors and changing their unhealthy behaviors. The secondary preventive program could be characterized as an Employee Assistance Program. The main goal here was setting up policy and procedures for assistance for workers with alcohol problems and training social medical workers and supervisors in skills that are necessary for signaling alcohol problems and for giving assistance to problem drinkers. Workers were educated about the worksite alcohol policy and about a healthy alcohol drinking behavior.

Two Municipal Garbage Collecting Departments from different cities were involved in a Health Promotion Program. These were mostly workers with a low level of education. The third work setting was involved in the Employee Assistance Program. This was a large Pharmaceutical Company with mostly highly educated workers. The workers of the Municipal Garbage Collecting Departments will be referred to as blue collar workers in this article and those from the Pharmaceutical Company white collar workers.

\section{Data gathering}

For this study we use data from 1992 on the blue collar workers and data from 1994 on the white collar workers. These data were gathered through a written questionnaire. White collar workers received the questionnaire at their home address and sent it back to the university. Blue collar workers did not receive the questionnaire at home because of the possibility of a low response using that method. They filled out 
the questionnaire in the worksite canteen during working hours. Project members were present to help them if they did not understand the questions. The workers sat separately and they had very little contact with each other. The questionnaire served as a diagnosis instrument for intervention programs.

\section{Measures}

To measure sickness absence, work stress and work stressors, a validated Dutch questionnaire on work and health was used (Dijkstra, Van der Grinten, Schlatmann, \& De Winter, 1989; see for example Houtman, Bongers, Smulders \& Kompier, 1994).

Sickness absence was measured by one question: Did you stay home from work one or more times during the last six months because of illness or an accident? (no $=0$, yes $=1$ ). So, this concerns self-reported sickness absence.

Work stress was measured by four questions on negative emotional feelings: Do you often feel: tense/nervous/hurried/down-hearted? (no=0, yes $=1)$. A sumscore was computed (alpha $=0.78$ ) and then divided by the number of questions (i.e. 4 ).

Work stressors were measured using 31 questions about working conditions (see Appendix A). Following the recommendations of the authors of the questionnaire (Dijkstra, Van der Grinten, Schlatmann, \& De Winter, 1989), eight subscales were computed: work pressure (alpha $=0.69$ ), work content (alpha $=0.61$ ), physical working conditions (alpha $=0.62$ ), work organization (alpha $=0.64$ ), relationship with supervisor and colleagues (alpha $=0.75$ ), payment ( 1 question), future prospects (1 question), and influence of work on private situation (1 question).

Alcohol drinking behavior was measured by frequency and quantity questions about respondents' average drinking habits. First, respondents were asked if they were abstainers. If not, they were asked on how many days, on average, during the week they drink alcohol (1-4 days) and how many glasses, on average, they drink on a weekday. This was also done for weekend days (Friday-Sunday). Based on these frequency/quantity measures the mean alcohol consumption per week was computed (i.e. number of glasses per week). Additionally, respondents were characterized as abstainers (no alcohol), moderate drinkers $(<21$ glasses per week for men, and $<14$ glasses per week for women), or excessive drinkers ( $\geq 21$ glasses per week for men, and $\geq 14$ glasses per week for women).

\section{Analyses}

The data were analyzed using the statistical computer program SPSSX Release 4.1. Chi square tests and analyses of variance were used to describe the prevalence of the sociodemographic and health variables among blue and white collar workers. To predict workstress (arrow a in the model), a multiple linear regression analysis was conducted. To predict alcohol consumption (arrow b) multiple linear regression was also used. To predict sickness absence (arrow c) a multiple logistic regression analysis was performed with the interaction stress by alcohol consumption. Furthermore, interactions of gender by stress and marital status by stress will be included in the model predicting alcohol use to test whether certain subgroups are more likely to use alcohol to cope with stress (arrow d). Finally, to test the direct associations of work 
stressors on alcohol and on sickness absence, work stressors were added in an extra step to the regression analyses on alcohol and on sickness absence.

Because of the differences in sociodemographic characteristics, type of work, and culture between the two worksites (see below), both sociodemographic variables and type of worksite (blue or white collar) were included in the analyses as covariates. Additionally, wo-way-interaction effects of type of worksite by the independent variable(s) of interest was tested in all analyses to see if the associations found differed for blue and white collar workers. In the regression on sickness absence, a test on the effect of type of worksite was not done because this would mean a threeway-interaction of stress $\mathrm{X}$ alcohol $\mathrm{X}$ worksite and the subgroups were too small to test this properly. Finally, in the regression on sickness absence, smoking is included as a covariate because it might confound the association between alcohol consumption and sickness absence (see Kozlowski \& Ferrence (1991) and Shaper $(1990 ; 1991)$ for a discussion about the confounding effects of smoking on the alcohol-mortality relationship).

\subsection{Results}

\section{Response}

The response was moderate: $47.7 \%(n=157)$ and $39.5 \%(n=47)$ for the two groups of blue collar workers and $53.6 \%(n=267)$ for the white collar workers. The total study population was 471 respondents.

\section{Sociodemographics}

Table 1 shows the sociodemographic characteristics of the blue and white collar workers. Chi square analyses revealed a significant difference between blue and white collar workers with respect to gender and education. In the blue collar companies more men were working and the educational level was lower.

The total sample was predominantly male $(74.9 \%)$, there were few older workers $(14.7 \%)$, the education level was roughly evenly spread $(42.7 \%$ lower, $57.3 \%$ higher), and most respondents had a partner (i.e. married or cohabitating) $(84.7 \%)$. 
Table 1: Sociodemograplic characteristics of blue collar and white collar workers.

\begin{tabular}{|c|c|c|c|c|}
\hline Sociodemographic wariables & $\begin{array}{l}\text { Blue collar } \\
(\mathrm{N}-204)\end{array}$ & $\begin{array}{l}\text { White collar } \\
(\mathrm{N}=267)\end{array}$ & & $\begin{array}{l}\text { Total } \\
(\mathrm{N}=471)\end{array}$ \\
\hline & of & $\%$ & $x^{2}$ & \% \\
\hline \multicolumn{5}{|l|}{ Gender: } \\
\hline- man & 90.1 & 63.3 & $44.2^{* \ldots}$ & 74.9 \\
\hline -woman & 9.9 & 36.7 & & 25.1 \\
\hline \multicolumn{5}{|l|}{ Age: } \\
\hline$-\leq 34$ years & 40.6 & 38.6 & 1.8 & 39.5 \\
\hline$-35-49$ years & 47.2 & 44.7 & & 45.8 \\
\hline$-\geq 50$ years & 12.2 & 16.7 & & 14.8 \\
\hline \multicolumn{5}{|l|}{ Education } \\
\hline -lower & 77.9 & 16.9 & $171.3^{* * *}$ & 42.7 \\
\hline -higher & 22.1 & 83.1 & & 57.3 \\
\hline \multicolumn{5}{|l|}{ Marital status } \\
\hline -partner & 84.0 & 85.3 & 0.14 & 84.7 \\
\hline -no pariner & 16.0 & 14.7 & & 15.3 \\
\hline
\end{tabular}

' all percentages are column percentages

“** $P<0.001, " * P<0.01, " P<0.05$

\section{Representativeness of the sample}

Respondents were compared with the total working populations of the blue and white worksites and with the whole Dutch working population (CBS, 1993). Both blue collar and white collar workers were representative of their worksites regarding gender, age and departments of the worksite. Information about education level and marital status was not available from the worksites. However, both samples were representative regarding occupational level, which can be considered as an indication of education level. So, the results of this study can be generalized to the total worksites.

Compared with the total Dutch working population (CBS, 1993) our total sample (blue and white collar workers) contains more men $(74.9 \%$ versus $64.2 \%)$, less younger and more middle aged respondents $(39.5 \%$ versus $47.7 \%$ and $45.8 \%$ versus $38.8 \%$ ), and more respondents with a lower education ( $42.7 \%$ versus $33.6 \%$ ). So, the results of this study can be best generalized to worksites with relatively more male, middle aged workers with a lower educated of education than the average Dutch working population.

\section{Prevalence of health variables}

Table 2 shows the prevalence of health variables among blue and white collar workers. It appears that blue and white collar workers differed on several variables. Firstly, the sickness absence rate was higher among blue collar workers. Secondly, the mean alcohol consumption is higher among blue collar workers as are the rates of abstinence and excessive drinking. So, in general white collar workers could be characterized as the more moderate drinkers. Blue and white collar workers did not 
differ in the amount of stress they experience. But they did differ on five of the eight work stressors measured (i.e. complaints about working conditions). Blue collar workers had more complaints about their work content, physicall working conditions and payment. While white collar workers had more complaints about their relationships with supervisors and colleagues, and their future prospects.

The total sample could be characterized as follows: $18.6 \%$ were abstainers, $68.9 \%$ drank moderately and $12.5 \%$ drank excessively. The mean alcohol consumption of drinkers was 10.1 glasses per week. About one third (39.1\%) experienced stress. Most complaints concerned work pressure $(80.5 \%)$, work organization, relation with supervisor/colleagues and physical working conditions (all about $60 \%$ ). Finally, $40.0 \%$ had been ill at least once during the last six months.

Table 2: Prevalence of health variables among blue and white collar workers.

\begin{tabular}{|c|c|c|c|c|}
\hline Health variables & $\begin{array}{l}\text { Bilue collar } \\
(\mathrm{N}=204)\end{array}$ & $\begin{array}{l}\text { White collar } \\
(\mathrm{N}=267)\end{array}$ & & $\begin{array}{l}\text { Total } \\
(\mathrm{N}=471)\end{array}$ \\
\hline & w 1 & $\%$ & & $\%$ \\
\hline \multicolumn{5}{|l|}{ Sickness absence } \\
\hline -no & 54.5 & 64.2 & $\chi^{2}=4.49^{*}$ & 60.0 \\
\hline$-y e s$ & 45.5 & 35.8 & & 40.0 \\
\hline \multicolumn{5}{|l|}{$\begin{array}{l}\text { Alcohol consumption } \\
\text { a) categories: }\end{array}$} \\
\hline -abstainer & 33.3 & 7.3 & $x^{2}=58.2^{\cdots}$ & 18.6 \\
\hline -moderate drinker & 51.5 & 82.2 & & 68.9 \\
\hline -excessive drinker & 15.2 & 10.4 & & 12.5 \\
\hline b) mean ${ }^{2}$ consumption (glasses/week) & 14.1 & 7.8 & $\mathrm{~F}=25.4^{\mathrm{m*}}$ & $10.1^{4}$ \\
\hline mean ${ }^{b}$ consumption (glasses/week) & 9.4 & 7.2 & $F=4.17^{*}$ & $8.2^{4}$ \\
\hline \multicolumn{5}{|l|}{ Stress } \\
\hline- no & 60.9 & 60.8 & $x^{2}=0.00$ & 60.9 \\
\hline -yes & 39.1 & 39.2 & & 39.1 \\
\hline \multicolumn{5}{|l|}{ Work stressors ${ }^{3}$} \\
\hline Work pressure & 77.2 & 82.9 & $\chi^{2}=2.25$ & 80.5 \\
\hline -work content & 51.3 & 29.9 & $x^{2}=21.65^{\circ+4}$ & 39.1 \\
\hline work organization & 64.6 & 67.2 & $x^{2}=0.33$ & 66.1 \\
\hline -relation supervisor/colleagues & 53.8 & 65.7 & $\chi^{2}=6.36$ & 60.6 \\
\hline -physical working conditions & 81.0 & 52.9 & $\chi^{2}=37.37^{6+*}$ & 64.9 \\
\hline - negative influence on private life & 23.7 & 26.3 & $x^{2}=0.40$ & 25.2 \\
\hline payment & 50.0 & 35.6 & $x^{2}=9.63^{* *}$ & 41.8 \\
\hline future prospects & 25.5 & 42.9 & $x^{2}=13.99^{2+\ldots}$ & 35.1 \\
\hline
\end{tabular}

$" \mathrm{P}<0.001, " * \mathrm{P}<0.01, " \mathrm{P}<0.05$

1 all percentages are column percentages

${ }^{2}$ exluding abstainers

${ }^{3}$ including abstainers

" mean

sonly the percentage of respondents who answered "yes" are shown (i.e. those who had complaints on that area) 


\section{Predicting stress}

Table 3 shows the results of the multiple linear regression analysis of sociodemographic variables and work stressors on stress. In step 1 the sociodemographic variables were entered in the model; they explained a small, but significant amount of variance $(3 \%)$. In the second step work stressors were added to the model, contributing a much larger significant amount of variance $(38 \%)$. None of the interactions of work stressors by type of worksite was significant; so findings did not differ for type of worksite. The final model showed significant associations for complaints about work pressure $($ Beta $=0.44, \mathrm{P}<0.001)$, work content $(\mathrm{Beta}=0.13, \mathrm{P}<0.01)$, the negative influence of work on private life $(B e t a=0.14, P<0.01$ ), and relation with supervisor/colleagues (Beta $=0.14, P<0.05$ ). The total explained variance $\left(R^{2}\right)$ was high: $42 \%(\mathrm{P}<0.001)$.

Table 3: Linear regression of sociodemographic variables and work stressors on perceived stress.

\begin{tabular}{|c|c|c|c|}
\hline & $\mathrm{r}$ & Beta & $\mathrm{R}^{2}$ change \\
\hline Step 1: & & : & $0.03^{*}$ \\
\hline Gender $(0=$ man, $1=$ woman $)$ & -.02 & 0.05 & \\
\hline Age (cont.) & $0.16^{* *}$ & 0.03 & \\
\hline Education (cont.) & 0.01 & -.06 & \\
\hline Marital status ( $0=$ partner, $1=$ no partner $)$ & 0.04 & 0.05 & \\
\hline Worksite $(0=$ blue collar, $1=$ white collar $)$ & 0.01 & 0.03 & \\
\hline Step 2: & & & $0.38^{* * *}$ \\
\hline Work pressure (cont.) & $0.53^{* *}$ & $0.44^{* * *}$ & \\
\hline Work content (cont.) & $0.17^{* *}$ & $0.13^{* *}$ & \\
\hline Physical working conditions (cont.) & $0.17^{\circ * *}$ & 0.06 & \\
\hline Negative influence on private life (dich.) & $0.39^{* *}$ & $0.14^{* *}$ & \\
\hline Payment (dich.) & $0.12^{* * *}$ &. .05 & \\
\hline Future prospects (dich.) & $0.20^{* 6}$ & 0.07 & \\
\hline Work organization (cont.) & $0.38^{* *}$ & 0.03 & \\
\hline \multirow[t]{4}{*}{ Rellation with supervisor/colleagues (cont) } & $0.40^{* *}$ & $0.14^{*}$ & \\
\hline & & & $R=0.64$ \\
\hline & & & $\mathrm{R}^{2}=0.42^{* * *}$ \\
\hline & & & $\operatorname{adj} \mathbf{R}^{2}=0.39$ \\
\hline
\end{tabular}

a work stressors are coded so that higher scores represent more complaints

- Betas of the model including all main effects (step $1+$ step 2)

$\therefore \mathrm{P}<0.001, \cdots \mathrm{P}<0.01, " \mathrm{P}<0.05$ 


\section{Predicting alcohol consumption}

Table 4 summarizes the results of the multiple linear regression analysis of sociodemographic variables, stress, individual difference variables (gender and marital status), and work stressors on alcohol consumption. In step 1 the sociodemographic variables entered the model; they explained a significant amount of variance (12\%). In step 2 stress entered the model, explaining a small, but significant amount of variance $(4 \%)$. In step 3 three interaction variables entered the model, stress by worksite, stress by gender and stress by marital status, but they did not add a significant amount of variance. The interaction between stress and worksite was deleted from the model because it served only to check if the association between stress and sickness absence differed for the two types of worksites. The other two interactions were part of the hypothesized model and were therefore kept in the analysis. However, their nonsignificance indicated that being male or female, or having a partner or not did not influence the vulnerability to drinking to cope with stress. Finally, in step 4 work stressors were added to the model. They did not explain a significant amount of variance. So, work stressors did not directly predict alcohol consumption. The end model showed main effects of gender $(B e t a=0.14, P<0.05)$ and stress $($ Beta $=0.20$, $P<0.01)$ on alcohol consumption. The total explained variance $\left(\mathbb{R}^{2}\right)$ of the model is moderately high: $16 \%$

$(\mathrm{P}<0.001)$.

\section{Predicting sickness absence}

Table 5 shows the results of the multiple logistic regression analysis of sociodemographic variables, alcohol consumption, stress, interaction of stress and alcohol consumption, and work stressors on sickness absence. In step 1 the sociodemographic variables and smoking entered the model; they explained a significant amount of variance $(\mathrm{P}<0.05)$. In step 2 alcohol consumption entered the model but did not add a significant amount of variance. In step 3 stress entered the model, contributing a significant amount of variance $(P<0.05)$. In step 4 the interaction of stress by alcohol consumption entered the model, also adding a significant amount of variance $(\mathrm{P}<0.05)$. Finally, in step 5 work stressors entered the model and again added a significant amount of variance $(\mathbb{P}<0.05)$. The final model shows significant main effects of gender $(B=0.62, P<0.05)$ and type of worksite $(B=-.82, P<0.05)$. Stratification by stress showed that, when there was no stress, the association between alcohol consumption and sickness absence was not significant ( $\mathrm{B}(\mathrm{abstinence})=$ $-0.04, \mathrm{P}>0.05 ; \mathrm{B}$ (excessive) $=-.29, \mathrm{P}>0.05$ ). But in the case of stress, both abstinence and excessive drinking were associated with an increased sickness absence compared with moderate drinking, although the association between excessive drinking and sickness absence was not significant. Figure 2 visualizes the risks for sickness absence (odds ratios controlied for sociodemographic variables, smoking and work stressors) of abstinence and excessive drinking compared with moderate drinking in the case of no stress and in the case of stress. The goodness of fit of the final model was fair $\left(\chi^{2}=336.21, P>0.10\right)$. 
Table 4: Linear regression of sociodemographic variables, perceived stress, interactions of stress and individual difference variables (gender and maritall status) and work stressors on allcohol consumption.

\begin{tabular}{|c|c|c|c|}
\hline & $\mathrm{r}$ & Beta & $\mathrm{R}^{2}$ change \\
\hline Step 1: & & & $0.12^{* * *}$ \\
\hline Gender $(0=$ man, $1=$ woman $)$ & $-.24 *$ & $-.14^{*}$ & \\
\hline Age $(0=\leq 34,1=35-49,2=\geq 50)$ & $0.15^{* *}$ & 0.09 & \\
\hline Education $(0=$ lower, $1=$ higher $)$ & $-.25^{*}$ & -.11 & \\
\hline Maritall status $(0=$ partner, $1=$ no partner $)$ & -.06 & 0.01 & \\
\hline Worksite $(0=$ blue collar, $1=$ white collar $)$ & $-.28^{* *}$ & -.12 & \\
\hline Step 2: & & & $0.04^{* *}$ \\
\hline Stress $(0=$ no stress, $1=$ stress $)$ & $0.15^{* *}$ & $0.20^{* *}$ & \\
\hline Step 3: & & & 0.00 \\
\hline \multicolumn{4}{|l|}{$\begin{array}{l}\text { Interaction stress } \times \text { gender } \\
\text { Interaction stress } x \text { marital status }\end{array}$} \\
\hline Step 4: & & & 0.01 \\
\hline Work pressure (cont.) $^{b}$ & 0.08 & 0.00 & \\
\hline Work content (cont.) & 0.04 & 0.02 & \\
\hline Physical working conditions (cont.) & $0.15^{\circ *}$ & 0.07 & \\
\hline Negative influence on private life (dich.) & 0.04 & -.03 & \\
\hline Payment (dich.) & 0.08 & -.02 & \\
\hline Future prospects (dich.) & -.03 & 0.01 & \\
\hline Work organization (cont.) & 0.05 & 0.02 & \\
\hline \multirow[t]{4}{*}{ Relation with supervisor/colleagues (cont.) } & 0.04 & -.04 & \\
\hline & & & $R=0.40$ \\
\hline & & & $\mathbb{R}^{2}=0.16^{* * *}$ \\
\hline & & & $\operatorname{adj~} R^{2}=0.11$ \\
\hline
\end{tabular}

\footnotetext{
a work stressors are coded so that higher scores represent more complaints

b. Betas of the model including all main effects (no interactions)

* $\mathrm{P}<0.001, " \mathrm{P}<0.01$, " $\mathrm{P}<0.05$
} 
Table 5: Logistic regression of sociodemographic variables, smoking, perceived stress, alcohol consumption the interaction of stress and alcohol consumption, and work stressors on sickness absence.

\begin{tabular}{|c|c|c|c|c|}
\hline & $r$ & $\mathbb{B}^{\sharp \infty}$ & OR & Improvement $\chi^{2}$ \\
\hline Step 1: Gender $(0=$ man, $1=$ woman $)$ & $0.09^{*}$ & $0.62^{*}$ & 1.85 & $15.82^{\circ}$ \\
\hline $\begin{array}{l}\text { Age } \\
\qquad \begin{array}{l}\leq 34 \\
35-49 \\
\geq 50\end{array}\end{array}$ & .02 & 0.31 & $\begin{array}{l}1.36 \\
1.59\end{array}$ & \\
\hline Education $(0=$ lower, $1=$ higher $)$ & $-.10^{*}$ & -.28 & 0.75 & \\
\hline Marital status $(0=$ partner, $1=$ no partner) & 0.05 & 0.03 & 1.03 & \\
\hline Worksite ( $0=$ blue collar, $1=$ white collar) & $-.10^{*}$ & $-.82^{*}$ & 0.44 & \\
\hline Smoking (conit.) & 0.07 & -.18 & 0.84 & \\
\hline Step 2: Alcohol consumption (categorical) & -.05 & & & 1.09 \\
\hline Step 3: Stress $(0=$ no stress, $1=$ stress $)$ & $0.11^{*}$ & & & $5.00^{*}$ \\
\hline Step 4: Interaction stress by alcohol & & & & $6.10^{*}$ \\
\hline $\begin{array}{l}\text { no stress } \\
\text { abstainer } \\
\text { moderate drinker (reference) } \\
\text { excessive drinker }\end{array}$ & & $\begin{array}{l}-.04 \\
-.29\end{array}$ & $\begin{array}{l}0.96 \\
0.75\end{array}$ & \\
\hline $\begin{array}{l}\text { - stress } \\
\text { abstainer } \\
\text { moderate drinker (reference) } \\
\text { excessive drinker }\end{array}$ & & $\begin{array}{l}1.53^{*} \\
0.63\end{array}$ & $\begin{array}{l}4.61 \\
1.88\end{array}$ & \\
\hline Step 5: Work pressure (cont.) & 0.02 & -.18 & 0.84 & $16.19^{\circ}$ \\
\hline Work content (cont.) & $0.12^{* *}$ & 0.38 & 1.47 & \\
\hline Physicall working conditions (cont.) & $0.12^{* *}$ & 0.33 & 1.39 & \\
\hline Negative influence on priwate life (dich.) & 0.08 & $0.59^{+}$ & 1.80 & \\
\hline Payment (dich.) & 0.02 & -.40 & 0.67 & \\
\hline Future prospects (dich.) & $0.10^{\circ}$ & 0.48 & 1.61 & \\
\hline Work organization (cont.) & $0.10^{\circ}$ & 0.68 & 1.97 & \\
\hline \multirow[t]{3}{*}{$\begin{array}{l}\text { Relation with superwisor/colleagues } \\
\text { (cont.) }\end{array}$} & $0.11^{\circ}$ & 0.08 & 1.09 & \\
\hline & & & & Goodness of fit $x^{2}=336.2$ (ns) \\
\hline & & & & $\begin{array}{l}\text { Correct classification } 68.28 \% \\
\text { (overall) }\end{array}$ \\
\hline
\end{tabular}

: Work stressors are coded so that higher scores represent more complaints

12 B's of the model including all main effects and the interaction stress $\mathrm{X}$ alcohol (step 1 - step 5),

${ }^{* * *} \mathrm{P}<0.001$, " $\mathrm{P}<0.01$, " $\mathrm{P}<0.05$, * $\mathrm{P}<0.10$ 
Figure 2: The interaction effect of stress and alcohol consumption on sickiness absence.

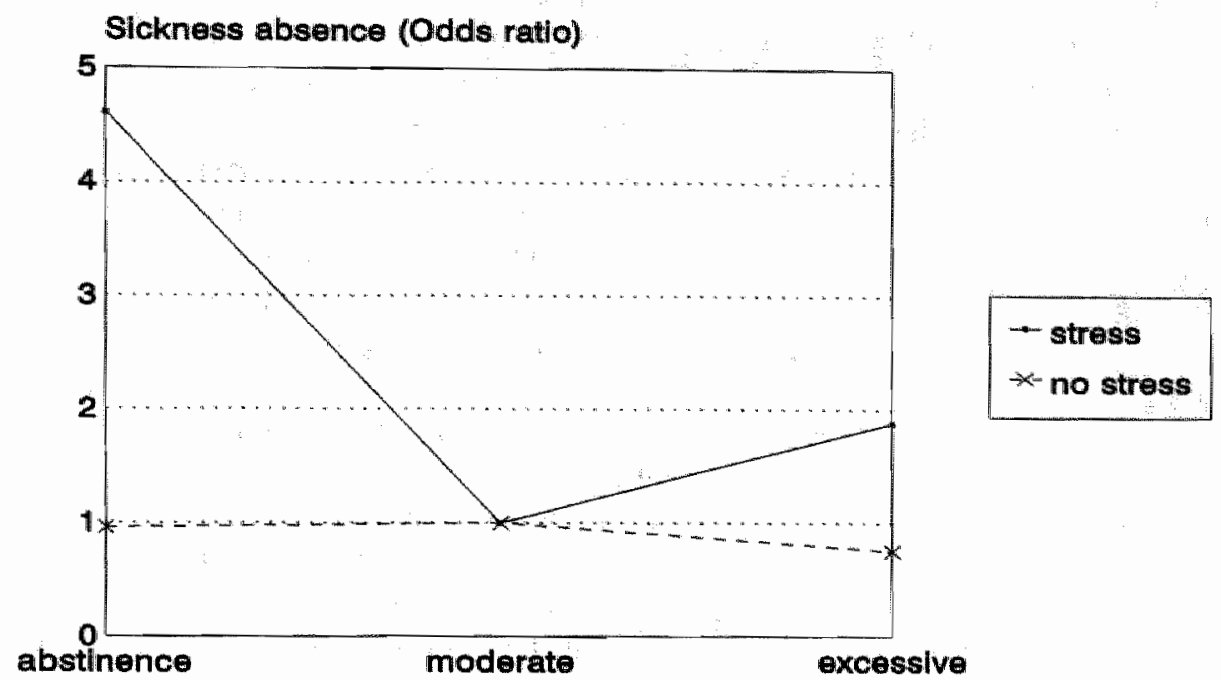

Alcohol consumption

\subsection{Discussion}

In a working population a model was tested that hypothesized stress and alcohol consumption to interact in their association with sickness absence (reflecting drinking to cope with stress), a mediating role of stress in the association between stressors and alcohol consumption and between stressors and sickness absence, and a moderating effect of individual difference variables on the association between stress and alcohol consumption. Finally, the direct associations between work stressors and alcohol consumption and between work stressors and sickness absence were examined. The results offer support for most of the hypothesized associations. Two associations were not supported namely the moderating effect of individual differences variables on the association between stress and alcohol consumption (arrow $d$ in the model, Figure 1) and the direct association between work stressors and alcohol consumption (arrow $e$ ). Also, we did not find a significant association between excessive drinking and sickness absence.

The association between stressors and stress (arrow a) was confirmed. Work stressors predicted a significant amount $(38 \%)$ of the perceived stress. Remarkably, the type of work stressors related to stress did not differ for blue and white collar workers. In both worksites work pressure was by far the largest stressor. Other significant stressors were work content, negative influence of work on private life, and relation with supervisor/colleagues. The second regression analysis confirmed the association between stress and alcohol consumption (arrow $b$ ). Stress predicted a significant 
amount $(4 \%)$ of the variance in alcohol consumption. Further, there was a strong association between sociodemographic variables and alcohol consumption especially for gender (men drank more than women). The association between stress and alcohol can be generalized to both type of worksites because the interaction of stress and worksite had no significant effect on alcohol consumption.

Arrow $d$ in our model was not confirmed. We expected that men and respondents without a partner (reflecting less social support) would be more likely to drink to cope with stress, but this was not supported. Having a partner or not might be an inadequate operationalisation of social support. Future research should measure social support in more direct ways. The nonsignificance of gender might indicate that drinking habits of working women differ from those of non-working women. The study by Cooper and colleagues (1992) concerned a general population sample. Dutch research (Neve, Knibbe \& Swinkels, 1994) indicates that, in certain subgroups, the drinking habits of women indeed increasingly resemble those of men. In addition to gender and social support, future research should include other individual difference variables like coping style and alcohol expectancies.

The final step in this regression revealed that work stressors had no direct associations with alcohol consumption. This implies that work stressors have only indirect associations with alcohol consumption through the increase in perceived stress.

The final regression on sickness absence did not support the hypothesis that drinking alcohol to cope with stress increases the risk of sickness absence. The interaction of stress and alcohol consumption added a significant amount of variance to sociodemographic variables and covariates. However, under stress only abstainers had higher absence rates than moderate drinkers. The association of sickness absence with excessive drinking was in the predicted direction but not significant. The nonsignificance of excessive drinking may have been due to lack of power because of the small subgroups. Alternatively it may only be present at levels well in excess of the threshold used in this study.

To test the lack of power hypothesis, we re-analyzed the model increasing the power by excluding some independent variables (i.e. smoking and the work stressors) but still controlling for sociodemographic variables and type of worksite. The results support the lack of power hypothesis because the same U-shaped relation appeared but now with a significant effect of both abstinence and excessive drinking in the case of stress (Improvement $\chi^{2}$ (interaction stress $\mathrm{X}$ alcohol) $=8.0, \mathrm{P}<0.05$, stratification by stress shows no effects of alcohol in case of no stress but significant effects in case of stress: $\mathrm{B}($ abstinence $)=1.12, \mathrm{P}<0.05, \mathrm{OR}=3.03$ and $\mathrm{B}$ (excessive drinking $)=0.94, P<0.05, O R=2.55$ ).

The results suggest that moderate drinking has a buffering effect on the association between stress and sickness absence and that abstinence is at least as unhealthy as excessive drinking. Although this is intuitively appealing and can even be explained in biological terms, epidemiologists warn that abstainers" health problems might be the real explanation for their increased morbidity and mortality (e.g. Sha- 
per, 1990). A lot of abstainers might be ex-drinkers who stopped drinking for medical reasons.

To gain insight into the determinants of abstinence we conducted a logistic regression on abstinence ( $0=$ moderate or excessive drinking, $1=$ abstinence) with sociodemographic variables and medicine use as independent variables. Medicine use served as an indicator of medical problems and was measured as follows: do you regularly use medicines? $(0=$ no, $1=$ yes $)$. Results indicate that a lower education and a younger age are significant predictors of abstinence (appendix B). Medicine use is not a significant predictor, neither is gender or marital status. Our finding that lower education is a strong predictor of abstinence supports the finding in the Whitehall II study among civil servants (Marmot, North, Feeney, \& Head, 1993) that employment grade is strongly related to abstinence (the lower the grade, the higher the proportion abstainers). So, we cannot exclude medical reasons of abstainers" increased sickness absence. But the non-significance of medicine use suggests that medical problems do not have strong effects in this population. Abstinence is most. strongly associated with a lower education. Future research should investigate the determinants of abstinence more thoroughly, by making an inventory of drinking history, reasons for abstinence, and actual health status.

Another possible explanation for the association between abstinence and sickness absence might be a lack of coping responses to stress among abstainers. As excessive drinking is explained by social learning theory as a way to cope with negative emotions when people lack other more adaptive coping responses, and moderate drinking is an adaptive coping response because it buffers stress, then abstainers might be in need of an alternative coping response as well. Future research should include skills to cope with stress. In the model coping skills should be located among the individual difference variables that moderate the association between stress and alcohol consumption.

Finally, it was found that work stressors added a significant amount of variance in the last step of the regression model. So, work stressors had a direct effect on sickness absence (arrow $e$ ) in addition to the indirect effect through stress. The more detailed analyses indicate that this association is the strongest for the negative influence of work on private life.

The present study has two major methodological limitations. Firstly, the wish to test more than one association in one model results in a relative large number of variables compared to the sample size. This decreases the power but also the chance of fake positive results. Future studies must try to increase sample size. Secondly, this study used cross-sectional data. So, nothing can be said about causality; only associations can tested. Future research should be prospective, so that stronger inferences about causal relations can be made.

We believe that our findings are generalizable to the total Dutch working population especially to worksites with relatively more workers with a low level of education. because our sample contained relatively more workers in this category. The preva- 
lence of alcohol drinking patterns in our sample did not differ much from the total Dutch working population (see Gründemann, 1989), although there was a major difference in abstinence rate: $18.6 \%$ in our study versus $7 \%$ in the total Dutch working population. This difference might be partly due to a higher numbers of workers with a low level of education in our sample. But different formulations of the questions on abstinence might also explain differences in abstinence rates. For example, Marmot et al (1993) found 18.3\% abstainers when they asked about alcohol consumption over the past 7 days and $4.3 \%$ when they asked about alcohol consumption over the past 12 months. According to Swinkels (1991), the best way to measure abstinence is asking if people drank any alcohol over the past 12 months because this results in the lowest proportion of abstinence which should best resemble the officially registered "per capita-consumption". Actual alcohol consumption should then be measured over the past week (separately for week and weekend days). The excessive drinking rate in our study $(12.5 \%)$ was comparable to that of the total Dutch working population (12\%; Gründemann; 1989). By way of comparison, another Dutch study among civil servants (Van Deursen, Raat \& Garretsen, 1989) found $14 \%$ abstainers and $9 \%$ excessive drinkers, and a Dutch study among the total general population (Knibbe and Swinkels, 1992) found $20.5 \%$ abstainers and $8.7 \%$ excessive drinkers. All these studies used slightly different measurement methods and norms for excessive drinking, and did not use different norms for men and women. Future research should take this into account. We recommend following Swinkels' recommendations to measure abstinence and weekly consumption, and to use 14 glasses per week as a norm for women and 21 glasses per week as a norm for men (Anderson, 1986; McDonald, 1982; Neve, Knibbe and Swinkels, 1994) because this has the practical meaning of maximum 2 and 3 glasses per day respectively.

The results indicate that identifying excessive drinkers and helping them with their drinking problems may reduce sickness absence costs, and that teaching abstainers to cope with stress might reduce these costs in so far as medical reasons do not account for the sickness absence. In practice, this would imply a two-way approach. First, supervisors and social medical workers should be trained to recognize early signals of alcohol problems in non-functioning workers and assisting them to solve their problems. Second, courses to cope with stress should be offered to all workers. Such courses would be useful for abstainers, excessive drinkers as well as moderate drinkers. Alcohol drinking can be part of the course and excessive drinking should be discussed as an ineffective coping response to stress. More effective alternatives should be offered. Such courses would be most effective if not only the workers change their coping behavior but bad working conditions are also improved. Alcohol and stress programs should be part of an integrative worksite policy on health, wellbeing and safety. 


\section{Acknowledgements}

We thank Gerard van Breukelen (Maastricht University, Department of Methodology and Statistics) for his advice on the statistical analyses. The project described in this article was carried out in cooperation with the Alcohol Consultancy Foundation The Netherlands (ALCON) and financed by the Dutch Ministry Welfare, Health and Cultural Affairs. 


\section{Work content:}

1 Do you have enough education for your work?

2 Does your work have enough variation?

3 Is your work interesting?

4 Do you enjoy your work?

5 Do you think your work is too easy?

Work pressure:

6 Is your work very exacting?

7 Do you often work under pressure of time?

8 Is your work often too exhausting?

9 Do you regularly have problems with the pace of your work?

10 Should you go about your work more calmly?

Physical working conditions:

11 Is your work physically hard?

12 Do changes in temperature hinder you in your work?

13 Does dry air hinder you in your work?

14 Does a lack of fresh air hinder you in your work?

15 Does noise hinder you in your work?

16 Do bad smells hinder you in your work?

17 Do you think your work is safe?

\section{Work organization:}

18 Is your work most of the time well organized?

19 Can you consult somebody about your work?

20 Do unexpected situations often hinder you in your work?

21 Do mistakes of others often hinder you in your work?

22 Does absence of others often hinder you in your work?

\section{Relationship with supervisor and colleagues:}

23 Is the working climate good at your work?

24 Do others often irritate you at your work?

25 Are you satisfied about your direct managers?

26 Do your direct managers have a right view of you in your work?

27 Do your direct managers take into account your opinions?

28 Do you meet with appreciation at your work?

\section{Payment:}

29 Is your payment in balance with the work you do?

\section{Future prospects:}

30 Do you have good prospects for the future at your work?

Influence of work on private life:

31 Does your work negatively influence your private life? 
Appendix B: Logistic regression of sociodemographic variables and medicine use on abstinence.

\begin{tabular}{|c|c|c|c|c|}
\hline & $\mathbf{r}$ & $\mathrm{B}^{\mathrm{b}}$ & OR & Inprovenent $x^{2}$ \\
\hline Step 1: & & & & $37.59^{\text {ina* }}$ \\
\hline Gender $(0=$ man, $1=$ woman $)$ & -.03 & -.17 & 0.84 & \\
\hline $\begin{array}{l}\text { Age } \\
\qquad \begin{array}{l}<34 \\
35-49 \text { (reference) } \\
\geq 50\end{array}\end{array}$ & $-15^{* *}$ & $\begin{array}{l}0.80^{\circ * *} \\
-.71\end{array}$ & $\begin{array}{l}2.23 \\
0.49\end{array}$ & \\
\hline Education ( $0=$ lower, $1=$ higher) & $-.25 *$ & $-1.30^{* * 2}$ & 0.27 & \\
\hline Marital status $(0=$ partner, $1=$ no partner $)$ & 0.01 & 0.02 & 1.01 & \\
\hline Step 2: & & & & $1.25(\mathrm{~ns})$ \\
\hline \multirow[t]{3}{*}{ Medicine use $(0=$ no, $1=$ yes $)$} & 0.06 & 0.43 & 1.54 & \\
\hline & & & & $\begin{array}{l}\text { Goodness of fit } x^{2}= \\
422.33 \text { (ns) }\end{array}$ \\
\hline & & & & $\begin{array}{l}\text { Correct classification } \\
82.2 \% \\
\text { (overall) }\end{array}$ \\
\hline
\end{tabular}

${ }^{2} B$ 's of the model including all main effects (step 1-step 2)

**P $<0.001,{ }^{*} \mathrm{P}<0.01, " \mathrm{P}<0.05$ 


\section{References}

Abrams, D.B. \& Niaura, R.S. (1987). Social learning theory. In: H.T. Blane \& K.E. Leonard (Eds.), Psychological theories of drinking and alcoholism (pp. 131-178). New York: Guilford Press.

Ajzen, L. (1988). Atritudes, personality, and behavior. Milton Keynes, UK: Open University Press. Ames, G.A. (1993). Research and strategies for the primary prevention of workplace alcohol problems. Alcohol Health \& Research World, 17, $19-27$.

Ames, G.A. \& Janes, C. (1992). A cultural approach to conceptualizing alcohol and the workplace. Alcahol Health \& Research World, 16, 112-119.

Ames, G.A. \& Delaney, W. (1992). Minimization of workplace allohol problems: The supervisor's role. Alcoholism: Clinical and Experimental Research, 16, 180-189.

Anderson, P. (1987). What is a safe level of alcohol consumption? Stress Medicine, 2 99-101.

Assema, P. Van, Steenbakkers, M., Eriksen, M. \& Kok, G. (1994-95). The process evaluation of a Dutch community health project. International Quarterly of Conmunity Health Education, 15, 187-207.

Assema, P. Van, Brug, J., Kok, G., \& Brants, H. (1992). The reliability and validity of a Dutch questionnaire on fat consumption as a means to rank subjects according to individual fat intake. European Journal of Cancer Prevention, 1, 375-380.

Bandura, A. (1986). Social foundation of thought and action. Englewood Cliffs, NJ: Prentice Hall.

Berridge, J. \& Cooper, C.L. (1993). Stress and coping in US organizations: the role of the Employee Assistance Programme. Work \& Stress, 7, 89-102.

Bertera, R.L. (1990a). Planning and implementing health promotion in the workplace: A case study of the Du Pont Company experience. Health Education Quarterly, 17, 307-327.

Bertera, R.L. (1990b). The effects of workplace health promotion on absenteeism and employment costs in a large industrial population. American Journal of Public Health, 80, 1101-1105.

Bijl, D.A. \& Ziekemeyer, M.A. (1990). Doeltreffend alcoholbeleid [Effective alcohol policy]. Methoden, technieken en analyses van personeelsmanagement, 16, 201-217.

Bowen, D.J., Fries, E., \& Hopp, H.P. (1994). Elfects of dietary fat feedback on behavioral and psychological variables. Journal of Behavioral Medicine, 17, 589-604.

Bracht, N. (1990). Community Organization Strategies for Health Promotion. New York: Sage.

Breslow, L. Fielding, J., Herrman, A.A., \& Wilbur, C.S. (1990), Worksite Health Promotion: Its evolution and the Johnsion and Johnson experience. Preventive Medicine, 19, 13-21.

Brody, B.E. (1988). Employee Assistance Programs: An historical and literature review. American Journal of Health Promotion, 2, 13-19.

Brug, J., Steenhuis, 1., Van Assema, P., \& De Vries, H. The impact of a computer-tailored nutrition intervention. Accepted for publication in Preventive Medicine.

Cahalan, D. (1976). Prablem drinkers. San Francisco: Jossey-Bass Publishers.

Campbell, M.K., DeVellis, B.M., Strecher, V.J., Ammerman, A.S. . DeVellis, R.F.。 \& Sandler, R.S. (1994). Improwing dietary behavior: The effectiveness of tailored messages in primary care settings. American Journal of Public Health, 84, 783-787.

Centraal Bureau voor de Statistiek (1993). Enquête beroepsbevolking 1992 /Working population questionnairel. Voorburg/Heerlen.

Cooper, M.L., Russell, M., Skinner, J.B., Frone, M.R. \& Mudar, P. (1992). Stress and alcohol use: Moderating effects of gender, coping, and alcohol expectancies. Journal of Abnormal Psychology, 101, 139-152.

Cooper, M.L., Russell, M. \& Frone, M.R. (1990). Work stress and alcohol effects: A tost of stress-induced drinking. Joumal of Health and Social Behavior, 31, 260-276. 
Cummings, T.G. \& Worley, C.G. (1993), Organization Development and Change. Minneapolis/St.Paul: West Publishing Company.

Deursen, C.G.L. Van, Raat, H. Garretsen, H.F.L. (1989). Alcoholgebruik, roken en verzuimdiagnoses bij Rotterdamse gemeenteambtenaren [Alcohol, smoking and diagnoses of sickness absence in Rotterdam civil servants]. Tijdschrift voor alcohol, drugs en andere psychotrope stoffen, $15,25-33$.

Dijkstra, A., Van der Grinten, M.P., Schlatmann, M.J.Th. \& De Winter, C.R. (1989). Functioneren in de arbeidssituatie. Uitgangspunten, ontwerp, en handleiding voor onderzaek onder werknemers waar gezondheid, werk en werkomstandigheden /Work performance. Basic asstumptions, design and a handbook for research among workers on health, work and working conditionsy. Leiden: Nederlands Instituut voor Praeventieve Gezondheidszorg TNO.

Dunton, \$. (1991). An introduction to Health Risk Appraisal at the workplace. In: J.P Mayer \& J.K. David (Eds.), Worksite Health Promotion: needs, approaches, and effectiveness (pp. 1973). Lansing MI: Michigan Department of Public Health.

Dute, J.C.J. (1994). Testen van werknemers op alcohol- en drugsgebruik [Testing employees on alcohol and drug use]. Tijdschrift voor alcohol, drugs en andere psychotrope stoffen, 20, 171 173.

Fielding, J.E. (1989). Frequency of Health Risk Assessment activities at U.S. worksites. American Journal of Preventive Medicine, 5, 73-81.

Fishbein, M. \& Ajzen, I. (1975). Belief, attitude, intention and behavior, Reading, MA: Addison Wesley.

Garretsen, H.F.L. (1983). Probleendrinken. Prevalentiebepaling, beïnwloedende factoren en preventiemogelijkheden. Theoretisch overwegingen en onderzoek in Rotterdam IProblem drinking. Prevalence, influencing factors and possibilities for prevention. Theoretical considerations and research in Rotterdam]. Lisse: Swets \& Zeitlinger.

Garretsen, H.F.L. \& Knibbe, R.A. (1983). Alcohol prevalentie onderzoek Rotterdam/Limburg, landelijk eindrapport [Alcohol prevalence research Rotterdam/Limburg, national report]. 'sGravenhage: Ministerie van WVC.

Geers, A.J.C.M., and Gevers, J.K.M. (1992). Het alcohol-en drugsbeleid in ondernemingen [Alcohol and drug policies at companies]. Nederlands Juristenblad, 67, 185-189.

Gerstein, L.H, Eicluenhofer, D.J., Bayer, G.A., Valutis, W. \& Jankowski, J (1989). EAP referral training and supervisors" beliefs about troubled workers. Employee Assistance Quarterly, 4. $15-30$.

Green, L.W. \& Kreuter, M.W. (1991). Health promotion planning; an educational and environmental approach. Palo Alio: Mayfield Publishing Company.

Green, L.W. \& Lewis, F.M. (1986). Measurement and evaluation in health education and health promotion. Palo Alto: Mayfield Publishing Company.

Gründemann, R.W.M. and Lourijsen, E.C.M.P. (1991). Gezondheidsbevorderende activiteiten op het werk in Nederland [Health Promotion activities at the warkplace in the Netherlands]. Leiden: Nederlands Institurut voor Preventieve Gezondheidszorg.

Gründemann, R.W.M. (1988). Alkoholgebruik onder de Nederlandse beroepsbevolking. Vervolgonderzoek alkohol en werk: Deel I /Alcohol consumption among the Dutch working. population. Research on alcohol and work: Part 1]. Den Haag: Ministerie van Sociale Zaken en Werkgelegenlieid.

Grüdemann, R.W.M. (1989a). Achtergronden wan het akkoholgebruik onder de Nederlandse beroepsbevolking. Onderzoek alkohol en werk: Deel 2 [Background of alcohol consumption among the Dutch working population. Research on alcohol and work: Part 2). Leiden: Nederlands Instituut voor Praeventieve Gezondheidszorg.

Gründemann, R.W.M. (1989b). Alkoholgebruik onder de Nederlandse beroepsbewolking 
[Alcohol consumption among the Dutch working population]. Tijdschrift Socialle Gezondheidszorg, 67, 61-66.

Houtman, I.L. D. Bongers, P.M., Smulders, P.G.W. \& Kompier, M.A. (1994). Psychosocial stressors at work and musculoskeletal problems. Scandinavian Joumal of Work and Enwrow mental Health, 20, 139-145.

Israel, B.A., Cummings, K.M., Dignan, M.B., Heaney, C.A., Perales, D.P., Simons-Morton, B.G. \& Zimmerman, M.A. (1995). Evaluation of health education programs: current assessment and future directions. Health Education Quarterly, 22, 64-389.

Kischuk, N., Peters, C., Towers, A.M., Sylvestre, M. Bourgault, C., \& Richard, L. (1994). Formative and effectiveness evaluation of worksite program promoting healthy alcohol consumption. American Journal of Health Promotion, 8, 353-362.

Kok, G. \& De Vries, H. (1989). Primary prevention of cancers: The need for health education and intersectoral health promotion. In: T. Heller, B. Davey, \& L. Bailey (Eds.) Reducing the risk of cancers (pp. 99-111). London: Hodder and Stoughton:

Kozlowski, L.T. \& Ferrence, R.G. (1991). Alcohol and mortality and smoking. British Journal of Addiction, 86, 380.

Knibbe, R.A. \& Swinkels, H. (1992). Alcoholgebruik in Nederland; een analyse van gegevens uit de CBS-gezondheidsenquête 1989 [Alcohol consumption in the Netherlands; an analysis of the data from the CBS health questionnaire 1989]. Tijdschrift voor Alcohol, Drugs en andere Psychotrope Stoffen, 18, 124-138.

Kroodsma, A. \& Bouwer, W. (1995). Het bedriffsalcoholbeleid: ontwikkeling, diagnose, uirwoering en continuiteit [Worksite alcohol policy: development, diagnosis, implementation and continuation]. Soest: Stichting Alcolnol Consultancy Nederland (ALCON).

Manders, Th. \& Kropman, J. (1987). Sport: ontwikkelingen en kosten [Sports: developments and costs]. Nijmegen: Instituut voor Toepgepaste Sociale Wetenschappen.

Marlatt, G.A. \& Gordon, J.R. (1985). Relapse prevention: Maintenance strategies in the treatment of addictive behaviors. New York: Guilford Press.

Marmot, M.G., North, F., Feeney, A. \& Head, J. (1993). Alcohol consumption and sickness absence: from the Whitehall II study. Addiction, $88,369-382$.

McDonald, J. (1982). Moderate amounts of alcoholic beverages and clinical nutrition. Journal of Nutrition Education, 14, 58-60.

McGuire, W.J. (1985). Attitudes and attitude change. In: G. Lindsay \& E. Alonson (Eds.). The handbook of social psychology (pp. 233-346). New York: Random House.

Meijer, J.W. \& Tjioe, B.K. (1990). Maatschappelijke kosten alcoholmisbruik en tabaksgebruik [Casts for the society related to alcohol abuse and smoking]. Rotterdam: Stichting Het Nederlands Economisch Instituut.

Ministry of Welfare, Health, and Cultural Affairs (1993). Feiren over alcohol [Facts about alcoholl. Rijswijk: Bureau Alcohol Voorlichtingsplan.

Neve, R., Knibbe, R. \& Swinkels, H. (1994). Gaan de drinkgewoonten wan vrouwen steedls meer lijken op die van mannen? [Do the drinking habits of women increasingly resemble those of men?] Tijdschrift voor alcohol, drugs en andere psychotrope stoffen, 20, 65-77.

Peirce, R.S., Frone, M.R., Russell, M. \& Cooper, M.L. (1996). Financial stress, social support " and alcohol involvement: A longitudinal test of the buffering hypothesis in a general population survey. Health Psychology, 15, 38-47.

Pratt, O.E. \& Tucker, M.M. (1989). Approaches to the alcohol problen in the workplace. Alcohol \& Alcoholism, 24, 453-464.

Prochaska, J.O, Velicer, W.F., Rossi, J.S., Goldstein, M.G., Marcus, B.H., Rakowski, W., Fiore, C., Harlow, L.L., Redding, C.A., Rosenbloom, D., \& Rossi, S.R. (1994). Stages of change and decisional ballance for 12 problem behaviors. Health Psychology, 13, 39-46.

Prochaska, J.O., DiClimente, C.C., Velicer, W.F. \& Rassi, J.S. (1993). Standardized, indiwidua 
lized, interative, and personalized self-help programs for smoking cessation. Health Psychology. 12, 399-405.

Prochaska, J,O. \& Diclimente, C.C. (1984). The transtheoretical approach; crossing traditional boundaries of therapy: Illinois: Dow Jones/Irwin Homewood.

Roman, P.M., \& Blum, T.C. (1996). Alcohol: A review of the impact of worksite interventions on health and behavioral outcomes. American Journal of Health Promotion, $11,136-149$.

Schoenbach, V.J. (1987). Appraising Health Risk Appraisal American Jowmal of Public Health, $77,409-411$.

Schroer, C.A.P. (1993). Ziekteverzuim wegens overspanning: een onderzoek naar de aard wan owerspanning, de hulpwerlening en het verzumbeloop [Sickness absence due to stress: A study on the nature of stress, treatment and course of sickness abstence]. Mastricht: Universitaire Pers Maastricht.

Shaper, A.G. (1991). Evidence that alcohol is beneficial to health has not been produced, British Journal of Addiction, 86, 380.

Shaper, A.G. (1990). Alcohol and mortality: a review of prospective studies. British Journal of Addiction, 85, 837-847.

Sonnenstuhl, W.J. (1988). Contrasting employee assistance, health promotion, and quality of work life programs and their effects on alcohol abuse and dependence. The Journal of Applied Behavioral Medicine, 24, 347-363.

Stichting van de Arbeid (1993). Advies alcohol en werk [Advice alcohol and work]. Den Haag. Stichting van de Arbeid.

Strecher, V.J., Kreuter, M., Den Boer, D.J., Kobrin, S., Hospers, H.J., \& Skinner, C.S. (1994). The effects of computer-tailored smoking cessation messages in family practice settings. The Journal of Family Practice, 39, 262-268.

Swinkels, H. (1991). Drankgebruik in Nederland - enkele onderzoeksmethoden vergeleken [Alcohol consumption in the Netherlands - the comparison of different research methods]. Maandbericht Gezondheid (CBS), 12, 5-12.

Towers, A.M., Kishuk, N., Sylvestre, M., Peters, C. \& Bourgault, C. (1994). A qualitative investigation of organizational issues in an alcohol awareness program for blue-collar workers. American Joumal of Health Promotion, 9, 56-63.

Trice H.M. \& Beyer, J.M. (1984). Work-related outcomes of the constructive confrontation strategy in a job-based alcoholism program. Journal of Studies on Alcohol, 45, 393-404.

Trice, H.M. \& Sonnenstuhl, W.J. (1990). On the construction of drinking norms in work organizations: Implications for research and prevention. Journal of Studies on Alcohol, 51, 201-220.

Trice, H.M. \& Sonnenstuhl, W.J. (1988). Drinking behaviors and risk factors related to the work place: Implications for research and prevention. Journal of Applied Behavioral Science, 24, 327-346.

Vasse, R.M., Nijhuis, F.J.M. and Kok, G.J. Associations between work stress, alcohol consumption and sickness absence. Accepted for publication in Addictions.

Weinstein, N.D. (1989). Effects of personal experience on self-protective behawior. Psychological Bulletin, 105, 31-50.

Wierik, E. Te (1991). Moderate and excessiwe drinking, problem drinking and alcoholism.

Definitions. In: D.G. Van Der Heij \& G. Schaafsma (Eds.), Biomedical and social aspects of alcohol use: A review of the literature (pp. 5-13). Wageningen: Pudoc.

Wills, T.A. \& Shiffman, S. (1985). Coping and substance abuse: A conceptual framework.

In: S. Shiffman \& T.A. Wills (Eds.), Coping and substance abuse (pp. 3-24). Orlando: Academic Press.

Tweede Kamer (1993-1994). Het gebruik wan woorspellend medisch onderzoek bij keuringen [The use of predictive medical examinations]. 23612 , no. 1. 


\section{Summary}

Excessive alcohol drinking can cause severe physical, psychological or social problems for drinkers themselves and for people in their environment. At the worksite alcohol problems among workers increase dysfunctioning and sickness absence. It is estimated that about $12 \%$ of the Dutch working population drink excessively and that about half of them have problems related to their alcohol use.

Therefore the Dutch Ministry of Welfare, Health and Cultural Affairs initiated in 1990 a research project to investigate the feasibility and effectiveness of two types of worksites programs aimed at preventing alcohol problems. One program should be a secondary preventive program aimed at early detection and treatment of problem drinkers, and the other program should be a primary preventive program aimed at promotion of healthy drinking.

This thesis describes the development, implementation and evaluation of these two programs. The project was conducted by two organizations: the Alcohol Consultancy (ALCON) Foundation Netherlands who was responsible for the practical part and the Maastricht University who was responsible for the research part of the project. The two programs were implemented at a pharmaceutical company (secondary preventive program) and at a Municipal Garbage Collecting Department (primary preventive program). The secondary preventive program consisted of an alcohol policy with regulations and procedures, skills training for social medical workers and supervisors, and educational activities for workers. The primary preventive program comprised a personalized Health Profile that gave workers tailored feedback about the healthiness of their behaviors. As a follow-up, behavioral change programs were planned but these were not implemented.

Chapter 1 of this thesis gives a general overview of all the steps taken in the project. It firstly reviews the literature on what is known about the prevalence and consequences of alcohol problems among workers. Secondly, it reviews the literature on determinants of workers' alcohol problems and the effectiveness of existing intervention programs. Thirdly it decribes two field studies on the development, implementation and evaluation of a primary and a secondary preventive worksite alcohol program. Besides the effectiveness also the process of implementation is evaluated. Fourthly, an additional theoretical study on determinants and consequences of workers' alcohol drinking behavior is described. Alcohol drinking is hypothesized a maladaptive coping response to stress. The overview closes with a general discussion and formulates conclusions and implications for research and practice.

Chapter 2 describes the study on the effectiveness of the secondary preventive program at the pharmaceutical company. The most important intervention elements were an Alcohol Policy, a skills training for social medical workers and supervisors, and educational activities for all workers. Therefore three study groups were included in the evaluation research: all social medical workers $(n=10)$, a sample of supervisors (pretest: $n=78$, posttest: $n=63$ ), and a sample of all workers (pretest: $n=319$, 
posttest: $n=267$ ). The study design was quasi-experimental (no control group, no randomization). Three study groups received written questionnaires before and after the intervention. Group and individual interviews gave background information. The results show that the Alcohol Policy was well known and accepted. The training on constructive confrontation skills was effective for social medical workers, but not for supervisors. The educational activities were not effective in improving awareness and intention to change excessive drinking behavior. It is concluded that worksite alcohol programs are useful. The subject must be carefully approached because of its sensitiveness. In future projects much more effort much be made to involve managers and supervisors in the program. Health education activities on alcoholl should emphasize "healthy drinking" instead of "problem drinking". The education should be more taillored to the individual worker. To prevent alcohol problems the subject can be integrated with other educational activities.

Chapter 3 describes the study on the effectiveness of the primary preventive program at the Municipal Garbage Collecting Department. This program was only partly implemented; the behavioral change programs did not take place, but the workers who responded to a pretest health questionnaire $(\mathrm{N}=63)$ received feedback on the healthiness of their behavior by means of a so-called Health Profile. The major goal of the Health Profile was to improve workers" awareness of own health behaviors and their intentions to change unhealthy behaviors. Additional goals were improvements in attitudes, self-efficacy and social support. The Health Profile consisted of a booklet in A4-format in which tailored information was given on health behaviors. The study design was quasi-experimental with a pretest and posttest (no control group). The results showed a significant improvement of awareness. Significant attitudinal changes were achieved too. There were no changes in social support and self-efficacy, nor was there a change in the intention to change behaviors. These results suggest that a personalized health profile is a promising means to make workers aware of their personal risk behaviors. Future Health Profiles should contain more specific information on how to change unhealthy behaviors. Furthermore, more opportunities should be created to discuss and compare results with colleagues and partners.

Chapter 4 presents the process evaluation of the two programs. The process evaluation focused on the feasibility of implementing these programs. Therefore five factors were investigated: 1) program implementation, 2) site response, 3) recipient response, 4) practitioner response, and 5) competencies of personnel. The results of both programs are discussed and compared with each other. Recommendations are made on the use of planning models, the role of external consultants, participation of the worksite, incorporation of research, the content of the programs and integration with other programs.

Chapter $\mathbf{5}$ of this thesis describes the theoretical study on the relationships between workstressors, stress, alcohol drinking and sickness absence. Excessive alcohol drinking is hypothesized to function as a maladaptive coping response to workstress and to increase the risk on sickness absence. Data from the pharmaceutical company, the municipal garbage collecting department and a control municipal 
garbage collecting department were used for this study (total $N=471$ ). Multiple linear and logistic regression analyses were used to predict stress, alcohol consumption and sickness absence. Three major findings result from this study. Firstly, in case of stress both abstinence and excessive drinking increased the risk on sickness absence. Although the effect of excessive drinking is not significant. This might be due to lack of power of the study (small groups) and/or the fact that the threshold used for excessive drinking was too low. The effect of abstinence could reflect medical problems of abstainers or a lack of skills to cope with stress. Abstinence was strongly related to a lower education. The effect of excessive drinking probably reflects drinking to cope with stress. Secondly, stress mediated the stressor-alcohol consumption and the stressor-sickness absence relationships, although stressors had also direct effects on sickness absence (especially the negative effects of work on private life). Thirdly, no moderating effects of individual difference variables on the stress-alcohol consumption relation were found. To conclude, this study supports the hypothesis that workers' alcohol drinking behavior is related to work stress and sickness absence. The results suggest that moderate drinking has a buffering effect on the relation between stress and sickness absence and that abstinence is at least as unhealthy as excessive drinking. Future research should examine underlying reasons for this finding.

In general, it can be concluded that an effective program to reduce and prevent alcohol problems must be tailored to the specific needs of the company in question. In practice no program will be the same. Based on a thorough diagnosis priorities can be given to primary and/or secondary preventive program components. New programs should be integrated as much as possible in existing policies or programs. A comprehensive program should contain a balance between changes in the environment (work stressors, regulations and procedures) and changes in personal behavior. It is very important to clearly communicate the company's vision that lies behind intervention programs and stimulate participation of relevant company members in developing and implementing the program. External consultants should find a balance between coaching and expertise parts of their role. Future alcohol education should pay attention to drinking to cope with stress. Program components that need further development are the Health Profile and the training in constructive confrontation skills for supervisors. 


\section{Samenvatting}

\section{De ontwikkeling, implementatie en evaluatie van twee bedrijfsgezondheids- programma's gericht op preventie van alcoholproblemen}

Excessief alcoholgebruik kan resulteren in ernstige fysieke, psychologische en sociale problemen voor drinkers zelf en voor hun omgeving. Op de werkplek veroorzaken alcoholproblemen van werknemers disfunctioneren en ziekteverzuim. Men schat dat $12 \%$ van de nederlandse beroepsbevolking excessief drinkt en dat ongeveer de helft van hen problemen ten gevolge van hun alcoholgebruik ondervindt.

Daarom initieerde het toenmalige nederlandse Ministerie van Welzijn, Volksgezondheid en Cultuur (WVC) een onderzoeksproject naar de (on)mogelijkheden van het invoeren van twee typen alcoholprogramma's in bedrijven. Ook de effectiviteit van deze programma's moest bepaald worden. Het ene programma moest secundair preventief van aard zijn en gericht zijn op vroegtijdige ontdekking en begeleiding van probleemdrinkers. Het andere programma moest primair preventief van aard zijn en gericht zijn op het bevorderen van gezond drinkgedrag.

Dit proefschrift beschrijft de ontwikkeling, implementatie en evaluatie van deze twee programma's. Het project is uitgevoerd door twee organisaties: de Stichting Alcohol Consultancy Nederland (ALCON) die verantwoordelijk was voor de praktische uitvoering van het project, en de Universiteit Maastricht (voorheen Rijksuniversiteit Limburg) die verantwoordelijk was voor de evaluatiestudie. De twee programma's zijn uitgevoerd in een groot farmaceutisch bedrijf (secundair preventief programma) en in een gemeentelijke reinigingsdienst van een grote stad in Nederland (primair preventief programma). Het secundair preventieve programma bestond uit een alcoholbeleid met regels en procedures, vaardigheidstraining voor leden van het sociaal medisch team en leidinggevenden, en voorlichtingsactiviteiten voor alle werknemers. In het primair preventieve programma werd werknemers persoonlijk feedback gegeven over de gezondheidstoestand van hun leefstijlgedragingen. Deze feedback verliep schriftelijk via het toezenden van het zogenaamde Gezondheidsprofiel, een boekje op A4-formaat. Als vervolg waren gedragsveranderingsprogramma's gepland, maar deze zijn niet uitgevoerd.

Hoofdstuk 1 van dit proefschrift geeft een algemeen overzicht van alle stappen die in het project gevolgd zijn. Het geeft ten eerste een literatuuroverzicht van de prevalentie van alcoholgebruik en de gevolgen voor bedrijven. Ten tweede geeft het een literatuuroverzicht van determinanten van alcoholgebruik van werknemers en van de effectiviteit van bestaande alcoholprogramma's in bedrijven. Ten derde worden twee veldstudies beschreven naar de ontwikkeling, implementatie en evaluatie van een primair en een secundair preventief alcoholprogramma in bedrijven. Behalve de effectiviteit wordt ook een procesevaluatie beschreven. Ten vierde wordt een theoretische studie beschreven naar determinanten en gevolgen van het drinkgedrag van werknemers. Verondersteld wordt dat alcoholgebruik een inadequate copingrespons 
is op stress en het ziekteverzuim verhoogt. Hoofdstuk 1 sluit af met een algemene discussie, conclusies en aanbevelingen voor onderzoek en praktijk.

Hoofdstuk 2 beschrijft de studie naar de effectiviteit van het secundair preventieve alcoholprogramma in het farmaceutische bedrijf. De belangrijkste programmaelementen waren een alcoholbeleid, vaardigheidstraining voor leden van het sociaal medisch team en leidinggevenden, en voorlichtingsactiviteiten voor alle wernemers. Drie onderzoeksgroepen werden bestudeerd in het evaluatieonderzoek: alle leden van het sociaal medisch team $(n=10)$, een steekproef van leidinggevenden $(n=78$ tijdens voormeting en $n=63$ tijdens nameting), en een steekproef van alle werknemers ( $n=319$ tijdens voormeting en $n=267$ tijdens nameting). Het onderzoeksdesign was quasi-experimenteel van aard (geen controlegroep, geen randomisatie). De drie onderzoeksgroepen ontvingen schriftelijke vragenlijsten voor en na de interventie. Groeps- en individuele interviews gaven achtergrond informatie. De resultaten laten zien dat het alcoholbeleid goed bekend was geworden en geaccepteerd werd. De vaardigheidstraining met betrekking tot constructieve confrontatie technieken was effectief bij leden van het sociaal medisch team, maar niet bij leidinggevenden. De voorlichtingsactiviteiten waren niet effectief in het vergroten van het bewustzijn ten opzichte van eigen drinkgedrag, en de intentie tot gedragsverandering. De conclusie is dat alcoholprogramma's zinvol zijn, maar dat het onderwerp heel gevoelig ligt en daarom voorzichtig benaderd moet worden. In toekomstige projecten moet meer aandacht worden besteed aan het betrekken van leidinggevenden bij het programma. Voorlichtingsactiviteietn zouden meer het gezond drinken moeten benadrukken in plaats van het probleemdrinken. Bovendien moet de voorlichting meer toegesneden worden op het individu. Integratie van het thema alcohol in andere gezondheidsprogramma's zou de implementatie kunnen vergemakkelijken.

Hoofdstuk 3 beschrijft de studie naar de effectiviteit van het primair preventieve programma bij de gemeentelijke reinigingsdienst. Dit programma is slechts gedeeltelijk ingevoerd; de gedragsveranderingsprogramma's hebben niet plaatsgevonden. De interventie is beperkt gebleven tot het terugzenden van het gezondheidsprofiel naar de werknemers die aan de voormeting meegedaan hadden $(n=63)$. Het belangrijkste doel van het gezondheidsprofiel was het bevorderen van het bewustzijn ten aanzien van eigen gezondheidsgedragingen en de intentie tot gedragsverandering indien nodig. Aanvullende doelen waren het bevorderen van attitudes, eigen effectiviteit en sociale steun. Het gezondheidsprofiel bestond uit een boekje op A4-formaat en bevatte informatie over de persoonlijke gezondheidsgedragingen van de werknemer. Het onderzoeksdesign was quasi-experimenteel met een voormeting en een nameting, zonder controlegroep. De resultaten laten een significante toename van het bewustzijn zien evenals van attitudes. Er waren geen veranderingen in sociale steun en eigen effectiviteit. Concluderend suggereren deze resultaten dat een gezondheidsprofiel een veelbelovend instrument is om het bewustzijn van werknemers ten aanzien van eigen gezondheidsgedragingen te bevorderen. In de toekomst zouden gezondheidsprofielen meer specifieke informatie moeten bevatten over hoe men ongezond gedrag veranderen kan ten einde de eigen effectiviteit te bevorderen. Bovendien zouden meer mogelijkheden geschapen moeten worden om resultaten te bespreken en 
te vergelijken met collega"s en partners. Dit laatste dient de sociale steun te bevorderen.

Hoofdstuk 4 presenteert de resultaten van de procesevaluatie van beide programma's. De procesevaluatie richt zich op de (on)mogelijkheden van het invoeren van alcoholprogramma's in bedrijven. Vijf factoren worden in kaart gebracht: 1) de implementatieproces van het programma, 2) algemene reacties op het programma, 3) reacties van deelnemers, 4) reacties van uitvoerders, en 5) bekwaamheden van uitvoerders. De resultaten van beide programma's worden vergeleken. Aanbevelingen worden gedaan ten aanzien van het gebruik van planningsmodellen, de rol van externe consulenten, participatie van het bedrijf, de integratie van onderzoek, de inhoud van de programma's, en integratiemogelijkheden van alcoholprogramma"s met andere programma's.

Hoofdstuk 5 van dit proefschrift beschrijft de theoretische studie naar de relaties tussen stressoren op het werk, ervaren stress, alcoholgebruik en ziekteverzuim. Excessief alcoholgebruik wordt verondersteld te functioneren als een inadequate copingrespons op werkstress en het ziekteverzuim te bevorderen. Voor deze studie zijn data gebruikt van het farmaceutisch bedrijf en van de gemeentelijke reinigingsdiensten (experimentele en controlegroep) ( $N=417$ ). Multiple lineaire en logistische regressie analyses zijn gebruikt om stress, alcoholgebruik en ziekteverzuim te voorspellen. Drie belangrijke resultaten komen uit dit onderzoek. Ten eerste vertonen, in combinatie met stress, zowel geheelonthouders als excessieve drinkers een verhoogd risico op ziekteverzuim in vergelijking met matige drinkers. Het effect van excessief drinken is echter niet significant, hetgeen veroorzaakt kan worden door gebrek aan power van de studie (kleine groepen) en/of door het feit dat de gebruikte norm voor excessief drinken relatief laag is; het effect van excessief drinken treedt misschien pas op bij een nog hoger consumptienivo. Het effect van geheelonthouding zou achterliggende medische problemen kunnen weergeven of een gebrek aan adequate copingvaardigheden voor stress. Geheelonthouding was sterk gerelateerd aan een laag opleidingsnivo. Het effect van excessief drinken zou een copingrespons voor stress kunnen weerspiegelen. Het tweede belangrijke resultaat is dat stress inderdaad een mediërende invloed heeft op de stressor-alcohol relatie en de stressor-verzuim relatie, hoewel enkele stressoren ook een directe relatie met verzuim vertonen (met name de negatieve invloed van het werk op de thuissituatie). Ten derde blijken individuele kenmerken zoals geslacht en het hebben van een partner geen modererende invloed op de stress-alcohol relatie te hebben. Dat wil zeggen dat de relatie hetzelfde is voor mannen en vrouwen en voor mensen met of zonder een partner. Concluderend toont deze studie aan dat het alcoholgebruik van werknemers gerelateerd is aan werkstress en ziekteverzuim. Matig alcoholgebruik lijkt een bufferend effect te hebben op de relatie tussen stress en ziekteverzuim en geheelonthouden lijkt minstens zo ongezond te zijn als excessief drinken. Toekomstig onderzoek zou moeten onderzoeken wat de achterliggende oorzaak van deze laatste bevinding is.

Algemene conclusie van het gehele onderzoek is dat een effectief bedrijfsprogramma gericht op het terugdringen en voorkomen van alcoholproblemen toegespitst moet zijn op de specifieke behoeften van bedrijven. In de praktijk zal geen 
enkel programma hetzelfde zijn. Gebaseerd op een degelijke diagnose kan prioriteit gegeven worden aan primair preventieve of secundair preventieve programmacomponenten. Nieuwe programma"s moeten waar mogelijk geïntegreerd worden in bestaand beleid en bestaande programma"s. Een integraal programma moet een balans vinden tussen veranderingen in de omgeving (stressoren, regels en procedures) en veranderingen in persoonlijk gedrag. Het is heel belangrijk om de achterliggende visie van het bedrijf helder over te brengen op het personeel en om participatie te bevorderen van vertegenwoordigers van leiding, staf en personeel in het ontwikkelen en uitvoeren van programma"s. Externe consulenten dienen een balans te vinden tussen de rol van inhoudsdeskundige en begeleider. Toekomstige alcoholvoorlichting zou aandacht moeten besteden aan de mate waarin men drinkt als reactie op stress. Concrete programmacomponenten die verdere verbetering behoeven zijn het gezondheidsprofiel en de training in constructieve confrontatie vaardigheden voor leidinggevenden. 


\section{Curriculum Vitae}

Remkina Margot (Rineke) Vasse was born on August 7, 1967 in Groningen. In 1985 she graduated at the secondary school "Rijksscholengemeenschap Het Ommelander College" in Appingedam and received her VWO diplome. That same year she started an university training in Health Sciences at the University of Limburg (now called Maastricht University). She got her MPH diplome in Health Sciences/Health Education in 1990. That same year she started at the Maastricht University (Department of Health Education and Promotion) the research study on worksite alcohol programs that is described in this thesis. In 1991 she gave birth to a daugther and in 1996 to a son. From January 1, 1997 she works as a Health Educator and researcher for the "Centraal Orgaan Bedrijfsgezondheidszorg voor het onderwijs" (COBGZ) in Heerlen. Her task concerns prevention of stress and burnout among teachers in primary and secondary schools. 


\section{Acknowledgements}

I would like to thank all the people I worked with during the project described in this thesis. First of all, Frans Nijhuis and Gerjo Kok: thank you for all those inspiring discussions and critical comments. You were important persons in my early carreer. Second, Anja Kroodsma from the ALCON Foundation: after a difficult start with a lack of clearity about division of "practical" and "research" tasks we worked together very well and learned a lot from each other. I also thank Rik Bijl and Wim Bouwer from the ALCON Foundation, and Ant Van Burg and Inez Verijken from the Netherlands Institute for Health Promotion and Disease Prevention (NIGZ) for making the project possible and for their useful advice. Third, I thank my colleagues from the Department of Health Education and Promotion for all the professional and social support they gave me. Especially, I thank the colleagues who participated in the working group "Work and Health", including Lucette Meillier from the University in Aarhus (Denmark). Finally, I thank Leo, Myrte, Hugo, and other family and friends who took my mind off things and helped me to put a promotion study in perspective, but at the same time encouraged me to finish this project. 